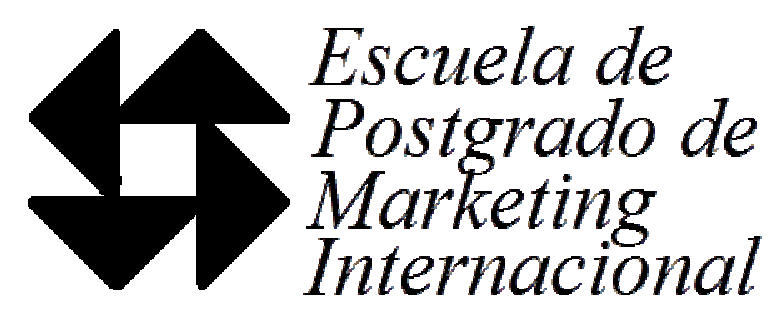

\title{
El Comercio Bilateral de Cosméticos entre Argentina y Brasil en el MERCOSUR entre 2009 y 2013
}

Trabajo científico libre para la obtención del grado de Magister en Marketing Internacional de la Escuela de Postgrado de Marketing Internacional - Facultad de Ciencias Económicas Universidad Nacional de La Plata

\author{
Profesor Director de Tesis: Autor: \\ Prof. Reinaldo Horacio Kopp Leila Aparecida Odorizzi \\ R Fritz Muller,376 Indaial/SC Brasil
}

Fecha de entrega: Febrero de 2016. 


\section{Agradecimientos}

A Dios, que permitió este logro.

A mi familia, por el apoyo incondicional.

Muy especialmente a mi director, el Profesor Reinaldo Horacio Kopp, por la disponibilidad, atención prestada, paciencia, dedicación y profesionalismo.

A todos en la coordinación de la Maestría en Marketing Internacional de la UNLP. 
Figura 1 - Porcentaje de inversiones de empresas brasileñas en suelo argentino $\quad 23$ Figura 2 - Cadena productiva del sector de higiene personal, perfumería y cosméticos

Figura 3 - Grandes empresas del mercado mundial y brasileño de cosméticos por player y grupo

Figura 4 - Comparación del crecimiento del consumo del sector de HPPC por clase social de 2005 y 2010

Figura 5 - Origen de las importaciones brasileñas de cosméticos

Figura 6 - Destino de las exportaciones brasileñas de cosméticos 46

Figura 7 - Principales productos intermedios en el sector de HPPC brasileño 47

Figura 8 - Formas de entrada de las exportaciones en el mercado argentino 
Gráfico 1 - Los 10 principales países de origen de las importaciones argentinas. $\quad 24$

Gráfico 2 - Los 10 principales destinos de las exportaciones argentinas

Gráfico 3 - Balanza comercial brasileña de importación y exportación de HPPC de 2003 a 2013

Gráfico 4 - Facturación del mercado brasileño de cosméticos de 1996 a 2013

Gráfico 5 - Porcentaje de productos HPPC brasileños exportados, por agrupación de segmento, en los años 2012 y $2013 \quad 44$

Gráfico 6 - Exportación e importación de cosméticos Argentina-Brasil 2009-2014 46

Gráfico 7 - Origen de las empresas que componen la muestra de la investigación $\quad 65$

Gráfico 8 - El MERCOSUR afectó a la industria cosmética entre Brasil y Argentina? 70

Gráfico 9 - ¿Cómo influyó el MERCOSUR en la industria cosmética? 71

Gráfico 10 - Perspectivas para el sector de cosméticos dentro del MERCOSUR 71

Gráfico 11 - Las empresas, ¿perciben las oportunidades para la industria cosmética?

Gráfico 12 - Resumen de las oportunidades del mercado cosmético Brasil - Argentina

Gráfico 13 - Resumen de las amenazas del mercado cosmético Brasil - Argentina 78

Gráfico 14 - ¿Qué es relevante para aumentar importaciones y exportaciones de cosméticos entre Brasil y Argentina? 
Cuadro 1 - Legislación en vigencia para la importación y exportación de cosméticos brasileños

Cuadro 2 - Empresas cosméticas consultadas en Brasil y en Argentina

Cuadro 3 -Construcción de la fundamentación teórica consultada para formular el cuestionario

Cuadro 4 - Estructura de la investigación

Cuadro 5 - Resumen de las perspectivas y alcance de las acciones

Cuadro 6 - Oportunidades percibidas en el área de cosméticos para la relación de

Brasil y Argentina en el MERCOSUR

Cuadro 7 - Amenazas percibidas en el área de cosméticos para la relación de Brasil y Argentina en el MERCOSUR 
Tabla 1 - Bloques económicos de destino de las exportaciones brasileñas

Tabla 2 - Bloques económicos de origen de las importaciones brasileñas

Tabla 3 - Exportaciones e importaciones brasileñas en el MERCOSUR entre 2013 y 2014

Tabla 4 - Exportaciones e importaciones entre Argentina y otros países

Tabla 5 - Balanza comercial Argentina de 2009 a 2013

Tabla 6 - Crecimiento medio de los países latinoamericanos entre 1994 y $2002 \quad 21$

Tabla 7 - Exportaciones e importaciones de Brasil con Argentina

Tabla 8 - Exportaciones e importaciones de Argentina con Brasil

Tabla 9 - Principales productos comprendidos en el intercambio comercial de Argentina con Brasil en 2013 (US\$ billones FOB)

Tabla 10 - Principales productos del intercambio comercial entre Argentina y Brasil en 2013 (US\$ billones FOB) 27

Tabla 11 - Los 10 mayores mercados mundiales de HPPC entre 2012 y 2013

Tabla 12 - Ranking de productos HPPC de Brasil y del mundo, por sector, y perspectiva de crecimiento

Tabla 13 - Oportunidades de trabajo en Brasil derivadas el sector de HPPC

Tabla 14 - Códigos y productos destacados de Brasil y Argentina en el mercado mundial de HPPC y facturación entre 2009 y 2013

Tabla $15-10$ principales orígenes de las importaciones y destinos de las exportaciones brasileñas de HPPC

Tabla 16 - PIB brasileño, industria en general y HPPC con sector deflacionado entre 1996 y 2013

Tabla 17 - Cosmética facial

Tabla 18 - Importación y exportación de productos HPPC Argentina-Brasil entre 2009 y 2013 según el código NCM 


\section{Lista de siglas}

ABDI

ABIHPEC

ABNT

ALADI

ALALC

ALCA

ANMAT

ANVISA

APEC

APEX

ASEAN

BNDES

CARICOM

CEI

CELAC

CNPJ

FDA

FOB

GATT

HPPC

IED

IDH

INAME

INMETRO

ITEHPEC

MERCOSUL

MSAS

NAFTA

NCM

OEA

OMC

ONU

OPEP

OTC

OTCA

PDS

PIB

SEBRAE

$\mathrm{SH}$

SIM

SISCOMEX

TEC

UE

UNASUL

UNCTAD

UNLP
Agencia Brasileña de Desarrollo Industrial

Asociación Brasileña de la Industria de Higiene Personal,

Perfumería y Cosméticos

Asociación Brasileña de Normas Técnicas

Asociación Latinoamericana de Integración

Asociación Latinoamericana de Libre Comercio

Área de Libre Comercio de las Américas

Administración Nacional de Medicamentos, Alimentos y Tecnología Médica

Agencia Nacional de Vigilancia Sanitaria

Cooperación Económica de Asia y el Pacífico

Agencia Brasileña de Promoción de Exportaciones e Inversiones

Asociación de las Naciones del Sudeste Asiático

Banco Nacional de Desarrollo Económico y Social

Comunidad del Caribe

Comunidad de los Estados Independientes

Comunidad de los Estados Latinoamericanos y Caribeños

Registro Nacional de Persona Jurídica

Food and Drug Administration

Free On Board

Acuerdo General de Tarifas y Comercio

Higiene Personal, Perfumería y Cosméticos

Inversión Extranjera Directa

Índice de Desarrollo Humano

Instituto Nacional de Medicamentos

Instituto Nacional de Medición, Normalización y Calidad Industrial

Instituto de Tecnología y Estudios de Higiene Personal, Perfumería

y Cosméticos

Mercado Común del Cono Sur

Ministerio de Salud y Acción Social

Acuerdo de Libre Comercio de América del Norte

Nomenclatura Común del MERCOSUR

Organización de los Estados Americanos

Organización Mundial de Comercio

Organización de las Naciones Unidas

Organización de los Países Productores de Petróleo

Over The Counter

Organización del Tratado de Cooperación Amazónica

Planes de Desarrollo Sectorial

Producto Bruto Interno

Servicio Brasileño de Apoyo a las Micro y Pequeñas Empresas

Sistema Armonizado

Sistema Informático MARIA

Sistema Integrado de Comercio Exterior

Tarifa Externa Común

Unión Europea

Unión de las Naciones Sudamericanas

Conferencia de las Naciones Unidas en Comercio y Desarrollo

Universidad Nacional de La Plata 
$\begin{array}{lr}\text { Resumen } & 9\end{array}$

1 Marco teórico $\quad 10$

1.1 La internacionalización de los mercados y la globalización $\quad 11$

1.2 Estrategias de marketing para la entrada en el mercado externo 12

$\begin{array}{ll}1.3 \text { EI MERCOSUR } & 16\end{array}$

1.4 El comercio bilateral entre Brasil y Argentina 22

1.4.1 Brasil en el contexto mundial de HPPC (Higiene Personal, Perfumería y Cosméticos) 30

1.4.2 El comercio bilateral Brasil / Argentina en el sector de cosméticos 39

1.4.3 Políticas del sector de productos cosméticos entre Brasil y Argentina $\quad 49$

1.4.3.1 Políticas de regulación y fiscalización de cosméticos 49

1.4.3.2 Políticas de Distribución $\quad 54$

2 Objetivo General 58

3 Objetivos específicos $\quad 59$

4 Tema de investigación e hipótesis $\quad 60$

4.1 Tema de investigación $\quad 60$

4.2 Hipótesis $\quad 61$

5 Metodología 63

5.1 Alcance de la investigación 63

5.2 Población y muestra $\quad 64$

5.3 Instrumento utilizado y colecta de datos $\quad 65$

$\begin{array}{ll}5.4 \text { Análisis de datos } & 67\end{array}$

5.5 Justificación del estudio del tema 68

6 Resultados $\quad 70$

6.1 Perspectivas para el sector cosmético y ventajas del MERCOSUR 70

6.2 Oportunidades para el sector de cosméticos de Brasil y Argentina 74

6.3 Amenazas para el sector de cosméticos de Brasil y Argentina 77

6.4 Sugerencias para aumentar importaciones y exportaciones de cosméticos entre los dos países $\quad 79$

7 Consideraciones finales 82

Bibliografía $\quad 85$

Anexo A: Carta de Presentación $\quad 91$

Anexo B: Encuesta realizada a las empresas 92

Aclaración 93 


\section{Resumen}

Esta investigación tiene como objetivo general analizar el sector industrial de cosméticos entre Brasil y Argentina. Para ello, se valió de metodología cuantitativa y análisis descriptivo, generando gráficos, cuadros y tablas capaces de representar los datos de forma dinámica. Las consideraciones finales responden a los objetivos e hipótesis de este estudio, así como a la pregunta de esta investigación, señalando que el crecimiento del sector de cosméticos alcanza un excelente rendimiento como producto del comercio bilateral entre Brasil y Argentina., siendo ambos países los que representan el mayor volumen de negocios dentro del MERCOSUR.

Los destinos de las mercancías responden a la proximidad geográfica y a los beneficios de pertenecer al bloque económico. Este hecho es confirmado por ser los países de América Latina los principales importadores y exportadores del sector de cosméticos. Se destaca el inestable contexto político actual, que en el intento de resguardar mercados utilizan barreras proteccionistas y burocráticas que impiden la ejecución de procedimientos que beneficien el crecimiento del MERCOSUR como bloque económico y de acciones efectivas de acercamiento entre los países miembro. Las variables de las hipótesis de estudio fueron totalmente confirmadas, teniendo en cuenta que se presupone que mejoraría la calidad de los productos, aumentaría la exportación de productos terminados y aumentaría la importación de materia prima. Aunque las empresas no han acreditado el desempeño del sector en el MERCOSUR, señalan perspectivas optimistas y oportunidades significativas, basadas en el crecimiento del mercado, el aumento del poder adquisitivo de la clase media, C y D, el elevado número de mujeres en el mercado laboral y el aumento de la esperanza de vida de la población. La falta de crédito para invertir en investigaciones e innovación, junto con la inestabilidad de los mercados constituyen las principales amenazas. La inversión en investigación e innovación y la reducción de costos del producto final sin disminuir la calidad fueron alternativas mencionadas para impulsar el crecimiento del sector.

Palabras clave: Comercio bilateral; Brasil; Argentina; MERCOSUR 


\section{Marco teórico}

El pensamiento económico de los mercados y empresas siempre estuvo orientado por el concepto de "administración". En este sentido, según Montana y Chernov ${ }^{1}$, la administración es un conjunto de principios y normas que tienen por objetivo organizar, dirigir, coordinar y controlar los esfuerzos de quien se asocia para alcanzar un resultado común. Administrar debe ser entendido como un esfuerzo para la realización de tareas, en todas las áreas y en todos los niveles, para lograr los objetivos deseados ${ }^{2}$.

La administración ${ }^{3}$ es el acto de trabajar para conseguir los objetivos de la organización y de sus miembros. Gil ${ }^{4}$ afirma que administrar es reconocer que las organizaciones son sistemas dentro de sistemas, es decir, una empresa está inserta en un macrosistema (social, externo: leyes gubernamentales, ambientales, comunidad, cultura, etc.) y en un microsistema (funcional, interno: producción, comercialización, recursos humanos, etc.) y que ambos influyen en su desempeño.

El microambiente está compuesto por el ambiente externo a la empresa e influye en sus decisiones ya que considera a la competencia del sector, los proveedores, los distribuidores, los clientes y las empresas reguladoras, es decir, aquellas que dictan las tendencias y la actuación del segmento. El macroambiente a su vez puede ser dividido en ambientes: el demográfico, el político/económico, el tecnológico, el ecológico, el cultural, el social, e incluye además a las variables legales. ${ }^{5}$

En el mundo globalizado en que se vive es necesaria la velocidad en las decisiones y en la comunicación, la gestión del conocimiento y de procesos y la búsqueda y análisis de informaciones, de manera que se generen reflexiones sobre datos externos e internos, se mida la actuación organizacional y se busque constantemente un espacio para crecer y fortalecerse ${ }^{6}$. Los contactos originados en alianzas y estrategias

\footnotetext{
${ }^{1}$ MONTANA; CHARNOV (2003). [67]

${ }^{2}$ TEIXEIRA (2003). [75]

${ }^{3}$ MONTANA; CHARNOV (2003, p. 2). [67]

${ }^{4}$ GIL (2001). [41]

${ }^{5}$ KOTLER (2006). [55]

${ }^{6}$ BARBOSA (2007). [15]
} 
proporcionan cada vez más ventajas competitivas a las empresas y son cada vez más importantes y necesarios para la entrada y el reconocimiento en nuevos mercados ${ }^{7}$.

Esta búsqueda por ampliar los mercados requiere nuevas formas de comportamiento en el contexto empresarial y político. Para que se desarrollen nuevos negocios, es imprescindible para las empresas y países la formación de conocimiento amplio sobre economía, cultura y política de los mercados extranjeros, que, junto a la identificación de oportunidades y amenazas, genera competitividad. ${ }^{8}$

La competitividad de las organizaciones y de los países depende, en gran parte, de su capacidad de adecuarse a la dinámica de los cambios que ocurren en el micro y/o macroambiente. Esta adaptación es lograda por la adopción de estrategias que permitan la diversificación de los negocios, la innovación de productos y procesos, la alteración de las formas de estructuración interna y el desarrollo de alianzas que permitan estar por encima de la competencia. ${ }^{9}$. Tubino ${ }^{10}$ afirma que las empresas/países deben decidir rápidamente ante la identificación de oportunidades y amenazas del mercado, optimizando sus ventajas competitivas y garantizando su perpetuación en el tiempo y en las relaciones.

Los tópicos a seguir comprenden una revisión de literatura sobre todos estos conceptos. Se profundiza, en primer lugar, la internacionalización de los mercados y la globalización.

\subsection{La internacionalización de los mercados y la globalización}

Para Alem y Cavalcanti ${ }^{11}$, la competitividad de las empresas y mercados se está moviendo rápidamente de los mercados domésticos hacia los mercados internacionales, intensificando la globalización. "Os benefícios do crescimento da globalização são mercados cada vez mais livres e competitivos"12. En este sentido, internacionalizar las actividades de una empresa/producto requiere que se defina de qué forma se dará la entrada en el mercado externo, exigiendo que se adopte una estrategia de internacionalización. También llamada "mundialización" o "globalización", la estrategia de internacionalización está involucrada con el fenómeno económico

\footnotetext{
${ }^{7}$ HITT; IRELAND; HOSKISSON (2002). [48]

${ }^{8}$ MCGAHAN; PORTER (2003). [63]

${ }^{9}$ WIND; MAIN (2002). [78]

${ }^{10}$ TUBINO (2000). [77]

11 ALEM; CAVALCANTI (2005). [5]

${ }^{12}$ SANTOS (2008, p. 81). [73] Traducción de Melisa Roldán: Los beneficios del crecimiento de la globalización son mercados cada vez más libres y competitivos.
} 
producido por las tecnologías de telecomunicación y de la informatización, eliminando fronteras y aproximando capitales financieros. ${ }^{13}$

Hoy la internacionalización está repleta de propuestas inéditas, pero su crecimiento depende cada vez más de tecnologías innovadoras, que buscan constantemente la sustentabilidad y la competitividad. Según Kotler y Armstrong ${ }^{14}$ la economía mundial actual es globalizada.

Cabe resaltar que las relaciones internacionales entre países son más amplias y abarcadoras que cuando se analiza la internacionalización de una empresa aislada. Los conceptos de cultura, economía, legalización de procedimientos y soporte de negociaciones incluyen mucho más que la logística, elección de plaza y determinación de precios; abarca un sinnúmero de variables a ser consideradas, incluso, en relación a la política de los países involucrados. Sin embargo, la internacionalización es aún una de las mejores opciones para adquirir competitividad frente a la globalización de los mercados. Ello exige, sobre todo, buscar estrategias, como una selección de datos de marketing internacional, que es aplicada específicamente al estudio de cómo se dará la entrada en un mercado externo específico. En este contexto, un mercado puede presentar opciones y estrategias totalmente diferenciadas de otros mercados externos, lo que exige un estudio amplio y detallado de las estrategias a adoptar.

Para comprender mejor el tema, se detalla en el tópico a continuación cómo las estrategias de marketing pueden contribuir a la inserción en el mercado externo.

\subsection{Estrategias de marketing para la entrada en el mercado externo}

La función de evaluar un bloque de informaciones prestando atención a todos los aspectos de la empresa/producto/mercado es una tarea del marketing. Es por medio de él que las organizaciones pueden proyectar y listar esas acciones buscando acercar a los clientes a sus productos y/o servicios. Kotler y Armstrong ${ }^{15}$ definen al marketing como un proceso administrativo y social en el que los individuos y grupos obtienen lo que precisan y desean, por medio de la creación, oferta e, intercambio de productos y valor con otros.

De acuerdo con Porter ${ }^{16}$, entre los aspectos a ser trabajados por el marketing están: la investigación, la planificación, la identificación, el conocimiento, la segmentación del mercado, el estudio sobre el comportamiento de compra del consumidor, las decisiones de producto, precio, canales de distribución y comunicación de marketing.

\footnotetext{
${ }^{13}$ MAÑAS; GIORDANO (2007). [62]

${ }^{14}$ KOTLER; ARMSTRONG (2003). [54]

${ }^{15}$ KOTLER; ARMSTRONG (2003). [54]

${ }^{16}$ PORTER (2004). [70]
} 
Las relaciones establecidas en el mercado internacional, tanto las que involucran empresas como relaciones y acuerdos entre diferentes países formando los bloques económicos, son áreas de estudio relacionadas al marketing internacional, cuyo estudio evalúa diferentes aspectos, como: el estudio individual del país, de su cultura (lengua, símbolos, fechas conmemorativas), economía (PIB, tasa de crecimiento, inflación, etc.), política (inestabilidad y riesgos), leyes y normas (de importación y exportación, por ejemplo), reglas de marcas, patentes, licencias y cambio, entre otros aspectos. Cada variable de éstas puede facilitar o dificultar el proceso de marketing internacional, así como interferir en la estrategia o elección de la inversión a realizar. ${ }^{17}$ $\mathrm{Gil}^{18}$ afirma que el funcionamiento de esas estructuras obedece a algunos patrones como el control accionario, la rama de actividad en el mercado externo, el tamaño organizacional, las demandas ambientales, las expectativas de los clientes, el tamaño del componente administrativo, etc. $Y$ para Etzoini ${ }^{19}$, ambientes organizacionales $y$ estructuras pensadas y sistematizadas para la competitividad, en todo tipo de empresa, cualquiera sea su porte, influyen en el desempeño alcanzado, sobre todo en el proceso de internacionalización.

Sin embargo, cuando se consideran los deseos de una empresa/país en desplazar su producción hacia los mercados internacionales, que en la mayoría de las veces ocurre porque el mercado interno no es amplio o suficiente para absorber la capacidad productiva o no representa más desafíos a su capacidad; el marketing internacional es el que debe ocuparse del proceso de internacionalización.

Kotler y Keller $^{20}$ defienden que entre las decisiones primordiales en el marketing internacional están aquellas ligadas a la decisión de entrar en el mercado extranjero: la elección del (los) mercado(s) internacional(es) en que se ingresará, de qué forma ello se dará, el diseño de un plan de marketing y la organización de procedimientos sobre las decisiones tomadas. Los estudios de Hymer $^{21}$ (1976) identificaron tres motivos principales por los que las empresas deciden invertir en el exterior: neutralizar a los competidores, explorar ventajas competitivas o diversificarse ${ }^{22}$.

De acuerdo con Johanson y Wiedersheim-Paul ${ }^{23}$, el proceso de internacionalización y de entrada en un determinado mercado externo puede realizarse mediante la adopción de medidas como:

a) Actividades de exportación no regulares

\footnotetext{
${ }^{17}$ KEEGAN; GREEN (1999). [52]

${ }^{18}$ GIL (2001). [41]

${ }^{19}$ ETZOINI (1981). [33]

${ }^{20}$ KOTLER; KELLER (2006). [56]

${ }^{21}$ HYMER (1976). [49]

${ }^{22}$ BARRETO; ROCHA (2003). [16]

${ }^{23}$ JOHANSON; WIEDERSHEIM-PAUL (1990). [51]
} 
b) Exportación a través de agentes independientes

c) Filiales de ventas

d) Producción en el exterior

La concepción del proceso de internacionalización en estas cuatro etapas evidencia el grado de desarrollo que la empresa posee en el mercado externo y de la red que compone sus relaciones. De este desarrollo derivan el compromiso de recursos sustanciales y la adquisición de diferentes experiencias y calidad de información ${ }^{24}$. Conocer los factores determinantes para el proceso de internacionalización se ha mostrado importante para el desarrollo de negocios en el exterior, pues posibilita la percepción de los riesgos de inversión, el grado de incertidumbre sobre el retorno de la inversión y las oportunidades de crecimiento. ${ }^{25}$

Los medios de entrada en el mercado externo también pueden alterar los resultados de la inversión. Una de las formas más usadas actualmente para el proceso de internacionalización es la exportación, que puede ser directa o indirecta. En la exportación directa la negociación es realizada por la propia empresa a través de un intermediario con sede en el mercado externo. En el caso de la exportación indirecta la empresa posee un intermediario con sede en el país y cuenta con la ayuda de una empresa especializada en exportación, es decir, una trading o un corredor. ${ }^{26}$

Otra forma de entrada al mercado externo es la licencia, que involucra un contrato permitiendo que una empresa con licencia en el mercado externo produzca un producto o marca bajo la condición del pago de una tasa, o royalty. El licenciante (propietario del producto o marca) consigue entrar en un nuevo mercado con un bajo riesgo y el licenciatario se beneficia agregando nuevos conceptos traídos por la nueva producción. ${ }^{27}$.

La franquicia también es una de las opciones para entrar en el mercado extranjero. Levy y Weitz señalan las ventajas del sistema de franquicias: "método de negócio comprovado; treinamentos e manuais disponíveis; nome e imagem conhecidos; obtenção de economia de escala em virtude de compras terceirizadas" ${ }^{28}$ En cuanto a las desventajas citan la "falta de flexibilidade e as restrições impostas pelo franqueador para a condução do negócio"29.

\footnotetext{
${ }^{24}$ HILAL; HEMAIS (2001). [46]

${ }^{25}$ STONER; FREEMAN (1995). [54]

${ }^{26}$ KOTABE; HELSEN (2000). [53]

${ }^{27}$ MAÑAS; GIORDANO (2007). [62]

${ }^{28}$ LEVY; WEITZ (2000, p. 634). [57]. Tradu cción de Melisa Roldán: "método de negocio comprobado; capacitaciones y manuales disponibles; nombre e imagen conocidos; obtención de economía de escala en virtud de compras terciarizadas".

${ }^{29}$ LEVY; WEITZ (2000, p. 634). Traducción de Melisa Roldán: "falta de flexibilidad y las restricciones impuestas por el franquiciador para la conducción del negocio".
} 
Otra modalidad de entrada en el mercado externo es la subcontratación, o sea, la tercerización de productos o parte de ellos a otra empresa en base a especificaciones preestablecidas. $^{30}$

Las joint ventures son definidas ${ }^{31}$ como formas altamente lucrativas para la entrada en el mercado internacional. En esta modalidad la empresa extranjera acuerda compartir capital y recursos con socios, empresas y autoridades locales para formar una nueva entidad en el mercado objetivo, compartiendo ganancias, perjuicios y la adquisición de autonomía jurídica. Cuando los acuerdos involucran solamente acciones de naturaleza comercial, las joint ventures pueden ser llamadas consorcio.

La red de relaciones (o networks) también son una forma de entrada en el mercado internacional. La realización de estos nuevos acuerdos favorece el acceso a recursos, conocimientos (a través del intercambio de experiencias), estabilidad, interacción con los clientes, proveedores, competidores, instituciones financieras, etc.; calificando el flujo de informaciones, actuando sobre la complejidad tecnológica, acelerando los cambios en el mercado y ofreciendo flexibilidad y ventaja competitiva en los negocios entre los componentes de la red ${ }^{32}$.

Estudios sobre las empresas brasileñas revelan que el volumen comercial de negocios identifica a la exportación como la estrategia de internacionalización más utilizada en Brasil, sobre todo, en las actividades iniciales con el mercado internacional ${ }^{33}$.

La tendencia de la globalización en la actualidad no es la de estandarizar todos los comportamientos, sino de coexistir, respetando las culturas locales, el medio ambiente, utilizando medios de comunicación para interconectar diferentes regiones de todo el planeta; hacer fusiones, alianzas políticas y financieras para mejorar la integración entre países, comercios y pueblos ${ }^{34} 35$.

La economía mundial globalizada viene creando bloques comerciales y acercando países que juntos buscan fortalecerse y enfrentar barreras comerciales para entrar en mercados extranjeros. Esta tendencia tiende a intensificarse ${ }^{36}$. Brasil, para aumentar su fuerza en mercados externos, firmó un acuerdo con países de América del Sur, componiendo el Mercado Común del Cono Sur (MERCOSUR), como se explica en el próximo tópico.

\footnotetext{
${ }^{30}$ BRITO (1993). [25]

${ }^{31}$ LORANGE; ROOS (1996). [58]

${ }^{32}$ HITT; IRELAND; HOSKISSON (2002). [48]

${ }^{33}$ BRASIL, TEC (2012). [20]

${ }^{34}$ KOTLER; ARMSTRONG (2003). [54]

${ }^{35}$ CIGNACCO (2009). [29]

${ }^{36}$ MORAN (2000). [68]
} 


\subsection{EI MERCOSUR}

Los bloques comerciales son acuerdos intergubernamentales que reducen de forma total o parcial las barreras de entrada y salida de mercancías/servicios/impuestos y, según el nivel de integración económica entre sus componentes, pueden alcanzar diferentes categorías de integración, como: zona de preferencia tarifaria, zona de libre comercio, unión aduanera, mercado común y unión económica monetaria ${ }^{37}$.

Entre las ventajas que se derivan de la formación de bloques entre países está la reducción o eliminación de las tarifas de importación/exportación; productos más baratos; reducción en la tasa aduanera; mayor facilidad para que las personas se muevan de un país a otro; beneficios en la aplicación de economías de escala al sector productivo reduciendo costos y aumentando la eficiencia; y la posibilidad de proteger productores ineficientes dentro del bloque contra aquellos más eficientes fuera del mismo. Las desventajas incluyen la diferencia de precio de los productos en relación con otro país del mismo bloque y un menor ingreso del productor naciona ${ }^{38}$.

Brasil participa además en grupos como UNASUR (Unión de las Naciones Sudamericanas), que incluye 12 Estados de América del Sur; la CELAC (Comunidad de los Estados Latinoamericanos y Caribeños), que abarca 33 países; y la OTCA (Organización del Tratado de Cooperación Amazónica), compuesto por Brasil, Bolivia, Colombia, Ecuador, Guyana, Perú, Surinam y Venezuela. ${ }^{39}$

Para Brasil, en relación a la participación en estos bloques económicos, se destaca el MERCOSUR (Brasil, Argentina, Paraguay, Uruguay y, recientemente, Venezuela, además de Bolivia, que solicitó su ingreso al bloque a partir de diciembre de 2012 y se encuentra en proceso de adhesión), que ocupa el tercer lugar en el planeta como bloque económico, quedando atrás solamente del NAFTA (Acuerdo de Libre Comercio de América del Norte) y de la UE (Unión Europea) ${ }^{40}$.

Existen también otros países de América del Sur que suscribieron acuerdos con el MERCOSUR, como Chile, Colombia, Ecuador y Perú. Estos países son llamados Estados Asociados ${ }^{41}$.

La relación comercial de Brasil acontece con muchos de esos bloques económicos ${ }^{42}$, tanto en la exportación como en la importación de productos. Los principales bloques económicos y, dentro de ellos, los países que más se destacan en las exportaciones

\footnotetext{
${ }^{37}$ MILNER (2005). [65]

${ }^{38}$ CIGNACCO (2009). [29]

${ }^{39}$ RIBEIRO; PINCHEMEL (2011). [72]

${ }^{40}$ RIBEIRO; PINCHEMEL (2011). [72]

${ }^{41}$ BRASIL, TEC (2012). [20]

${ }^{42}$ FIGUEIREDO (2014). [38]
} 
brasileñas, pueden ser observados en la Tabla 1, que presenta datos provistos por la balanza comercial brasileña de 2013.

Tabla 1 - Bloques económicos de destino de las exportaciones brasileñas

\begin{tabular}{|c|c|c|c|c|c|}
\hline & \multicolumn{2}{|c|}{ Janeiro/Dezembro } & \multirow{2}{*}{$\begin{array}{l}\text { Var.\% 2013/12 } \\
\text { p/média diária }\end{array}$} & \multicolumn{2}{|c|}{ Part. \% } \\
\hline & 2013 & 2012 & & 2013 & 2012 \\
\hline Ásia & 77.657 & 75.325 & 2,3 & 32,1 & 31,1 \\
\hline . China & 46.026 & 41.228 & 10,8 & 19,0 & 17,0 \\
\hline América Latina e Caribe & 53.700 & 50.445 & 5,6 & 22,2 & 20,8 \\
\hline - Mercosul (2) & 29.533 & 27.856 & 5,2 & 12,2 & 11,5 \\
\hline Argentina & 19.616 & 17.998 & 8,1 & 8,1 & 7,4 \\
\hline - Demais da AL e Caribe & 24.167 & 22.589 & 6,1 & 10,0 & 9,3 \\
\hline Uniăo Europeia & 47.722 & 49.102 & $-3,6$ & 19,7 & 20,2 \\
\hline EUA (1) & 24.856 & 26.849 & $-8,2$ & 10,3 & 11,1 \\
\hline Africa & 11.087 & 12.213 & $-9,9$ & 4,6 & 5,0 \\
\hline Oriente Médio & 10.954 & 11.528 & $-5,7$ & 4,5 & 4,8 \\
\hline Europa Oriental & 4.179 & 4.327 & $-4,2$ & 1,7 & 1,8 \\
\hline Demais & 12.023 & 12.788 & $-6,7$ & 5,0 & 5,3 \\
\hline TOTAL & 242.178 & 242.577 & $-1,0$ & 100,0 & 100,0 \\
\hline
\end{tabular}

Fuente: Brasil (2013, p. 12, balanza comercial) ${ }^{43}$.

(1) Incluye Puerto Rico.

(2) Incluye Venezuela, a partir de agosto de 2012.

(3)

Se observa que es China el principal destino de las exportaciones brasileñas, seguido de los Estados Unidos y Caribe y de Argentina. El menor valor alcanzado por las exportaciones fue para Europa Oriental, lo que puede representar un mercado a ser conquistado por Brasil. En el caso de las importaciones brasileñas, los principales países de origen dentro de los bloques económicos son mostrados por la Tabla 2.

${ }^{43}$ BRASIL (2013). [21] 
Tabla 2 - Bloques económicos de origen de las importaciones brasileñas

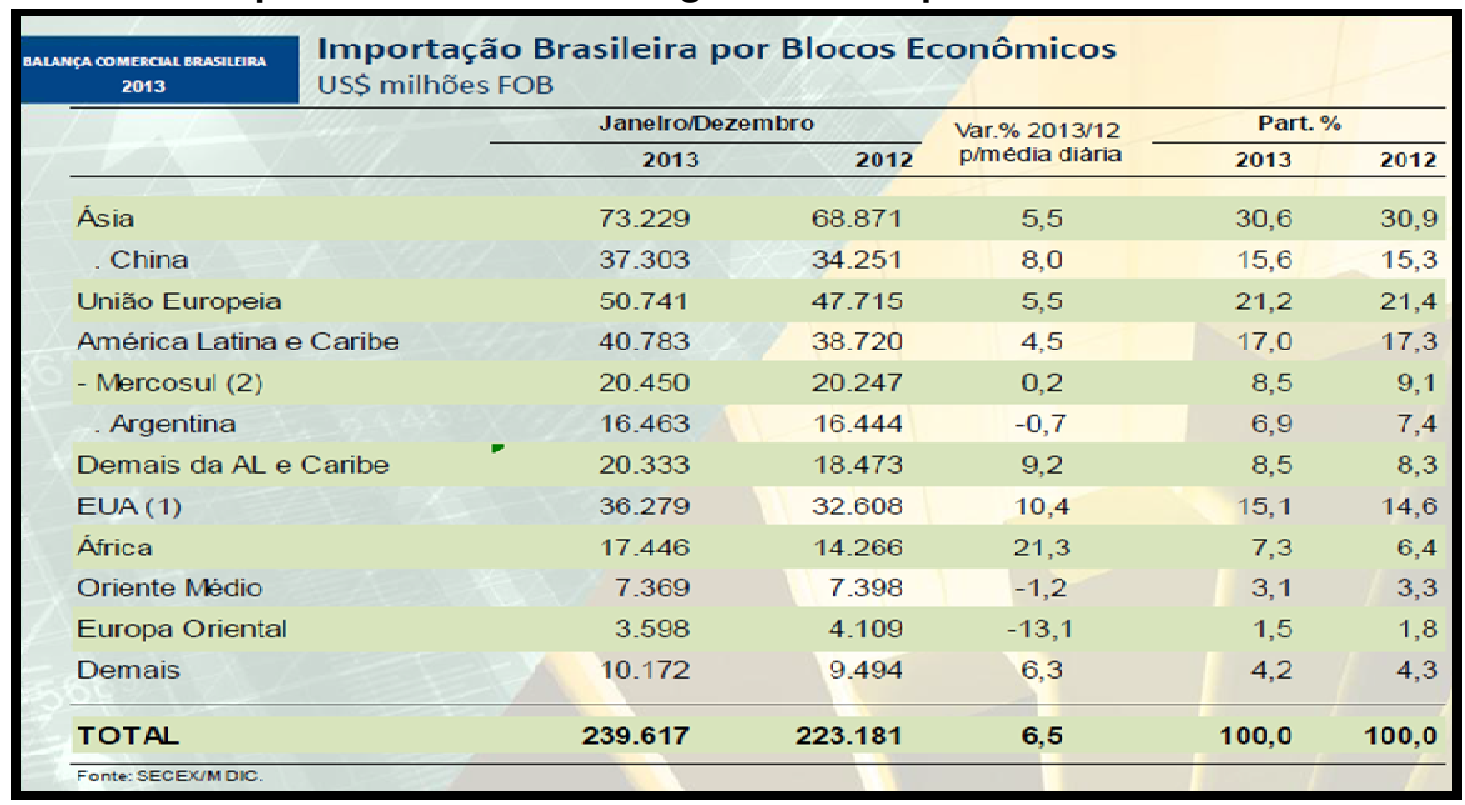

Fuente: Brasil (2013, p. 14, balanza comercial).

(1) Incluye Puerto Rico.

(2) Incluye Venezuela, a partir de agosto de 2012.

China se destaca también en las importaciones hechas por Brasil, en relación a los demás países. Sin embargo, dentro del MERCOSUR, Argentina se destaca como principal destino de los negocios brasileños. Para comprender el volumen de importaciones y exportaciones brasileñas en relación a los países que componen el MERCOSUR, se observa la Tabla 3, que presente datos hasta agosto de $2014 .{ }^{44}$

Tabla 3 - Exportaciones e importaciones brasileñas en el MERCOSUR entre 2013 y 2014

\begin{tabular}{c|c|c|c|c|c|c|c|c}
\hline \multicolumn{4}{c|}{ Agosto de 2014 (US\$ millones FOB) } & \multicolumn{3}{c}{ Agosto de 2013 (US\$ millones FOB) } \\
\hline & MERCOSUL & Argentina & Paraguay & Uruguay & MERCOSUL & Argentina & Paraguay & Uruguay \\
\hline EXP. & 1.621 & 1.163 & 265 & 193 & 2.376 & 1.814 & 247 & 316 \\
\hline IMP. & 1.328 & 1.078 & 110 & 140 & 1.519 & 1.280 & 110 & 129 \\
\hline SALDO & 293 & & & & 857 & & & \\
\hline
\end{tabular}

Fuente: Brasil (2014, p. 2, balanza comercial).

La Tabla 3 destaca la superioridad de las relaciones comerciales mantenidas entre Brasil y Argentina (cuyas exportaciones aumentaron un 9\% en 2013). Para Chile y Venezuela las exportaciones brasileñas crecieron un 4\% en 2013. La relación de Brasil con los demás países que componen el MERCOSUR viene creciendo. ${ }^{45}$

\footnotetext{
${ }^{44}$ BRASIL (2014, p. 2, balança comercial). [22]

${ }^{45}$ BREDA; PEREZ (2012). [24]
} 
En la Tabla 4 se describen las relaciones de importaciones y exportaciones entre Argentina y otros países. ${ }^{46}$

Tabla 4 - Exportaciones e importaciones entre Argentina y otros países

\begin{tabular}{|c|c|c|c|c|c|}
\hline \multicolumn{3}{|c|}{ Exportaciones Argentinas (U \$ billones) } & \multicolumn{3}{|c|}{ Importaciones Argentinas (U $\$$ billones) } \\
\hline Países & 2011 & Part. \% Total & Países & 2013 & $\begin{array}{c}\text { Part. \% } \\
\text { Total }\end{array}$ \\
\hline Brasil & $\overline{16,2}$ & $21,2 \%$ & Brasil & 19,1 & $26,1 \%$ \\
\hline China & 5,5 & $7,2 \%$ & China & 11,2 & $15,3 \%$ \\
\hline USA & 4,3 & $5,6 \%$ & USA & 8,0 & $10,9 \%$ \\
\hline Chile & 3,9 & $5,1 \%$ & Alemania & 3,9 & $5,3 \%$ \\
\hline Venezuela & 2,2 & $2,8 \%$ & México & 2,2 & $2,9 \%$ \\
\hline Países Bajos & 1.9 & $2.5 \%$ & Francia & 2.1 & $2.8 \%$ \\
\hline Uruguay & 1,8 & $2,3 \%$ & Trinidad y Tobago & 1,8 & $2,5 \%$ \\
\hline España & 1,7 & $2,2 \%$ & Bolivia & 1,7 & $2,3 \%$ \\
\hline Canadá & 1,7 & $2,2 \%$ & Rusia & 1,7 & $2,3 \%$ \\
\hline Alemania & 1,6 & $2,1 \%$ & Italia & 1,7 & $2,3 \%$ \\
\hline Otros Países & 35,8 & $46,7 \%$ & Otros Países & 20,0 & $27,2 \%$ \\
\hline Total & 76,6 & $100 \%$ & Total & 73,3 & $100 \%$ \\
\hline
\end{tabular}

Fuente: Adaptado de Argentina (2014, p. 6-7).

Se observa que, tanto en las exportaciones como en las importaciones, la mejor relación comercial es con Brasil. Aunque venga enfrentando una crisis política, el comercio exterior de Argentina presentó en 2013 un crecimiento de 58\% en relación a 2009. En el ranking de la ONU/UNCTAD (Organización de las Naciones Unidas y Conferencia de las Naciones Unidas sobre Comercio y Desarrollo, respectivamente) de 2013 Argentina figuró como el $42^{\circ}$ mercado mundial, siendo el $44^{\circ}$ exportador y el $43^{\circ}$ importador. El saldo de la balanza comercial de Argentina presentó superávit en todo el período, totalizando en 2013 saldo positivo de US\$ 3,3 billones ${ }^{47}$, como se puede observar en la Tabla 5 que presenta el valor alcanzado por el país en las relaciones de importación y exportación de 2009 a 2013.

Tabla 5 - Balanza comercial Argentina de 2009 a 2013

\begin{tabular}{|c|c|c|c|c|c|c|c|}
\hline \multirow{2}{*}{ Anos } & \multicolumn{2}{|c|}{ Exportações } & \multicolumn{2}{|c|}{ Importações } & \multicolumn{2}{|c|}{ Intercâmbio Comercial } & \multirow{2}{*}{ Saldo } \\
\hline & Valor & Var.\% & Valor & Var.\% & Valor & Var. $\%$ & \\
\hline 2009 & 12,8 & $-27,4 \%$ & 11,3 & $-14,9 \%$ & 24,1 & $-22,0 \%$ & 1,5 \\
\hline 2010 & 18,5 & $44,9 \%$ & 14,4 & $27,9 \%$ & 33,0 & $36,9 \%$ & 4,1 \\
\hline 2011 & 22,7 & $22,6 \%$ & 16,9 & $17,1 \%$ & 39,6 & $20,2 \%$ & 5,8 \\
\hline 2012 & 18,0 & $-20,7 \%$ & 16,4 & $-2,7 \%$ & 34,4 & $-13,1 \%$ & 1,6 \\
\hline 2013 & 19,6 & $9,0 \%$ & 16,5 & $0,1 \%$ & 36,1 & $4,8 \%$ & 3,2 \\
\hline 2013 (jan-jul) & 11,2 & $8,3 \%$ & 10,3 & $18,2 \%$ & 21,5 & $12,9 \%$ & 0,9 \\
\hline 2014 (jan-jul) & 8,7 & $-22,6 \%$ & 8,3 & $-19,7 \%$ & 16,9 & $-21,2 \%$ & 0,4 \\
\hline $\begin{array}{c}\text { Var. } \% \\
2009-2013 \\
\end{array}$ & \multicolumn{2}{|c|}{$53,4 \%$} & \multicolumn{2}{|c|}{$45,9 \%$} & \multicolumn{2}{|c|}{$49,9 \%$} & n.c. \\
\hline
\end{tabular}

Fuente: Argentina (2014, p. 10).

\footnotetext{
${ }^{46}$ ARGENTINA (2014, p. 6-7). [14]

${ }^{47}$ ARGENTINA (2014). [14]
} 
En 2009 Argentina presentó un déficit de $-27,4 \%$ en las exportaciones y de $14.9 \%$ en las importaciones. Aunque recuperó inversiones de forma significativa en 2010, con saldo positivo de $44,9 \%$ en las exportaciones y 27,9\% en las importaciones. En 2011 mantuvo saldo positivo y en 2012 cayó nuevamente. En 2013, cerró la balanza comercial de las exportaciones con saldo de $9 \%$ y $0,1 \%$ en las importaciones. Argentina enfrentó algunos momentos de crisis política en ese contexto, claramente observada en los números presentados.

La evolución comercial entre Brasil y Argentina hace que dicha relación sea cada vez más importante para el MERCOSUR como bloque económico. En verdad, el Mercado Común del Sur puede ser visto como una asociación en América Latina para huir de la significativa influencia de los Estados Unidos. Aunque represente una forma de represión, aún queda recorrer muchos caminos para disminuir la influencia del norte americano en la cultura y la tradición latina, entre otros aspectos. De forma general, la creación del MERCOSUR nació de ideas periféricas oriundas de otros acuerdos comerciales. El embrión del proceso integrador en América Latina fue el ALALC (Asociación Latinoamericana de Libre Comercio) y ALADI (Asociación Latinoamericana de Integración). En aquella época (entre 1980 y 1990), Brasil y Argentina iniciaron conversaciones y firmaron acuerdos bilaterales (la Declaración de Iguazú en 1985 y el Tratado de Integración, Cooperación y Desarrollo en 1988), en vistas de incrementar el comercio entre sí y crear un mercado mayor, abierto a los países que quisieran participar del mismo. "Diante disso, Paraguai e Uruguai passam a integrar o grupo em 1991 a partir da assinatura do Tratado de Assunção, criando assim o MERCOSUL (Mercado Comum do Sul)"48.

EI MERCOSUR cuenta con una estructura funcional que alberga órganos como el Consejo de Mercado Común, responsable de la política de integración del bloque y representada por los cancilleres y ministros de la hacienda de los estados miembros; el Grupo de Mercado Común, responsable de los acuerdos y tratados para la implantación de las políticas económicas y comerciales entre los países; la Comisión de Comercio, órgano técnico que asesora al Grupo de Mercado Común en sus decisiones; una Secretaría General, con sede en Montevideo y una Comisión Parlamentaria Conjunta. Esta estructura se ocupa de establecer acuerdos no sólo con áreas relacionadas a la economía, sino también con la cultura, la educación, desplazamientos poblacionales, laborales, entre otros. ${ }^{49}$

\footnotetext{
${ }^{48}$ BRASIL (2013). [21]Traducción de Melisa Roldan:”Frente a ello, Paraguay y Uruguay pasaron a integrar el grupo en 1991 a partir de la firma del Tratado de Asunción, creando así el MERCOSUR (Mercado Común del Sur)

${ }^{49}$ TEIXEIRA (2003). [75]
} 
Lo que concierne destacar es que el MERCOSUR viene dando lugar al crecimiento de sus países miembros, como muestra la Tabla 6 , que considera el crecimiento medio entre los años 1994 y 2002, 2002 a 2010 y 2011 a $2012^{50}$

Tabla 6 - Crecimiento medio de los países latinoamericanos entre 1994 y 2002

\begin{tabular}{|c|c|c|c|}
\hline \multicolumn{4}{|c|}{ CRESCIMENTO MÉdIO NO PERÍODO } \\
\hline & $\begin{array}{l}1994 \\
\text { a } 20002\end{array}$ & $\begin{array}{l}2002 \\
\text { a 2010 }\end{array}$ & $\begin{array}{l}2011 \\
\text { a } 2012\end{array}$ \\
\hline Amêrica Latina & 2.2 & 4,1 & 3.8 \\
\hline Argentina & -0.8 & 7.6 & 5.7 \\
\hline Bolívia & 3.3 & 4.3 & 5.1 \\
\hline Brasil & 2.3 & 4.0 & 2.1 \\
\hline Chile & 4.6 & 4.4 & 5.4 \\
\hline Colômbia & 1.7 & 4.6 & 5.1 \\
\hline Equador & 1.9 & 4.4 & 5.9 \\
\hline México & 2,4 & 2,2 & 3.9 \\
\hline Paraguai & 1.0 & 4.4 & 1.4 \\
\hline Peru & 3.3 & 6,5 & 6.5 \\
\hline Uruguai & $-0,3$ & 5.3 & 4.6 \\
\hline Venezuela & 0.2 & 4.7 & 5.0 \\
\hline
\end{tabular}

Fuente: Franquilo (2014, p. 4).

El crecimiento de Argentina fue el mayor a partir de 2002, en relación a Brasil (7,6 y 4,0, respectivamente). Sin embargo, ambos perdieron mercado entre 2011 y 2012. Argentina alcanzó el crecimiento medio de 5,7, mientras Brasil no pasó de 2,1. La crisis mundial afectó de forma sistemática a los negocios y fue sentida también por Uruguay, que perdió potencial de crecimiento entre 2011 y 2012 (de 5,3 a 4,6).

Lo que importa destacar es que el MERCOSUR, en comparación con los demás bloques económicos formados en el mundo, toma fuerza dentro de América Latina no solo entre sus países integrantes y competidores, sino de forma general. No obstante, a diferencia del nivel económico, no posibilita que los países que componen el MERCOSUR adquieran potencial semejante de penetración en los diferentes mercados, lo que impide que haya un crecimiento igual en los diferentes sectores y representen equilibrio de inversión y de relaciones dentro del propio bloque. Eso, sin embargo, no impide que se intensifiquen las relaciones entre los componentes del bloque, mostrando diversos beneficios que pueden obtenerse por medio de la asociación de intereses y la reducción de barreras entre países con relaciones comerciales de interés común. Aunque las relaciones de importación y exportación brasileñas, de forma general, no tengan como principal destino los países del MERCOSUR, pues se dirigen a China, algunos productos son fuertemente dirigidos a esos mercados y corresponden a una parte significativa de las relaciones de Brasil con el mercado externo mundial.

\footnotetext{
${ }^{50}$ FRANQUILO (2014). [39]
} 
Cabe destacar también que dentro del MERCOSUR Argentina es el principal país de los negocios brasileños. Aunque al considerarse superior en el mercado brasileño en relación a los demás países miembros del MERCOSUR, y considerando en volumen de transacciones dentro del bloque, Brasil es el principal destino tanto de las importaciones como de las exportaciones de Argentina, el segundo miembro más fuerte dentro del bloque.

Considerando la superioridad de las relaciones comerciales entre Brasil y Argentina dentro del MERCOSUR, se resalta la importancia de investigar el comercio bilateral entre estos dos países, tema abordado por el tópico siguiente.

\subsection{El comercio bilateral entre Brasil y Argentina}

Actualmente, Brasil posee significativa parte de representatividad por el PBI de Argentina, pues es el principal inversor externo y está representado por grandes empresas brasileñas que establecieron filiales o hicieron adquisiciones e inversiones de gran porte en el territorio, sobre todo después de 2002. Se destacan entre ellas: Petrobras Argentina (PESA); AMBEV; Grupo Camargo Corrêa; Vale; Banco de Brasil; Gerdau; Grupo Itaúsa (Banco Itaú); Marfrig; Friboi; Votorantim; Brasil Foods S.A.; Pactual Capital Partners; TAM; América Latina Logística; Universo On-Line; Klabin; Coteminas; Tigre; Marcopolo; Grupo Dass; Randon; Bradesco; Moura; DixieToga; Verdi; Cotia Trading; Grupo AMAGGI; Localiza; Weg; y Natura Cosméticos entre otros. De acuerdo con estimaciones de SECOM (Secretaría de Comunicación) Buenos Aires, el valor de inversión extranjera directa (IED) realizado por empresas brasileñas entre 1997 y 2011 gira en torno a los US\$18.8 billones. En ese aspecto, el sector primario es responsable del $49 \%$ del IED y el sector secundario del $42 \%$. Grandes empresas brasileñas como Natura firmaron acuerdos y tercerizaron su producción de cosméticos, fragancias y productos de higiene personal en Argentina, desde 1994, pero durante algún tiempo enfrentaron dificultades para retirar sus productos de la aduana porteña. Los productos Natura ocupan el tercer lugar en la preferencia de los argentinos. ${ }^{51}$

Para comprender el índice de inversiones de Brasil en territorio argentino, se observa la Figura 1, que muestra el porcentaje invertido por el sector entre 1997 y 2012.

\footnotetext{
${ }^{51}$ ALICEWEB (2013). [6]
} 
Figura 1 - Porcentaje de inversiones de empresas brasileñas en suelo argentino

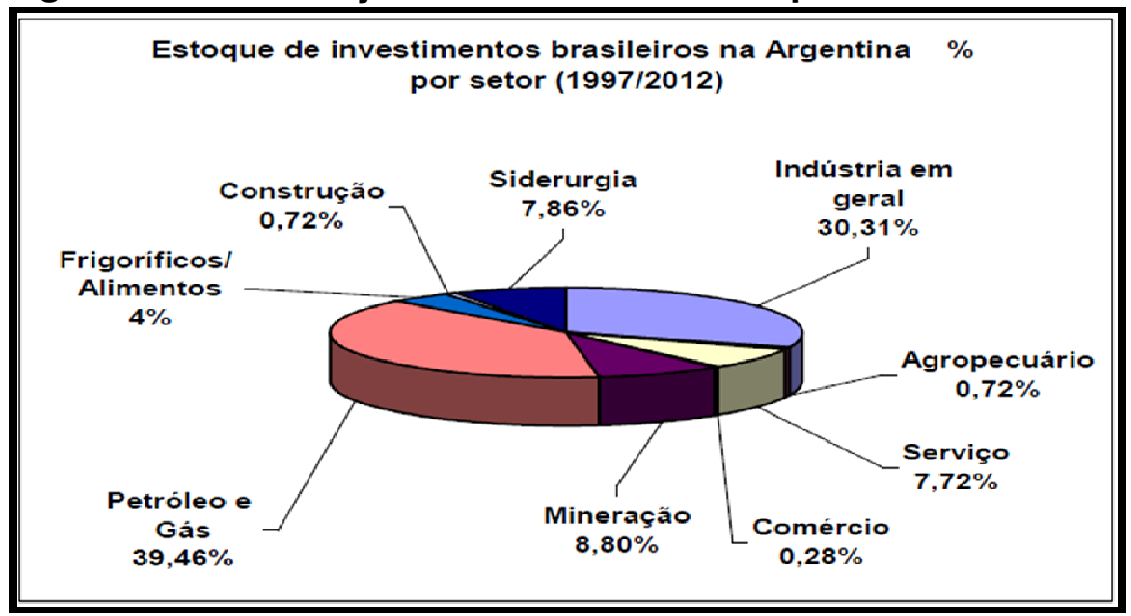

Fuente: Brasil (2012, p. 43).

Según la Figura 1, el petróleo/gas e industrias en general corresponden a las mayores fracciones del mercado argentino, considerando las inversiones de brasileños en el país. La minería, la siderurgia y los servicios también ocupan parte importante de ese mercado, seguidos por el sector alimenticio, la construcción civil y el comercio.

En 2013, Argentina mantuvo un total del 50\% de sus importaciones provenientes de sus vecinos del continente americano, pues son ellos los principales abastecedores del mercado argentino. América del Sur posee un 32\% de ese comercio; los países asiáticos $26 \%$ y la Unión Europea representan el $18 \%$ de las importaciones. Individualmente, Brasil es el principal proveedor de bienes a Argentina con 26,1\% del total.

Cabe aclarar que Argentina forma parte, entre otros, de las siguientes organizaciones y acuerdos internacionales: Organización de las Naciones Unidas (ONU); Organización Mundial del Comercio (OMC); Grupo de los 20 (G20); Grupo Cairns; Asociación Latinoamericana de Integración (ALADI)/MERCOSUR; Grupo de los 77 $(G 77)^{52}$. Los diez principales países que componen el mercado de importaciones argentino están descritos por el Gráfico 1.

\footnotetext{
${ }^{52}$ BRASIL (2012). [20]
} 
Gráfico 1 - Los 10 principales países de origen de las importaciones argentinas.

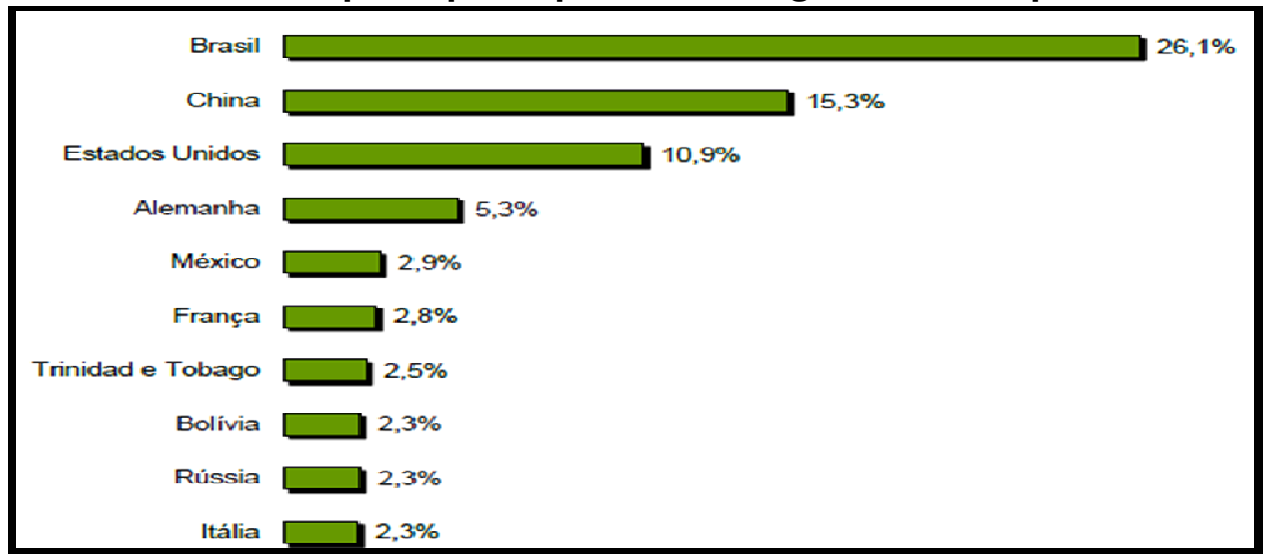

Fuente: Argentina (2014, p. 7).

Se desprende del Gráfico 2 (a continuación) que las ventas argentinas de 2013, el $49 \%$ fueron destinadas a los vecinos del continente americano. De esta cantidad, el $38 \%$ fueron dirigidos a América del Sur. Los países de Asia compraron 25\% de las ventas argentinas, seguidos de la Unión Europea con $13 \%$ y África con 7\%. ${ }^{53}$ Por su parte, Brasil fue el principal destino de las ventas argentinas con el $21,2 \%$ del total en 2013, como muestra el Gráfico 2.

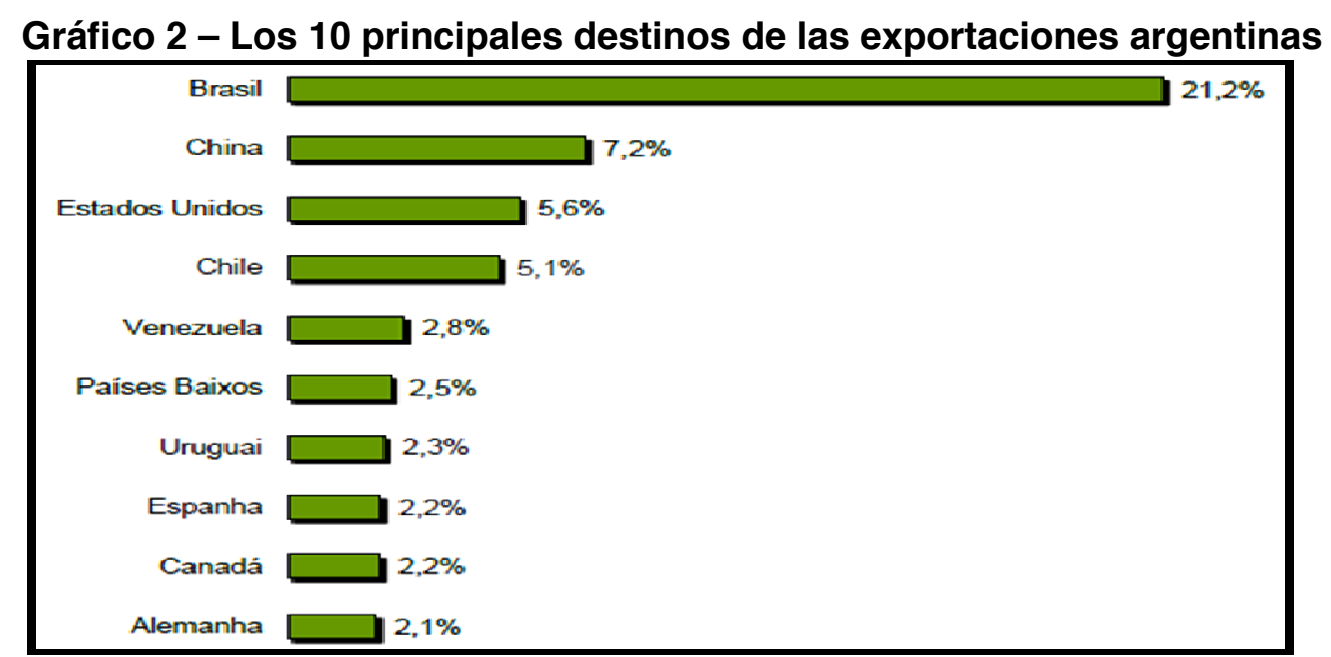

Fuente: Argentina (2014, p. 7).

Contemplando el gráfico anterior, Brasil recibe el 21,2\% de las exportaciones de Argentina, volviéndose el principal cliente del país. Se observa además que el volumen de relaciones con China, segundo mayor destino de las exportaciones de Argentina, es significativamente menor, alcanzando $14 \%$ menos de volumen de negocios que Brasil. Argentina fue el $3^{\circ}$ principal socio comercial brasileño, con participación de $7,5 \%$ en el comercio exterior de Brasil en 2013. Entre 2009 y 2013, el intercambio comercial brasileño con Argentina creció 49,9\%, de US\$24,1 billones a US\$ 36,1

${ }^{53}$ ARGENTINA (2014). [14] 
billones. En ese período, las exportaciones crecieron $53,4 \%$ y las importaciones 45,9\%. El saldo de la balanza comercial, favorable para Brasil en todo el período, registró superávit de US\$ 3,2 billones en $2013^{54}$. El intercambio bilateral puede observarse en la Tabla 7 , que muestra la evolución de la relación de Brasil con Argentina de 2007 a 2013.

Tabla 7 - Exportaciones e importaciones de Brasil con Argentina

\begin{tabular}{l|c|r|r|r|r|r}
\hline \multicolumn{4}{c|}{ Exportación } & \multicolumn{3}{c}{ Importación } \\
\hline Año & US\$ FOB (A) & Var. \% & Part. \%* & US\$ FOB (A) & Var. \% & Part. \%* $^{*}$ \\
\hline 2007 & 14.416 .945 .588 & 22,81 & 8,97 & 10.404 .245 .932 & 29,19 & 8,63 \\
\hline 2008 & 17.605 .620 .920 & 22,12 & 8,89 & 13.258 .441 .511 & 27,43 & 7,66 \\
\hline 2009 & 12.784 .966 .502 & $-27,38$ & 8,36 & 11.281 .656 .656 & $-14,91$ & 8,83 \\
\hline 2010 & 18.522 .520 .610 & 44,88 & 9,17 & 14.434 .593 .883 & 27,95 & 7,94 \\
\hline 2011 & 22.709 .344 .431 & 22,60 & 8,87 & 16.906 .351 .509 & 17,12 & 7,47 \\
\hline 2012 & 17.997 .706 .375 & $-20,75$ & 7,42 & 16.443 .910 .391 & $-2,74$ & 7,37 \\
\hline 2013 & 19.615 .414 .342 & 8,99 & 8,10 & 16.462 .684 .216 & 0,11 & 6,87 \\
\hline
\end{tabular}

Fuente: Brasil (2014, p. 5, balanza comercial MERCOSUL).

${ }^{*}$ Part. \% $\Rightarrow>$ Participación porcentual sobre el Total General de Brasil

IMPORTACIÓN => Base ALICEWEB - Ago/14, País de Origen.

EXPORTACIÓN => Base ALICEWEB - Ago/14, País de Destino Final.

El estancamiento observado en las importaciones y exportaciones de 2009 a 2012 se debe a la crisis enfrentada por el mercado mundial en general y por Argentina específicamente, considerándose la inestabilidad y las crisis en la organización política de dicho país.

La relación entre Argentina y Brasil en cuanto a las exportaciones e importaciones puede observarse en la Tabla 8 , que presenta el saldo de esta relación comercial, generalmente negativo, ya que Argentina importa más de lo que exporta hacia Brasil. ${ }^{55}$

Tabla 8 - Exportaciones e importaciones de Argentina con Brasil

\begin{tabular}{c|r|r|r}
\hline Ano & Exportación US\$ FOB (A) & Importación US\$ FOB (A) & \multicolumn{1}{c}{ Saldo US\$ FOB (A) } \\
\hline 2007 & 10.498 .013 .492 & 14.081 .313 .560 & -3.583 .300 .068 \\
\hline 2008 & 13.273 .278 .538 & 17.222 .540 .375 & -3.949 .261 .837 \\
\hline 2009 & 11.379 .790 .102 & 11.592 .814 .433 & -213.024 .331 \\
\hline 2010 & 14.420 .955 .017 & 17.279 .432 .528 & -2.858 .477 .511 \\
\hline 2011 & 17.249 .223 .317 & 21.165 .602 .389 & -3.916 .379 .072 \\
\hline 2012 & 16.332 .632 .986 & 17.354 .333 .287 & -1.021 .700 .301 \\
\hline 2013 & 15.827 .866 .050 & 18.715 .934 .209 & -2.888 .068 .159 \\
\hline
\end{tabular}

Fuente: ALICEWEB MERCOSUR (2014, p. 5, balanza comercial MERCOSUR).

Los números muestran valores bastante altos, aunque dicho volumen de negocios proviene de distintas fuentes.

Las exportaciones brasileñas hacia Argentina están compuestas, en mayor medida, por productos manufacturados, que representaron el $91,9 \%$ del total en 2013 ,

\footnotetext{
${ }^{54}$ BRASIL (2014). [22]

${ }^{55}$ ALICEWEB (2014, p. 5). [6]
} 
destacándose automóviles, máquinas, plásticos, caucho y papel. Considerando las importaciones, los productos manufacturados sumaron el $84,7 \%$ de las importaciones brasileñas provenientes de Argentina en 2013, representados por automóviles, máquinas y plásticos. Los automóviles (de paseo, tractores, chasis y vehículos de carga) sumaron $45,9 \%$ del total importado, seguidos de máquinas mecánicas (motores y piezas para motores automotores y agrícolas) con el $9,5 \%{ }^{56}$.

En este contexto, presentando los principales productos comprendidos en el intercambio comercial bilateral, quedan mostrados en la Tabla 9, que lista los productos que intervienen en las importaciones y exportaciones entre Brasil y Argentina hasta diciembre de 2013.

Tabla 9 - Principales productos comprendidos en el intercambio comercial de Brasil con Argentina en 2013 (US\$ billones FOB)

\begin{tabular}{l|l|l|l|l|l}
\hline \multicolumn{1}{c}{$\begin{array}{c}\text { Productos } \\
\text { Exportados }\end{array}$} & $\mathbf{2 0 1 3}$ & Part. Total & \multicolumn{1}{|c|}{$\begin{array}{c}\text { Productos } \\
\text { Importados }\end{array}$} & $\mathbf{2 0 1 3}$ & Part. Total \\
\hline Automóviles & 9,00 & $45,9 \%$ & Automóviles & 8,08 & $49,1 \%$ \\
\hline Máquinas mecánicas & 1,85 & $9,5 \%$ & Cereales & 1,18 & $7,1 \%$ \\
\hline Minerales & 0,97 & $4,9 \%$ & Combustibles & 1,03 & $6,2 \%$ \\
\hline Máquinas eléctricas & 0,87 & $4,4 \%$ & Máquinas mecánicas & 0,74 & $4,5 \%$ \\
\hline Plásticos & 0,85 & $4,3 \%$ & Plásticos & 0,68 & $4,1 \%$ \\
\hline Fierro y acero & 0,63 & $3,2 \%$ & $\begin{array}{l}\text { Preparaciones } \\
\text { hortícolas }\end{array}$ & 0,34 & $2,0 \%$ \\
\hline Caucho & 0,53 & $2,7 \%$ & $\begin{array}{l}\text { Diversos ind. } \\
\text { químicas }\end{array}$ & 0,32 & $2,0 \%$ \\
\hline Combustibles & 0,51 & $2,6 \%$ & Malta/almidones & 0,31 & $1,9 \%$ \\
\hline Químicos orgánicos & 0,42 & $2,1 \%$ & Frutas & 0,30 & $1,8 \%$ \\
\hline Papel & 0,41 & $2,1 \%$ & Leche/huevos/miel & 0,28 & $1,7 \%$ \\
\hline Subtotal & $\mathbf{1 6 , 0 3}$ & $\mathbf{8 1 , 7 \%}$ & Subtotal & $\mathbf{1 3 , 2 5}$ & $\mathbf{8 0 , 5 \%}$ \\
\hline Otros productos & $\mathbf{3 , 5 8}$ & $\mathbf{1 8 , 3} \%$ & Otros productos & $\mathbf{3 , 2 1}$ & $\mathbf{1 9 , 5 \%}$ \\
\hline Total & $\mathbf{1 9 , 6 2}$ & $\mathbf{1 0 0 , 0} \%$ & Total & $\mathbf{1 6 , 4 6}$ & $\mathbf{1 0 0 , 0} \%$ \\
\hline Fuent: Adapta & & & & \\
\hline
\end{tabular}

Fuente: Adaptado de Argentina (2014, p. 12-13).

La Tabla 10 comprende los valores de la exportación y de la importación de Argentina con Brasil hasta diciembre de 2013. Teniendo en cuenta los datos que aporta dicha

\footnotetext{
${ }^{56}$ ARGENTINA (2014). [14]
} 
tabla, los principales productos que Argentina exportó a Brasil fueron: las sobras de las industrias alimentarias (como salvado de soja), que fue el principal grupo de productos exportados, representando el 15,7\% del total en 2013; los automóviles (autos de paseo, para transporte de mercancías, partes y accesorios, automóviles para turismo) se posicionaron luego con $13,2 \%$, seguidos de cereales (maíz, cebada, trigo, soja y arroz) con el 10,8\%; grasas y aceites (aceite de soja, de girasol, margarina) con 6,8\% y granos (soja, cacao, semillas de girasol) con 6,0\%. La lista de las importaciones de Argentina se concentró en automóviles, combustibles y máquinas.

En 2013, la suma de estos grupos representó el 59,8\% del total ${ }^{57}$.

Tabla 10 - Principales productos del intercambio comercial de Argentina con Brasil en 2013 (US\$ billones FOB)

\begin{tabular}{|c|c|c|c|c|c|}
\hline Productos Exportados & 2013 & $\begin{array}{l}\text { Part. } \\
\text { Total }\end{array}$ & $\begin{array}{l}\text { Productos } \\
\text { Importados }\end{array}$ & 2013 & $\begin{array}{l}\text { Part. } \\
\text { Total }\end{array}$ \\
\hline $\begin{array}{l}\text { Sobras de las industrias } \\
\text { alimenticias (salvado de } \\
\text { soja) }\end{array}$ & 12,03 & $15,7 \%$ & Automóviles & 14,33 & $19,5 \%$ \\
\hline Automóviles & 10,09 & $13,2 \%$ & Combustibles & 10,84 & $14,8 \%$ \\
\hline Cereales & 8,30 & $10,8 \%$ & $\begin{array}{l}\text { Máquinas } \\
\text { mecánicas }\end{array}$ & 10,30 & $14,1 \%$ \\
\hline Grasas y Aceites & 5,18 & $6,8 \%$ & Máquinas eléctricas & 8,40 & $11,5 \%$ \\
\hline Granos & 4,62 & $6,0 \%$ & Químicos orgánicos & 3,03 & $4,1 \%$ \\
\hline Combustibles & 3,56 & $4,6 \%$ & Plásticos & 2,77 & $3,8 \%$ \\
\hline Oro y piedras preciosas & 2,05 & $2,7 \%$ & Fármacos & 2,13 & $2,9 \%$ \\
\hline $\begin{array}{l}\text { Diversos de las ind. } \\
\text { químicas }\end{array}$ & 1,93 & $2,5 \%$ & $\begin{array}{l}\text { Instrumentos de } \\
\text { precisión }\end{array}$ & 1,65 & $2,3 \%$ \\
\hline Carnes & 1,89 & $2,5 \%$ & $\begin{array}{l}\text { Diversos de las ind. } \\
\text { químicas }\end{array}$ & 1,57 & $2,1 \%$ \\
\hline Máquinas mecánicas & 1,88 & $2,4 \%$ & Caucho & 1,42 & $1,9 \%$ \\
\hline Subtotal & 51,52 & $67,2 \%$ & Subtotal & 56,43 & $77,0 \%$ \\
\hline Otros & 25,11 & $32,8 \%$ & Otros & 16,88 & $23,0 \%$ \\
\hline Total & 76,63 & $100,0 \%$ & Total & 73,31 & $100,0 \%$ \\
\hline
\end{tabular}

Fuente: Adaptado de Argentina (2014, p. 8-9).

${ }^{57}$ ARGENTINA (2014). [14] 
Para exportar productos, según la política brasileña, el exportador deberá clasificarlos de acuerdo con un método internacional de clasificación de mercancías, denominado Sistema Armonizado de Designación y de Codificación de Mercancías, o Sistema Armonizado (SH). Creado para promover el desarrollo del comercio internacional, facilitando las negociaciones comerciales internacionales, la fijación de las tarifas de fletes y de las estadísticas relacionadas a los diferentes medios de transporte de mercancías y de otras informaciones utilizadas por el comercio internacional. ${ }^{58}$

Brasil, Argentina, Paraguay y Uruguay adoptan, desde enero de 1995, la Nomenclatura Común del MERCOSUR (NCM), que se basa en el Sistema Armonizado. Es en base a esta nomenclatura que los países miembros del MERCOSUR definen las alícuotas de sus impuestos de exportación. La Tarifa Externa Común (TEC) define los valores de los derechos de importación aplicados por todos los países miembros del MERCOSUR. Resultantes de estos acuerdos, la tarifa cobrada para la exportación de diversos productos entre Brasil y Argentina (y a los demás países componentes) es cero; pero, en la importación de algunos productos, sobre todo del azúcar de caña y remolacha, la alícuota no obedece a este parámetro y la tasa puede ser modificada según la variación del precio del producto en el mercado, obedeciendo a regulaciones legales específicas (cerca de $18 \%$ de tasas de importación); es decir, hay restricciones a algunos de los acuerdos establecidos. ${ }^{59}$

Las relaciones entre Brasil y Argentina son marcadas, especialmente, por la política a lo largo de la historia y por la constante importación y exportación de productos, dada la proximidad geográfica y los conflictos derivados de su proximidad. Sin embargo, hasta el momento no hubo movimientos significativos con la intención de crear un real acercamiento entre estos dos países ${ }^{60}$. Por lo contrario, recientemente fueron impuestas algunas restricciones por parte de los países en relación a sus tratados comerciales.

Si bien los conflictos en el comercio bilateral entre Brasil y Argentina siempre fueron superados, dejaron marcas en la relación. Entre dichos conflictos se encuentran aquellas situaciones que involucran a la diplomacia. Por ejemplo, en 1999 Brasil recorrió la OMC (Organización Mundial del Comercio) para pedir que Argentina retirase las barreras comerciales a la entrada de algodón y lana al país. De la misma manera, Argentina reclama los subsidios que Brasil invierte en la producción de azúcar, bajando considerablemente el precio del producto en el mercado y

\footnotetext{
${ }^{58}$ BRASIL (2014). [22]

${ }^{59}$ ARGENTINA (2014). [14]

${ }^{60}$ MOREIRA; MIRANDA (2012). [69]
} 
perjudicando la producción local; así como reivindica sello de calidad para los calzados producidos en Brasil y genera una competitividad equilibrada en el sector. Después de 1991, con la formación del MERCOSUR y más específicamente a partir de 1995, cuando la zona se convirtió en unión aduanera (área de libre comercio y tarifa común para todos los miembros), algunas de dichas barreras desaparecieron o fueron minimizadas en el campo diplomático. ${ }^{61}$

Entre los acuerdos bilaterales firmados entre Brasil y Argentina están: ${ }^{62}$

- El Acuerdo sobre Sanidad Animal en Áreas de Frontera

- El Protocolo de Intenciones sobre Requisitos Sanitarios para el Comercio de Animales y Productos de Origen Animal

- El Acuerdo de Cooperación Científica y Tecnológica

- El Ajuste Complementario al Acuerdo de Cooperación Científica y Tecnológica en el Campo de la Investigación Agropecuaria

- El Ajuste Complementario al Acuerdo de Cooperación Científica y Tecnológica en el Campo de la Sanidad Vegetal

- El Acuerdo de Cooperación Técnica

- El Programa de trabajo entre la Secretaría de Agricultura, Ganadería, Pesca y Alimentos de la Argentina.

- Mapa para equivalencia de los sistemas de control sanitarios y fitosanitarios.

- Acuerdo sobre Localidades Fronterizas Vinculadas.

Algunas políticas, sobre todo en Brasil, han sido creadas para reducir los impactos de su liderazgo en el grupo, permitir el crecimiento de los demás miembros del bloque y la integración y el fortalecimiento de las relaciones dentro del bloque. Entre las medidas están: tasas de interés más bajas para préstamos y financiamiento; equipamientos y materias primas para nuevos parques industriales; incentivo a la generación de ingresos en los demás países, lo que estimulará la demanda de productos brasileños; compatibilidad de producción según los patrones de Uruguay y Paraguay. Sin embargo, considerando que Brasil lidera el grupo que compone el MERCOSUR, carga además con la responsabilidad de mantenerlo en actuación y crecimiento, lo que demanda inversiones y compromiso con el bloque. ${ }^{63}$

Así, se confirma que Brasil es el mayor destino de las exportaciones argentinas y el principal proveedor de productos importados. Aunque esa relación bilateral es amparada por algunos acuerdos que establecen criterios y definen normas de regulación para esa alianza política, no siempre está libre de conflictos y barreras

\footnotetext{
${ }^{61}$ RIBEIRO; PINCHEMEL (2011). [72]

${ }^{62}$ ARGENTINA (2012). [14]

${ }^{63}$ ALTEMANI (2008). [8]
} 
proteccionistas. Las alícuotas e impuestos a la exportación y a la importación son nulos para los países que componen el MERCOSUR y son reguladas por el Sistema Armonizado ( $\mathrm{SH}$, de acuerdo con sus siglas en portugués), lo que implica respetar normas y procedimientos de embalaje, fabricación, componentes específicos y regulación fiscal de los productos. En este marco, la asociación comercial viene dando lugar al surgimiento de industrias brasileñas en suelo argentino y viceversa. Estas industrias contribuyen mucho al PBI de ambos países, reforzando las relaciones dentro del bloque. Este contexto es más marcado en la industria de cosméticos, ya que en ambos países hay grandes empresas (multinacionales), cuyos productos son aceptados en los mercados más importantes del mundo en la rama de los cosméticos. De esta forma, entre los diversos sectores hacen que el comercio bilateral entre Brasil y Argentina sea rentable, se destaca en el presente trabajo el sector de los cosméticos. Antes de presentar las relaciones específicas entre Brasil y Argentina, es importante situar a Brasil en el contexto mundial y su desenvolvimiento en el amplio mercado de los cosméticos, lo cual se encontrará en el siguiente ítem.

\subsubsection{Brasil en el contexto mundial de HPPC (Higiene Personal, Perfumería y Cosméticos)}

La industria de perfumería y cosméticos es uno de los sectores más dinámicos y viene alcanzando excelente desempeño, tanto en el mercado brasileño como en el internacional.

Según la Asociación Brasileña de la Industria de Higiene Personal, Perfumería y Cosméticos $^{64}$ "houve um crescimento acumulado de $270 \%$ nas exportações entre 2003 e 2012, na balança comercial, as importações cresceram 508\% no mesmo período".

Sin embargo, es preciso aclarar qué nomenclaturas de qué productos forman parte del amplio mercado que compone al sector de cosméticos. Las definiciones del concepto son elaboradas por la Agencia Nacional de Vigilancia Sanitaria (ANVISA) y constan en la Resolución $n^{\circ} 79$ del 28 de agosto de 2000. La clasificación de cosméticos, productos de higiene, perfumes y otros de naturaleza y finalidad idéntica está basada en los artículos $3^{\circ}$ y $26^{\circ}$ de la Ley $6.360 / 76$ y artículos $3^{\circ}, 49^{\circ}$ y $50^{\circ}$ del Decreto 79.094/77. Según el anexo I de ANVISA ${ }^{65}$ :

\footnotetext{
${ }^{64}$ ABIHPEC (2013,p. 1). [2] Traducción de Melisa Roldán: "hubo un crecimiento acumulado de $270 \%$ de las exportaciones entre 2003 y 2012, en la balanza comercial, las importaciones crecieron $508 \%$ en el mismo período."

${ }^{65}$ ANVISA (2005, p. 4). [13] Traducción de Melisa Roldán: “Cosméticos, productos de higiene y perfumes como preparaciones constituídas por sustancias naturaleso sintéticas, de uso externo en las diversas partes del cuerpo humano, piel, sistema capilar, uñas, labios, órganos genitales externos, dientes
} 
Cosméticos, produtos de higiene e perfumes como preparações constituídas por substâncias naturais ou sintéticas, de uso externo nas diversas partes do corpo humano, pele, sistema capilar, unhas, lábios, órgãos genitais externos, dentes e membranas mucosas da cavidade oral; com o objetivo exclusivo e principal de limpá-los, perfumá-los, alterar sua aparência e ou corrigir odores corporais e ou protegê-los ou mantê-los em bom estado.

Esa definición prevé el encuadramiento de los productos en cuatro categorías distintas en cuanto a la finalidad del uso: ${ }^{66}$

1) Productos de higiene: jabones, productos para higiene del cabello, productos para higiene bucal, desodorantes, productos para afeitar y después de afeitarse.

2) Cosméticos: productos para los labios, productos para el área de los ojos, bloqueadores solares, bronceadores, tinturas para el cabello, productos para aclarar el cabello y el bello corporal, productos para ondular y alisar el cabello, neutralizantes capilares, productos de higiene bucal, talcos y otros polvos corporales, cremas de belleza, máscaras faciales, lociones de belleza, aceites, productos para uñas y cutículas, repelentes.

3) Perfumes: productos para baño e inmersión, pañuelos perfumados, extractos, aguas perfumadas, colonias, lociones y perfumes.

4) Productos de uso infantil: aceites, lociones, productos para la higiene del cabello, productos para la higiene bucal, jabones toallas húmedas, talco, bloqueadores solares, colonias.

No obstante, se puede afirmar que las "linhas de separação entre tais subdivisões são bastante tênues, dadas as fortes interações dos agentes que atuam no setor de cosméticos com outros segmentos da indústria e mesmo com outras indústrias como farmacêutica, química e de alimentos." 67

En ese sentido, el BNDES ${ }^{68}$ describe la estructura de la cadena productiva brasileña en el sector de higiene personal, perfumería y cosméticos, identificando formas mixtas y específicas de actuación, como muestra la Figura 2.

y membranas mucosas de la cavidad oral; con el objetivo exclusivo y principal de limpiarlos, perfumarlos, alterar su apariencia y/o corregir olores corporales y/o protegerlos o mantenerlos en buen estado."

${ }^{66}$ GARCIA; FURTADO (2002). [40]

${ }^{67}$ GARCIA; FURTADO (2002, p. 50). [40] Traducción de Melisa Roldán: "líneas de separación entre tales subdivisiones son bastante tenues, dadas las fuertes interacciones de los agentes que actúan en el sector de cosméticos con otros segmentos de la industria, así como con otras industrias como la farmacéutica, la química y la alimenticia"

${ }^{68} \operatorname{BNDES}(2010$, p. 3). [27] 


\section{Figura 2 - Cadena productiva del sector de higiene personal, perfumería y} cosméticos

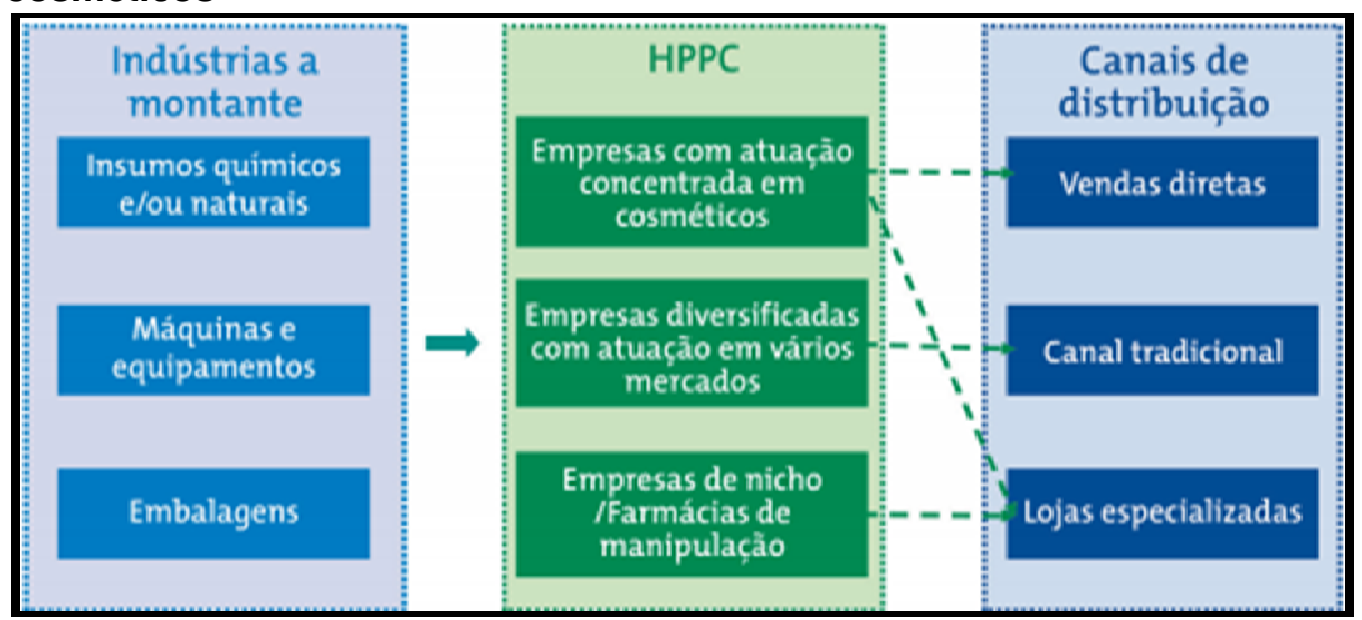

Fuente: BNDES (2010, p. 3).

Se observa que la cadena productiva está interconectada, considerándose que la materia prima e insumos de las industrias, máquinas, equipamientos y embalajes son necesarios para la formulación de los productos del sector de HPPC. Dicho sector está compuesto por las empresas específicas y diversificadas y por los nichos de manipulación, que dependen del éxito del funcionamiento de los canales de distribución, responsables de hacer llegar esos productos al consumidor.

Según Euromonitor ${ }^{69}$, de manera general el mercado brasileño de HPPC ocupa el tercer lugar en el ranking mundial, teniendo en cuenta que Estados Unidos se encuentra en el primer puesto y China en el segundo.

En este escenario Brasil ocupa el primer lugar en el mercado de perfumes, desodorantes y protección solar; el segundo en productos para el cabello, productos masculinos e infantiles, productos para baño y depilación; el tercero en cosméticos (maquillaje y esmalte de uñas) e higiene oral; y el cuarto en productos para la piel. La Tabla 11 presenta los 10 mayores mercados mundiales de HPPC y los porcentajes de participación de este sector entre 2012 y $2013 .^{70}$

\footnotetext{
${ }^{69}$ EUROMONITOR (2013). [34]

${ }^{70}$ ABIHPEC (2014, p. 12). [4]
} 
Tabla 11 - Los 10 mayores mercados mundiales de HPPC entre 2012 y 2013

\begin{tabular}{|c|c|c|c|c|}
\hline \multirow[b]{2}{*}{$\begin{array}{l}\text { Higiene Pessoal, Perfumaria } \\
\text { e Cosméticos }\end{array}$} & \multicolumn{2}{|c|}{$\begin{array}{c}\text { US\$̦ Bilhōes (Preço ao } \\
\text { consumidor) }\end{array}$} & \multicolumn{2}{|c|}{ (\%) Em percentual } \\
\hline & 2.012 & 2.013 & Participaçāo & $\begin{array}{l}\text { Variaçāo } \\
2013 \times 2012\end{array}$ \\
\hline Mundo & 446.7 & 454.1 & & 1.7 \\
\hline EUA & 72.0 & 73.3 & 16.1 & 1.8 \\
\hline China & 39.9 & 44.2 & 9.7 & 10.8 \\
\hline Brasil & 41.8 & 43.0 & 9.5 & 2.7 \\
\hline Japão & 47.4 & 39.1 & 8.6 & $-17,7$ \\
\hline Alemanha & 18.1 & 19.1 & 4.2 & 5.2 \\
\hline Reino Unido & 16.8 & 16.9 & 3.7 & 1.0 \\
\hline França & 16.1 & 16.8 & 3.7 & 4.2 \\
\hline Russia & 14.2 & 14.2 & 3.1 & 0.1 \\
\hline Itália & 11.9 & 12.2 & 2.7 & 2.3 \\
\hline México & 10.0 & 10,8 & 2,4 & 8,1 \\
\hline TOP TEN & 288,2 & 289,5 & 63,7 & 0,4 \\
\hline
\end{tabular}

Fuente: ABIHPEC (2014, p. 12).

Según los datos observados en la Tabla 11, Estados Unidos, Japón y Brasil figuran entre los principales mercados mundiales en 2012 y Estados Unidos, China y Brasil en 2013. Es decir, Brasil consigue mantener el tercer lugar en el mercado mundial de HPPC, alcanzando el 9,5\% del mercado mundial en el sector. En la Figura 3 se muestran las mayores empresas mundiales brasileñas del sector de HPPC. Se destaca el alcance en la producción de masa o de productos diferenciados para el mercado cosmético y apunta el share del mercado en cada empresa líder del mercado.

Figura 3 - Grandes empresas del mercado mundial y brasileño de cosméticos por player y grupo

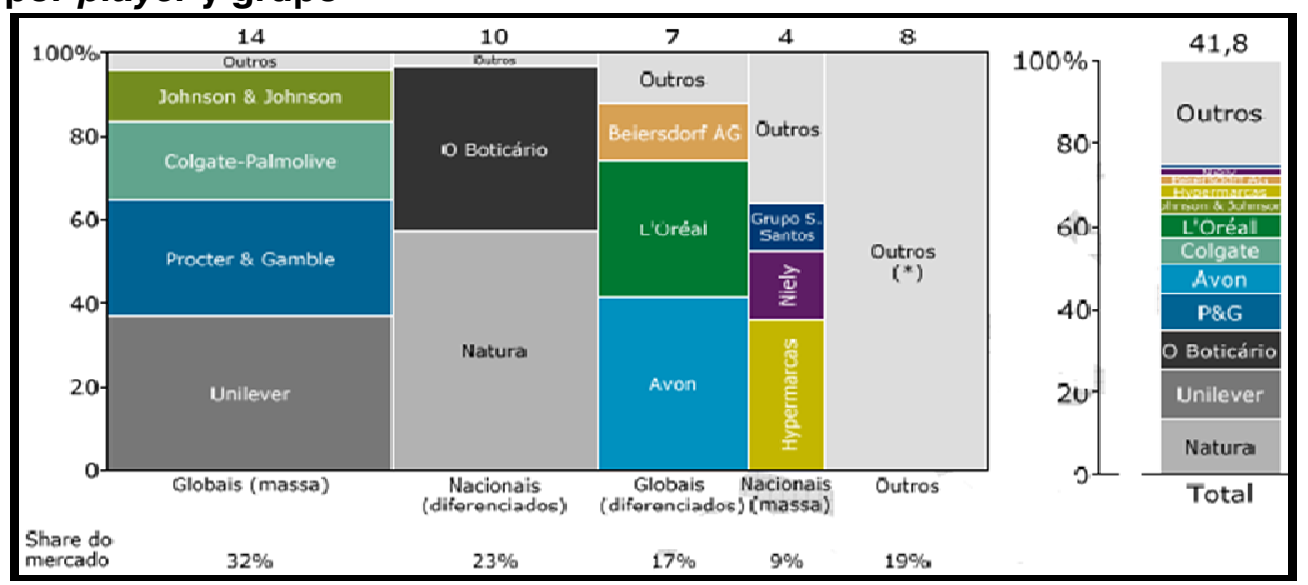

Fuente: BNDES (2014, p. 21)

Se observa en la Figura 3 que entre las empresas brasileñas que participan en el mercado de cosméticos más destacadas están O Boticário y Natura, como marcas diferenciadas e Hypermarcas, Niely y Grupo S. Santos como fabricadora de productos nacionales de forma masiva. Las perspectivas de 2013 a 2017 y la comparación de la tasa de crecimiento del mercado HPPC en Brasil y en el mundo entre los años 2008 y 
2012, así como la facturación en las distintas ramas que componen el sector cosmético pueden ser observadas en la Tabla 12, que también apunta al posicionamiento de Brasil en el ranking global $^{71}$.

Tabla 12 - Ranking de productos HPPC de Brasil y del mundo, por sector, y perspectiva de crecimiento

\begin{tabular}{|c|c|c|c|c|c|c|c|}
\hline \multirow[b]{2}{*}{ Aplicaçăo } & \multicolumn{2}{|c|}{$\begin{array}{c}\text { Mercado } \\
\text { (US\$B, 2012) }\end{array}$} & \multicolumn{2}{|c|}{$\begin{array}{l}\text { Crescimento Histórico } \\
\text { (2008-2012, CAGR) }\end{array}$} & \multicolumn{2}{|c|}{$\begin{array}{l}\text { Crescimento Futuro } \\
\text { (2013-2017, CAGR) }\end{array}$} & \multirow{2}{*}{$\begin{array}{c}\begin{array}{c}\text { Ranking } \\
\text { Global }\end{array} \\
2012 \\
\end{array}$} \\
\hline & Brasil & Mundo & Bras! & Mundo & Brasil & Mundo & \\
\hline Produtos para cabelo & 9,3 & 74,6 & $11,9 \%$ & $3,6 \%$ & $9,1 \%$ & $5,2 \%$ & $2^{\circ}$ \\
\hline Perfumes & 6,5 & 43,2 & $11,5 \%$ & $3,1 \%$ & $8,3 \%$ & $5,4 \%$ & 10 \\
\hline Produtos para pele & 4,6 & 99,4 & $9,8 \%$ & $4,4 \%$ & $8,5 \%$ & $5,5 \%$ & 40 \\
\hline Desodorantes & 4,3 & 20,7 & $12,9 \%$ & $4,9 \%$ & $7,7 \%$ & $4,8 \%$ & 10 \\
\hline Maquiagem & 3,5 & 54,2 & $15,2 \%$ & $4,4 \%$ & $10,9 \%$ & $5,0 \%$ & $3^{\circ}$ \\
\hline Higiene oral & 3,4 & 40,5 & $8,2 \%$ & $4,0 \%$ & $9,4 \%$ & $5,0 \%$ & $3^{\circ}$ \\
\hline Banho & 3,3 & 37,8 & $9,2 \%$ & $3,9 \%$ & $5,6 \%$ & $4,3 \%$ & 20 \\
\hline Produtos para barbear & 2,6 & 16,9 & $20,7 \%$ & $3,7 \%$ & $11,4 \%$ & $4,9 \%$ & $2^{\circ}$ \\
\hline Proteçăo Solar & 1,4 & 9,1 & $16,0 \%$ & $4,9 \%$ & $9,5 \%$ & $5,7 \%$ & 10 \\
\hline Outros cosméticos & 3,0 & 37,0 & $17,9 \%$ & $4,7 \%$ & $10,2 \%$ & $5,5 \%$ & $3^{\circ}$ \\
\hline Total & 41,8 & 433,3 & $12,4 \%$ & $4,1 \%$ & $8,9 \%$ & $5,2 \%$ & $\mathbf{3 0}^{\circ}$ \\
\hline
\end{tabular}

Fuente: BNDES (2013, p. 9).

El mercado brasileño de HPPC representa el 10\% del mercado global y el crecimiento anual del consumo de productos HPPC en el mundo viene alcanzando el 5,2\%, sobre todo aquellos relacionados a la piel, el cabello y el maquillaje. Sin embargo, los sectores más destacados están directamente relacionados a los perfumes, desodorantes y bloqueadores solares, que se destacaron hasta 2012 como los productos de mayor crecimiento, ocupando el primer lugar en el mercado mundial. En 2013 y acompañando las perspectivas de crecimiento, deben destacarse en el ranking el maquillaje y los productos para el cabello.

Prado $(2012)^{72}$ afirma que los datos de la balanza comercial en ítems de belleza muestran que los productos fabricados en Brasil y exportados a otros países son más baratos que los que hacen el camino inverso. En algunos productos puede haber variación superior a US\$ 8 en el kilo del producto importado en relación al brasileño. Esto se debe a las constantes inversiones de los fabricantes brasileños de productos para mercados de bajos ingresos.

Los resultados de los movimientos brasileños de importación y exportación en volumen de negocios en el sector de HPPC son mostrados en el Gráfico 3, que apunta

\footnotetext{
${ }^{71}$ BNDES (2013, p. 9). [18]

${ }^{72}$ PRADO (2012). [71]
} 
la balanza comercial de los últimos diez años, es decir, entre 2003 y 2013 y el crecimiento alcanzado durante dicho período. ${ }^{73}$.

\section{Gráfico 3 - Balanza comercial brasileña de importación y exportación de HPPC de 2003 a 2013}

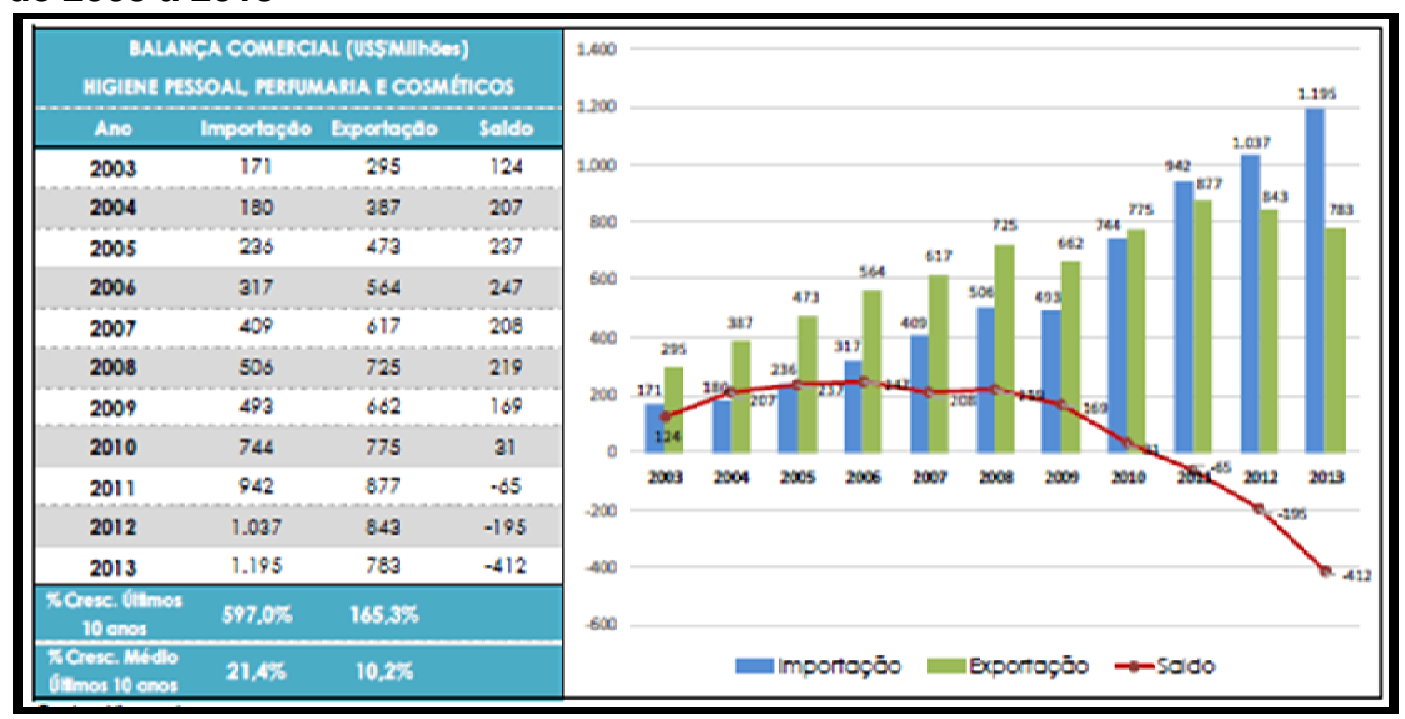

Fuente: ABIHPEC (2014, p. 6).

El saldo negativo de 2011 a 2013 mostrados en el Gráfico 3, no comprometió el desempeño del sector, que continúa creciendo más que el PBI brasileño y presenta crecimiento superior a los demás sectores de la industria del país y del desempeño del mercado mundial de HPPC. Según ABHIPEC ${ }^{74}$, el aumento del acceso de las clases D y $E^{75}$ a los productos HPC fue uno de los grandes responsables por el impulso en el consumo de los últimos dos años, que también sufrió influencia del aumento de la clase media, de la participación femenina en el mercado de trabajo y de consumo, del estancamiento de precios producido por el perfeccionamiento de la tecnología aplicada en los procesos de producción y distribución, del lanzamiento frecuente de nuevos productos y del aumento de la expectativa de vida de los brasileños que acompañaron la tendencia mundial de preservar una apariencia joven.

Para comprender la importancia del consumo en las diferentes clases sociales brasileñas y el crecimiento derivado de esa participación en el mercado, se observa la Figura 4, que compara el desarrollo en los años 2005 y $2010^{76}$.

\footnotetext{
${ }^{73}$ ABIHPEC (2014, p. 6). [4]

${ }^{74}$ ABHIPEC (2014). [4]

${ }^{75}$ En Brasil, el Gobierno clasifica a la población de acuerdo con el ingreso familiar, separándolas en clases sociales A, B, C, D y E según su nivel de ingresos. El órgano gubernamental que define esta clasificación es la SAE (Secretaría de Asuntos Estratégicos). www.sae.gov.br
}

${ }^{76}$ ABHIPEC (2012). [3] 
Figura 4 - Comparación del crecimiento del consumo del sector de HPPC por clase social de 2005 y 2010

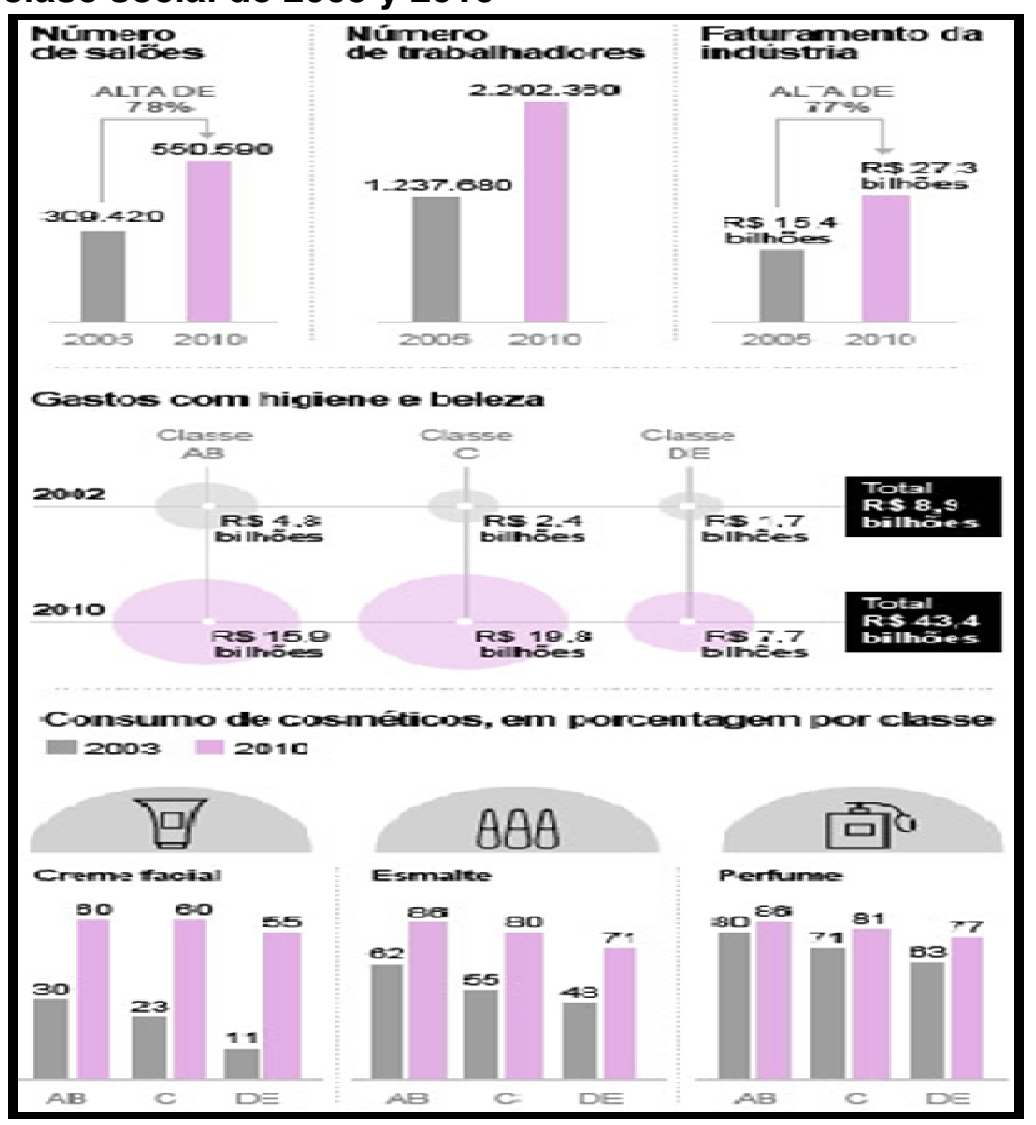

Fuente: ABIHPEC (2012, p. 1).

Según la figura 4, el número de salones de belleza y de trabajadores en el área de HPPC se duplicó desde 2005 a 2010. La facturación de la industria creció un 58\%. Todas las clases sociales contribuyeron a ese índice de crecimiento, pero la clase $\mathrm{C}^{77}$ aumentó el consumo de 2002 (de 2,5 billones) a 19,8 billones en 2010, interfiriendo en el crecimiento de la demanda. Este aumento se detectó, sobre todo, en productos de higiene y belleza. Entre los cosméticos, las cremas faciales, esmaltes y perfumes fueron los productos que más representatividad tuvieron en el aumento de ese consumo.

De 2009 a 2013, los precios del sector de HPPC en el mercado nacional brasileño crecieron menos que la inflación, lo que motivó el interés del consumidor y a su vez, creció el interés comercial por parte de la industria brasileña.

En 2009, 2010 y 2013 los precios de los productos de belleza aumentaron en relación a los precios de los productos de higiene, aunque en los demás años $(2007,2008$, 2011 y 2012) los valores se estancaron, lo cual puede explicar el aumento del consumo, principalmente por parte de las clases de menor poder adquisitivo. Según

${ }^{77}$ www.sae.gov.br 
datos de diciembre de 2013, Brasil contaba en ese momento con 2470 empresas actuando en el mercado de productos de Higiene Personal, Perfumería y Cosméticos, siendo 20 empresas de gran porte, con facturación líquida de impuestos por encima de los $\mathrm{R} \$ 100$ millones, que representaban el 73\% de la facturación total. "Os produtos do setor HPPC são distribuídos por meio de três canais básicos: a) Distribuição tradicional, incluindo o atacado e as lojas de varejo; b) Venda direta, evolução do conceito de vendas domiciliares; c) Franquia, lojas especializadas e personalizadas."78 La evolución del sector cosmético brasileño muestra que entre 2004 y 2013, según Franquilo (2014), la región Nordeste fue la que más creció en número de empresas, con variación de 160,2\% en el período, seguido por el sur del país, sólo en Santa Catarina hay 90 empresas pertenecientes al sector. En el Centro-Oeste en 2012, cerca del $70 \%$ de las empresas de cosméticos estaban instaladas en el Estado de Goiás, que es el sexto mayor polo de producción de cosméticos en Brasil y anhela alcanzar el tercer lugar en los próximos años.

La fortaleza de la región Norte no está en las pocas empresas productoras, ya que la mayoría es de medio y pequeño porte, sino en la riqueza de sus materias primas, como açaí, andiroba, babassu, buriti, castaña de Brasil, copaíba, murumuru y urucum, frutos y especies de vegetación nativa de la selva amazónica de Brasil, que abastecen grandes industrias nacionales y seducen al mercado internacional. La región metropolitana de San Pablo y la Bajada Fluminense se destacan en la región sudeste, con 1.257 empresas y reúnen fabricantes de cosméticos, embalajes, empresas dedicadas a envasar y proveer de materias primas, además del $63 \%$ de de las multinacionales instaladas en Brasil y $38 \%$ de las cien mayores empresas privadas del país (Franquilo, 2014) ${ }^{79}$.

Las mayores y más numerosas empresas de HPPC brasileñas están localizadas en San Pablo, Río de Janeiro y Minas Gerais, es decir, en la región Sudeste del país. El mapa muestra que todas las regiones de Brasil son contempladas y que se destacan las regiones Nordeste y Centro Oeste como productores de HPPC. El sector contribuye además a un avance significativo en las oportunidades laborales a partir de los canales de distribución, lo cual es presentado en la Tabla 13 (datos hasta diciembre de 2013). ${ }^{80}$

\footnotetext{
${ }^{78}$ ABIHPEC (2014, p. 12). [4] Traducción de Melisa Roldán: "Los productos del sector HPPC son distribuidos por medio de tres canales básicos: a) Distribución tradicional, incluyendo ventas mayoristas y minoristas; b) Venta directa, evolución del concepto de ventas a domicilio; c) Franquicia, tiendas especializadas y personalizadas."

${ }^{79}$ FRANQUILO (2014). [39]

${ }^{80}$ ABIHPEC (2014, p. 13). [4]
} 
Tabla 13 - Oportunidades de trabajo en Brasil derivadas el sector de HPPC

\begin{tabular}{|c|c|c|c|c|}
\hline \multicolumn{5}{|c|}{ OPORTUNIDADES DE TRABALHO ('000) } \\
\hline & 1994 & 2013 & $\begin{array}{c}\text { \% Cresc. } 19 \\
\text { anos }\end{array}$ & $\begin{array}{c}\text { \% Cresc. } \\
\text { Médio } 19 \text { anos }\end{array}$ \\
\hline INDÚSTRIA & 30.1 & 126.0 & 318.6 & 7.8 \\
\hline CENTROS DE DISTRIBUIÇĀO & & 35.0 & N.A. & N.A. \\
\hline FRANQUIA & 11.0 & 195.6 & 1678.5 & 16.4 \\
\hline CONSULTORA VENDA DIRETA & 510.0 & 4053.6 & 694.8 & 11.5 \\
\hline SALÖEs DE BELEZA & 579.0 & 1205.0 & 108,1 & 3.9 \\
\hline TOTAL & 1130,1 & 5615,2 & 396,9 & 8,8 \\
\hline
\end{tabular}

Fuente: ABIHPEC (2014, p. 13).

Las franquicias y las ventas directas tuvieron el mayor porcentaje de crecimiento entre 1994 y 2013; seguidos por la industria y los salones de belleza. El porcentaje medio de crecimiento de estos ítems en el mismo período quedó en $8,8 \%$, es decir, por encima del índice mundial de 5\%. El gobierno brasileño ha buscado desarrollar incentivos a la internacionalización de empresas y crecimiento de los índices de exportación, que a pesar de la crisis global y de fluctuaciones en la tasa de cambio, se mantiene por sobre el crecimiento del comercio internacional sectorial ${ }^{81}$. Una de las inversiones en el sector que viene siendo desarrollada desde el año 2000 es el Proyecto Sectorial Beautycare.

Según ABHIPEC (2014), entre las acciones de Beautycare Brasil está la adopción de criterios más rigurosos para la selección de mercados objetivo prioritarios, la apertura de nuevos focos de mercado y la consolidación del mercado nacional e internacional. Diversos proyectos sectoriales ligados a esas iniciativas de incentivo vienen siendo desarrollados en el sector de investigación, innovación y fomento; en la creación de documentos de referencia.

La misma asociación indica que por ser el tercer mayor mercado mundial el mayor volumen en productos HPPC, Brasil posee un gran volumen de importaciones y exportaciones en esa área y es responsable por el 10\% del mercado mundial. El territorio brasileño contiene más de 2.400 empresas de la rama HPPC, siendo 20 de ellas de gran porte (como Natura y O Boticário) y el mayor volumen de crecimiento en el consumo de esos productos está dirigido al mercado de las clases $\mathrm{D}$ y $\mathrm{E}^{82}$, así como al aumento de la clase media del país. Las inversiones adquirieron incentivos gubernamentales en los últimos años y el país posee interés especial en el mercado argentino, ya que posee diversas fuentes de algunas materias primas necesarias para la producción de estos productos, así como gran cantidad de consumidores de las marcas brasileñas de productos terminados.

\footnotetext{
${ }_{82}^{81}$ BNDES (2014). [19]
} 
El tópico a seguir aborda aspectos orientados al comercio bilateral entre Brasil y Argentina en el sector de cosméticos.

\title{
1.4.2 El comercio bilateral Brasil / Argentina en el sector de cosméticos
}

Además del significativo volumen de negocios entre Brasil y Argentina, involucrando otros tipos de productos, los dos mayores miembros del MERCOSUR mantienen una relación comercial dentro del bloque marcada también por la importación y exportación de productos HPPC.

Una de las características principales de la industria HPPC es la dificultad de delimitación de sus fronteras, tanto en lo que se refiere a la definición de la unidad de análisis como para los organismos de regulación del sector. La industria de cosméticos presenta límites muy tenues con otros sectores industriales, como el farmacéutico, el químico, el médico y, "de forma mais distante, mas com aproximação crescente, com o setor de alimentos. Além disso, algumas das principais empresas que atuam no setor são bastante diversificadas e sua carteira de produtos pode variar desde alimentos até produtos de higiene e limpeza" ${ }^{83}$.

\begin{abstract}
A estrutura produtiva da indústria de cosméticos no Brasil constitui-se por produtores bastante distintos no que se refere à sua atuação no mercado. Atuam no Brasil empresas estrangeiras especializadas em cosméticos, como Avon, L'Oreal, Johnson \& Johnson, Colgate Palmolive, Nívea e Revlon, e empresas bastante diversificadas com atuação importante no mercado de cosméticos, como Unilever e Procter\&Gamble. Há também grandes empresas nacionais que concentram suas atividades apenas no setor, como Natura e $O$ Boticário, e outras, que passaram a integrar o setor a partir de estratégias de diversificação via integração vertical para a frente, como os frigoríficos Friboi e Bertin (o ingresso desses dois frigoríficos no mercado de cosméticos e higiene pessoal esteve associada, por um lado, às complementaridades técnico-produtivas entre a agroindústria de corte e a indústria de cosméticos e higiene pessoal. Mas também, por outro lado, essa diversificação teve como motivação uma distorção do sistema de tributação no Brasil, uma vez que, por meio das vendas de produtos cosméticos no mercado domestico, é permitido às empresas utilizar créditos de impostos indiretos obtidos nas vendas externas de carnes ${ }^{84}$.
\end{abstract}

\footnotetext{
${ }^{83}$ BNDES (2013,p. 135). [18] Traducción de Melisa Roldán: “de forma más distante, pero con un creciente acercamiento con el sector alimenticio. Además, algunas de las principales empresas que actúan en el sector son bastante diversificadas y su cartera de productos puede variar desde alimentos hasta productos de higiene y limpieza"

${ }^{84}$ BNDES (2010, p. 140). [17] Traducción de Melisa Roldán: "La estructura productiva de la industria de cosméticos en Brasil se constituye por productos bastante distintos en lo que se refiere a su actuación en el mercado. Actúan en Brasil empresas extranjeras especializadas en cosméticos, como Avon, L'Oreal Johnson \& Johnson, Colgate Palmolive, Nivea y Revlon, y empresas bastante diversificadas con actuación importante en el mercado de cosméticos, como Unilever y Procter \& Gamble. También hay grandes empresas nacionales que concentran sus actividades sólo en el sector, como Natura o O Boticário,
} 
Sin embargo, de forma general, el mercado de los productos de belleza pretende alcanzar algunos mercados específicos como los productos femeninos y masculinos (lo relativo a la piel masculina, principalmente al rostro, cabello y manos, vienen presentando un marcado crecimiento); productos para consumidores de diferentes franjas etarias - personas mayores, adultos, adolescentes y bebés; productos hipoalergénicos y productos para diversos tipos de piel y cabellos. " $A$ área do corpo em que será aplicado o produto e o objetivo que dele se espera constituem a base de outra importante segmentação: produtos para cabelos, para a pele, para as unhas, para a limpeza bucal, entre outros" que forman parte de ese mercado. ${ }^{85}$

No obstante, esta segmentación de productos también posee un código llamado Nomenclatura Común del MERCOSUR (NCM). Él detalla los productos y servicios incluidos en el segmento HPPC de forma general. Entre los principales representantes del MERCOSUR y en el mercado mundial están los cosméticos, lo cual se muestra en la Tabla 14, que relaciona el volumen de importación y exportación en el MERCOSUR, considerando las relaciones entre Brasil y Argentina entre los años 2009 y 2013.

\footnotetext{
y otras que pasaron a integrar el sector a partir de estrategias de diversificación e integración vertical hacia adelante, como los frigoríficos Friboi y Berlín (el ingreso de esos dos frigoríficos en el mercado de cosméticos e higiene personal estuvo asociada, por un lado, a las complementariedades técnicoproductivas entre la agroindustria de corte y la industria de cosméticos y de higiene personal. Aunque también, por otro lado, esta diversificación tuvo como motivación una distorsión del sistema de tributación en Brasil, ya que por medio de las ventas de productos cosméticos en el mercado doméstico se permite a las empresas utilizar créditos de impuestos indirectos obtenidos en las ventas externas de carnes."

${ }^{85}$ BNDES (2013, p. 136). [18] Traducción de Melisa Roldán: "El área del cuerpo en la que será aplicada el producto y el objetivo que se espera de él constituyen la base de otro segmento importante: productos para cabellos, para la piel, para las uñas, para la limpieza bucal, entre otros".
} 
Tabla 14 - Códigos y productos destacados de Brasil y Argentina en el mercado mundial de HPPC y facturación entre 2009 y 2013

\begin{tabular}{|c|c|c|c|c|c|c|}
\hline \multicolumn{7}{|c|}{ Importaciones de Brasil (US\$ FOB) } \\
\hline $\begin{array}{l}\text { Código } \\
\text { NCM }\end{array}$ & HPPC & 2013 & 2012 & 2011 & 2010 & 2009 \\
\hline 3304 & $\begin{array}{l}\text { Productos de } \\
\text { belleza, } \\
\text { maquillaje para } \\
\text { ojos, labios, } \\
\text { cuidados para la } \\
\text { piel... }\end{array}$ & 16.945 .030 & 20.779 .466 & 18.657.106 & 9.962 .867 & 5.011 .425 \\
\hline 330300 & $\begin{array}{l}\text { Perfumes } \\
\text { (extractos) y } \\
\text { aguas de colonia }\end{array}$ & 167.419 & 975.845 & 453.496 & 163.025 & 45.741 \\
\hline 330720 & $\begin{array}{l}\text { Desodorantes y } \\
\text { antitranspirantes }\end{array}$ & 232.426.274 & 205.357 .828 & 182.983 .266 & 153.244 .469 & 98.949 .532 \\
\hline 3305 & $\begin{array}{l}\text { Preparaciones } \\
\text { capilares }\end{array}$ & 2.103 .982 & 1.617.421 & 1.624 .802 & 1.028 .625 & 894.185 \\
\hline 3306 & $\begin{array}{l}\text { Preparaciones } \\
\text { para higiene } \\
\text { bucal o dental }\end{array}$ & 612.878 & 331.129 & 900 & 20.594 & n.d.* \\
\hline 3307 & $\begin{array}{l}\text { Preparaciones } \\
\text { para afeitar (para } \\
\text { antes, durante o } \\
\text { después) }\end{array}$ & 244.024 .471 & 217.560 .129 & 193.346 .183 & 163.504 .420 & 104.439 .518 \\
\hline \multicolumn{7}{|c|}{ Exportaciones de Brasil (US\$ FOB) } \\
\hline $\begin{array}{l}\text { Código } \\
\text { NCM }\end{array}$ & HPPC & 2013 & 2012 & 2011 & 2010 & 2009 \\
\hline 3304 & $\begin{array}{l}\text { Productos de } \\
\text { belleza, } \\
\text { maquillaje para } \\
\text { ojos, labios, } \\
\text { cuidados para la } \\
\text { piel... }\end{array}$ & 18.283 .112 & 19.676.334 & $\begin{array}{r}21.729 .31 \\
9 \\
\end{array}$ & 16.766.338 & n.d. ${ }^{*}$ \\
\hline 330300 & $\begin{array}{l}\text { Perfumes } \\
\text { (extractos) y } \\
\text { aguas de colonia }\end{array}$ & 1.851 .802 & 2.641 .581 & 1.015 .479 & 779.636 & 1.203 .030 \\
\hline 330720 & $\begin{array}{l}\text { Desodorantes y } \\
\text { antitranspirantes }\end{array}$ & 21.215 .528 & 21.987 .517 & $\begin{array}{r}27.347 .90 \\
8 \\
\end{array}$ & 24.744 .250 & 23.598 .311 \\
\hline 3305 & $\begin{array}{l}\text { Preparaciones } \\
\text { capilares }\end{array}$ & 56.086 .007 & 70.444 .209 & \begin{tabular}{|l|}
101.461 .39 \\
7
\end{tabular} & 98.506 .526 & 91.869 .832 \\
\hline 3306 & $\begin{array}{l}\text { Preparaciones } \\
\text { para higiene } \\
\text { bucal o dental }\end{array}$ & 39.904 .674 & 41.971 .584 & $\begin{array}{r}40.837 .70 \\
8\end{array}$ & 42.987 .456 & 41.878 .403 \\
\hline 3307 & $\begin{array}{l}\text { Preparaciones } \\
\text { para afeitar (para } \\
\text { antes, durante o } \\
\text { después) }\end{array}$ & 22.802 .004 & 23.299.690 & $\begin{array}{r}29.793 .01 \\
0\end{array}$ & 26.529 .920 & 24.972 .889 \\
\hline
\end{tabular}

Fuente: ALICEWEB (2014, p. 1).

Los productos HPPC son clasificados por área, considerándose la parte del cuerpo y la utilidad y finalidad del producto. En este sentido, los productos mejor posicionados en el mercado consumidor de Brasil y Argentina se ubican en los segmentos de 
productos de higiene (productos para el cabello, barba, higiene bucal y desodorantes); productos cosméticos (maquillaje para la piel y la cara, área de los ojos y los labios, protectores solares y cremas de belleza); y perfumes (extractos y aguas de colonia, lociones y escencias).

Los valores alcanzados en las importaciones y exportaciones demuestran la importancia de esos segmentos para el mercado mundial. Se destaca, sin embargo, que algunos productos están descritos por 4 dígitos identificadores y otros por 6 . Este procedimiento permite identificar y detallar cada segmento de producto, aunque muchos de ellos, para ser descriptos, utilizan códigos de hasta 8 dígitos. Particularidades, como la presencia de aceites y esencias, grasas concentradas, ceras y materiales similares, así como subproductos, forman parte de dicho detalle, dificultando la segmentación de cada ítem. Sin embargo, la importancia del comercio bilateral de estos productos se destaca claramente al observar los destinos de las importaciones y exportaciones brasileñas. Los 10 principales mercados explorados son listados en la Tabla $15^{86}$.

Tabla 15 - 10 principales orígenes de las importaciones y destinos de las exportaciones brasileñas de HPPC

\begin{tabular}{|c|c|c|c|c|c|c|}
\hline \multicolumn{7}{|c|}{ Acumulado janeiro a dezembro (FOB - US\$'milhōes) } \\
\hline & Descricāo do País! & 2.012 & 2.013 & $\begin{array}{l}\% \text { var. } \\
13 / 12 \\
\end{array}$ & $\begin{array}{l}\% \text { Partic. } \\
\text { Total } 2012 \\
\end{array}$ & $\begin{array}{l}\% \text { Partic. } \\
\text { Total } 2013 \\
\end{array}$ \\
\hline 1 & Argentina & 213.434 & 188.227 & -11.8 & 25.3 & 24,1 \\
\hline 2 & Chile & 103.798 & 81.773 & $-21,2$ & 12.3 & 10,4 \\
\hline 3 & México & 60.441 & 76.061 & 25.8 & 7.2 & 9.7 \\
\hline 4 & Colombia & 58.581 & 58.429 & -0.3 & 7.0 & 7.5 \\
\hline 5 & Venezuela & 61.645 & 45.207 & -26.7 & 7.3 & 5,8 \\
\hline 6 & Peru & 48.410 & 44.050 & -9.0 & 5.7 & 5,6 \\
\hline 7 & Panamá & 30.323 & 41.531 & 37.0 & 3.6 & 5,3 \\
\hline 8 & Paraguai & 41.832 & 41.397 & -1.0 & 5.0 & 5,3 \\
\hline 9 & Uruguai & 27.580 & 26.873 & -2.6 & 3.3 & 3,4 \\
\hline 10 & Bolivia & 27.037 & 22.514 & $-16,7$ & 3.2 & 2,9 \\
\hline & Total HPPC & 842.583 & 782.610 & -7.1 & 100,0 & 100,0 \\
\hline & Total Top Ten & 673.082 & $=626.060$ & $-7,0$ & 79.9 & 80,0 \\
\hline
\end{tabular}

\begin{tabular}{|c|c|c|c|c|c|c|}
\hline \multicolumn{7}{|c|}{ Acumulado janeiro a dezembro (FOB - USS'milhōes) } \\
\hline & Descrição do País $\square$ & 2012 & 2013 & $\begin{array}{l}\% \mathrm{Var} \text {. } \\
13 / 12 \\
\end{array}$ & $\begin{array}{l}\% \text { Partic. } \\
\text { Total } 2012 \\
\end{array}$ & $\begin{array}{l}\% \text { Partic. } \\
\text { Total } 2013 \\
\end{array}$ \\
\hline 1 & Argentina & 273.523 & 272.282 & -0.5 & 26.4 & 22,8 \\
\hline 2 & Estados Unidos & 141.290 & 168.317 & 19.1 & 13.6 & 14,1 \\
\hline 3 & México & 81.472 & 149.767 & 83.8 & 7.9 & 12,5 \\
\hline 4 & França & 135.628 & 133.517 & -1.6 & 13.1 & 11.2 \\
\hline 5 & China & 92.417 & 98.644 & 6.7 & 8,9 & 8,3 \\
\hline 6 & Alemanha & 56.668 & 69.768 & 23.1 & 5.5 & 5,8 \\
\hline 7 & Espanha & 29.857 & 36.135 & 21.0 & 2,9 & 3.0 \\
\hline 8 & Colômbia & 23.121 & 33.836 & 46.3 & 2,2 & 2.8 \\
\hline 9 & Índia & 13.537 & 28.209 & 108,4 & 1,3 & 2,4 \\
\hline 10 & Canadá & 23.949 & 27.575 & 15.1 & 2,3 & 2,3 \\
\hline & Total Importaçōes & 1.037 .167 & 1.194 .649 & 15,2 & 100,0 & 100,0 \\
\hline & Total Top Ten & 871.461 & 1.018 .050 & 16,8 & 84,0 & 85,2 \\
\hline
\end{tabular}

Fuente: ABIHPEC (2014, p. 8-9).

${ }^{86}$ ABIHPEC (2014, p. 8-9). [4] 
Las exportaciones brasileñas tienen entre los 10 principales destinos a todos los países componentes del MERCOSUR. Pero en las importaciones, solamente Argentina es representativa dentro del MERCOSUR. Tanto en las importaciones como en las exportaciones, Argentina representa el mayor volumen de negocios con Brasil. Entre 2003 y 2013 las importaciones brasileñas crecieron más rápido que las exportaciones. En 2012, Brasil exportó a 143 países, principalmente de América Latina (en ese marco se destaca Argentina) e importó productos de 68 países en 2013 (también se destaca Argentina). En 2013, Brasil registró un crecimiento de 4,9\% en el sector cosmético, con facturación de $\mathrm{R} \$ 38$ billones. El considerable crecimiento del sector cosmético es fuertemente influenciado por el aumento de la población mundial, del poder adquisitivo y del nivel de vida especialmente en países emergentes, por el aumento de la esperanza de vida y el envejecimiento de la población mundial (con un creciente número de ancianos y disminución de niños), por la preocupación constante por mantener un aspecto joven, lo cual combinado con las constantes innovaciones tecnológicas en los productos viene conquistando consumidores y ampliando mercados, principalmente el masculino. ${ }^{87}$

El Gráfico 4 muestra la evolución del mercado brasileño en el sector de cosméticos de 1996 a 2013, considerando la facturación en reales y en dólares. ${ }^{88}$

\section{Gráfico 4 - Facturación del mercado brasileño de cosméticos de 1996 a 2013}

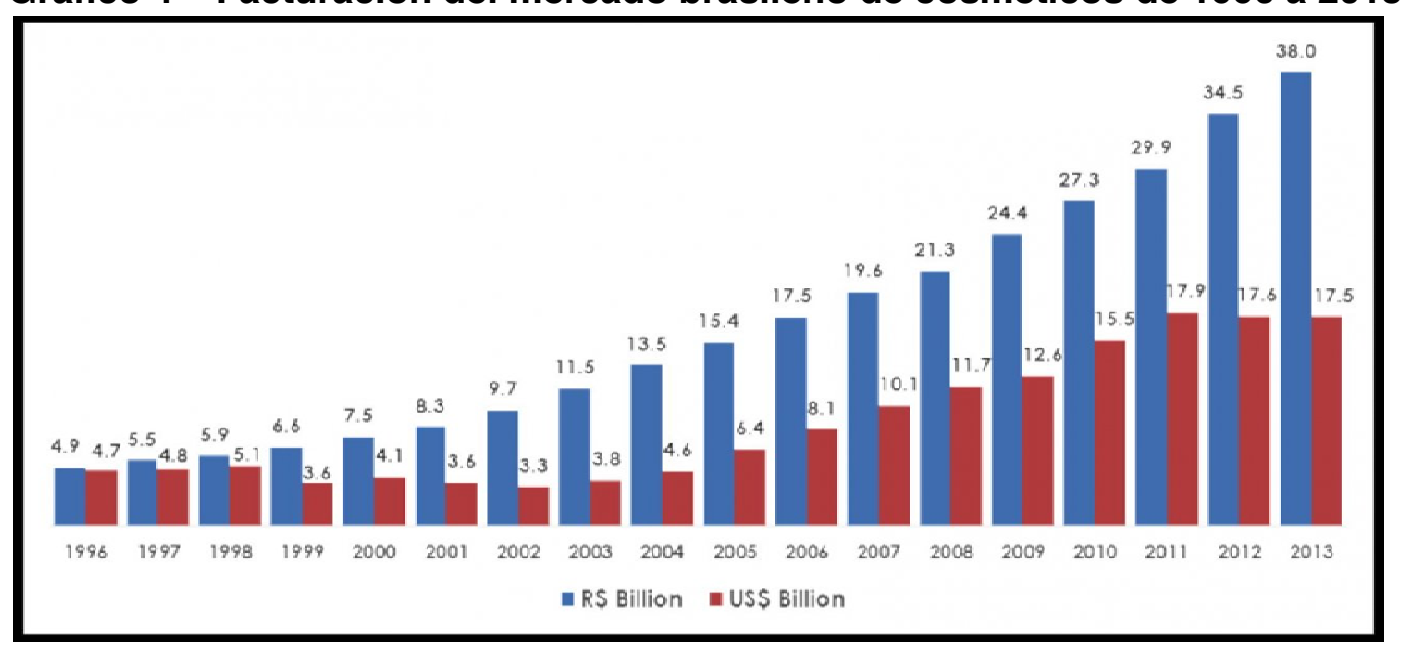

Fuente: ABIHPEC (2014, p. 2).

El crecimiento alcanzado entre 1996 y 2013 fue significativo (de 4,9 billones a 38 billones). En ningún momento se estancó el crecimiento del sector, por lo cual los resultados apuntan al desarrollo y a la potencial expansión que puede experimentar aún el segmento.

\footnotetext{
${ }^{87}$ BNDES (2013). [18]

${ }^{88}$ ABIHPEC (2014, p. 2). [4]
} 
Sin embargo, la importancia de este contexto sólo es comprendida cuando se compara la facturación de la industria de HPPC con el Producto Bruto Interno (PBI) brasileño y el desarrollo de la industria del país en general; como muestra la Tabla 16, que retrata la evolución entre 1996 y 2013 y apunta que el crecimiento del sector HPPC superó tres veces el PBI y cuatro veces los demás sectores industriales. ${ }^{89}$

Tabla 16 - PIB brasileño, industria en general y HPPC con sector deflacionado entre 1996 y 2013

\begin{tabular}{|c|c|c|c|}
\hline \multicolumn{4}{|c|}{ Variaço Anual (9\%) } \\
\hline Ano & PIB & Indústria Geral & Setor Deficioiona \\
\hline 1996 & 2.7 & 3.3 & 17.2 \\
\hline 1997 & 3.3 & 4.7 & 13.9 \\
\hline 1998 & 0.2 & -1.5 & 10.2 \\
\hline 1999 & 0.8 & -2.2 & 2.8 \\
\hline 2000 & 4.3 & 6.6 & 8.8 \\
\hline 2001 & 1.3 & 1.6 & 10.0 \\
\hline 2002 & 2.7 & 2.7 & 10.3 \\
\hline 2003 & 1.1 & 0.1 & 5.0 \\
\hline 2004 & 5.7 & 8.3 & 15.0 \\
\hline 2005 & 3.2 & 3.1 & 13.5 \\
\hline 2006 & 4,0 & 2.8 & 15.0 \\
\hline 2007 & 6. 1 & 6.01 & 9.4 \\
\hline 2008 & 5.2 & 3.1 & 5.5 \\
\hline 2009 & -0.3 & -7.4 & 9.6 \\
\hline 2010 & 7.5 & 10.45 & 10.5 \\
\hline 2011 & 2.7 & 0.4 & 6.3 \\
\hline 2012 & 0.9 & -2.5 & 8.8 \\
\hline 2013 & 2.3 & 1.2 & 5.3 \\
\hline $\begin{array}{c}\text { Acum. Gltimos } 18 \\
\text { anos }\end{array}$ & 69.1 & 47.5 & 436.3 \\
\hline $\begin{array}{l}\text { Médio Composto } \\
\text { Gltimos } 18 \text { anos }\end{array}$ & 3.0 & 2.2 & 9.8 \\
\hline
\end{tabular}

Fuente: ABIHPEC (2014, p. 3).

Los principales segmentos exportados en 2012 y 2013 en el sector de cosméticos pueden contemplarse en el Gráfico 5, con los respectivos porcentajes en el volumen de negocios, considerando los grupos de productos. ${ }^{90}$

Gráfico 5 - Porcentaje de productos HPPC brasileños exportados, por agrupación de segmento, en los años 2012 y 2013

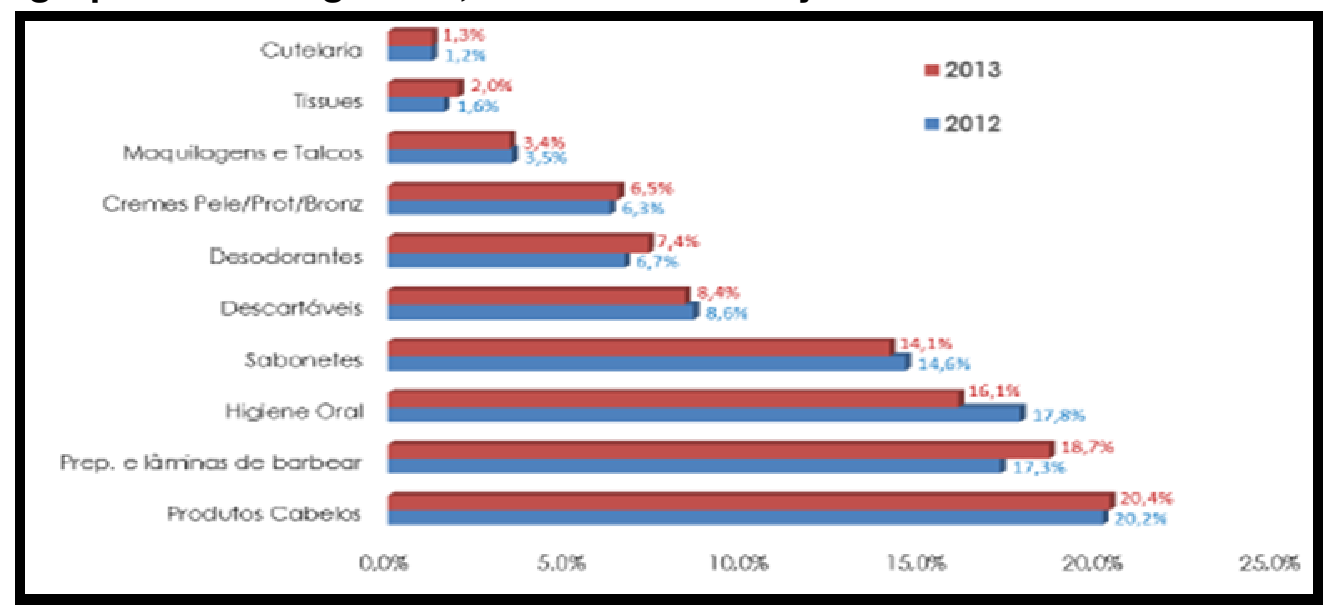

Fuente: ABIHPEC (2014, p. 7).

\footnotetext{
${ }^{89}$ ABIHPEC (2014, p. 3). [4]

${ }^{90}$ ABIHPEC (2014, p. 7). [4]
} 
Productos para el cabello, preparaciones y láminas para afeitar, higiene oral y jabones crecieron de forma exponencial en 2012 y 2013, destacándose como impulsores de las exportaciones del sector.

La relación comercial de Brasil con el sector de cosméticos apunta a que las importaciones brasileñas dependen mucho del mercado argentino cuando se consideran productos como desodorantes, maquillaje y productos para la piel, como puede observarse en la Figura 5, que refleja datos hasta $2012 .{ }^{91}$

Figura 5 - Origen de las importaciones brasileñas de cosméticos

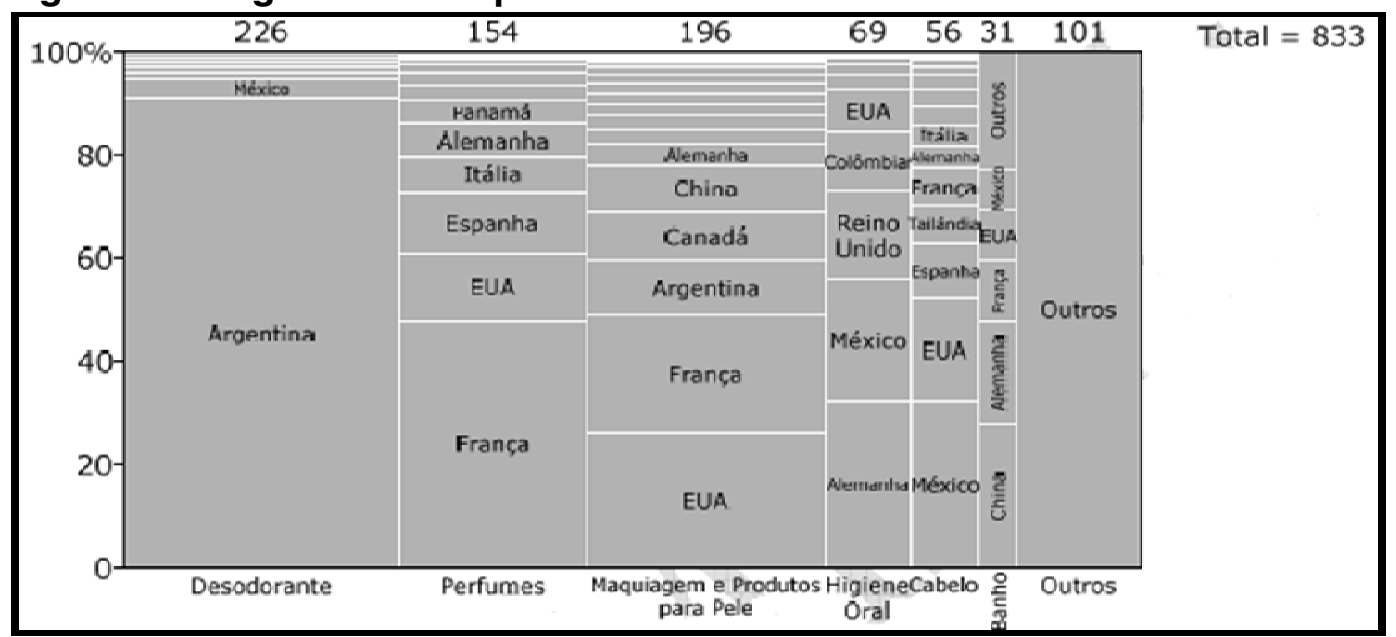

Fuente: BNDES (2014, p. 13).

Argentina es el principal importador de Brasil cuando se trata de desodorantes, con un volumen de más del $80 \%$ de los productos provenientes de dicho país y es el tercer proveedor de maquillajes y productos para la piel.

Al considerar los destinos de las exportaciones brasileñas de cosméticos, Argentina asume el liderazgo de las relaciones comerciales en todos los productos cosméticos producidos, como muestra la Figura $6 .^{92}$

\footnotetext{
${ }^{91}$ BNDES (2014, p. 13). [19]

${ }^{92}$ BNDES (2014, p. 14). [19]
} 
Figura 6 - Destino de las exportaciones brasileñas de cosméticos

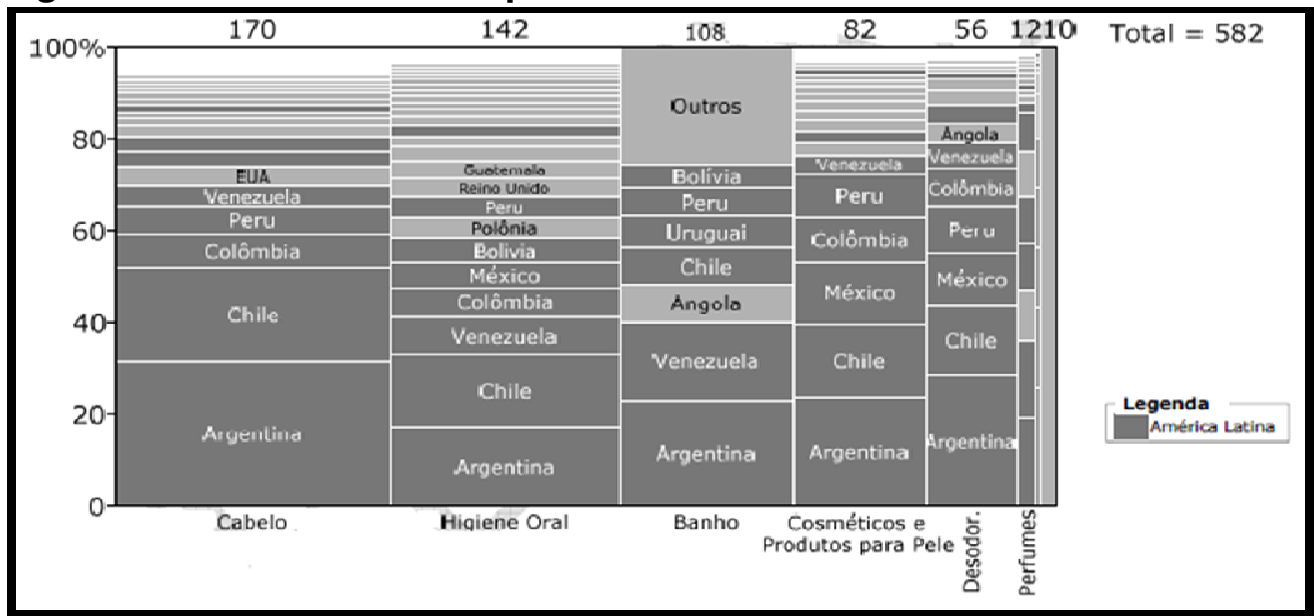

Fuente: BNDES (2014, p. 14)

Cuando Brasil exporta productos para el cabello, higiene oral, baño, cosméticos y productos para la piel, desodorantes y perfumes, su principal mercado es Argentina. Reafirmando la importancia de la relación bilateral.

Para comprender el volumen de esas negociaciones se observa el Gráfico 6, que presenta la relación de Argentina con Brasil en el sector de cosméticos en el período de 2009 hasta el primer semestre de 2014, considerando el volumen anual de ese comercio en las importaciones y exportaciones. Se observa que Argentina ocupa el primer lugar como consumidora de los productos brasileños, lo que reitera la importancia del contexto del comercio bilateral ${ }^{93}$.

\section{Gráfico 6 - Exportación e importación de cosméticos Argentina-Brasil 2009-2014}

\section{Comercio Argentina-Brasil en el Sector de Cosméticos}

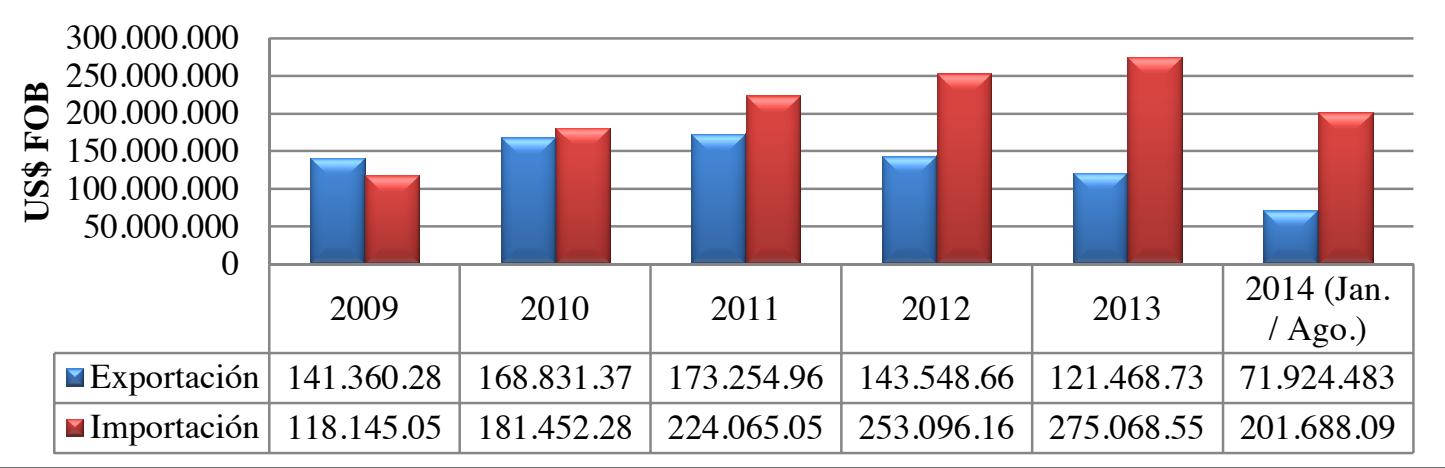

Fuente: ALICEWEB (2014, p. 1).

Sin embargo, considerándose el mercado argentino, en el primer trimestre de 2014 el saldo comercial fue de US\$ 121 millones (estancamiento de 91,9\% en relación al

\footnotetext{
${ }^{93}$ ALICEWEB (2014, p. 1). [6]
} 
mismo período de 2013). Se trata del valor más bajo de los últimos 14 años, siendo considerado el primer trimestre anual de las negociaciones dentro del bloque en el sector de cosméticos.

Las exportaciones totales en los tres primeros meses de 2014 fueron de US\$ 15,87 billones (estancamiento de 9,1\% en relación al primer trimestre de 2013), mientras las importaciones totales alcanzaron el monto de US\$15,75 billones (estancamiento de $1,3 \%$ en relación al primer trimestre de 2013). ${ }^{94}$

No obstante, no es sólo el mercado de productos finales lo que forma parte de la relación bilateral entre Brasil y Argentina. La cadena productiva de cosméticos involucra desde el cultivo/extracción/producción de materias primas naturales (aceites naturales, extractos, miel, etc.), asi como a las materias primas químicas (estabilizantes, conservantes, etc.). Las materias primas naturales constituyen la principal fuente de diferenciación de los productos cosméticos de alta categoría, mientras las materias primas químicas se utilizan para la elaboración de productos de gama media o baja, cuya facturación alcanzó US\$1,6 billones en 2012, representando el $4 \%$ del mercado total de cosméticos en Brasil. ${ }^{95}$

Entre los principales productos intermedios brasileños están las fragancias y tensoactivos/surfactantes (con $25 \%$ de representación cada uno), mostrados por la Figura 7 (datos hasta 2012), que presenta los productos intermedios más utilizados y la presencia de ellos en la composición de los productos finales del sector cosmético. ${ }^{96}$.

\section{Figura 7 - Principales productos intermedios en el sector de HPPC brasileño}

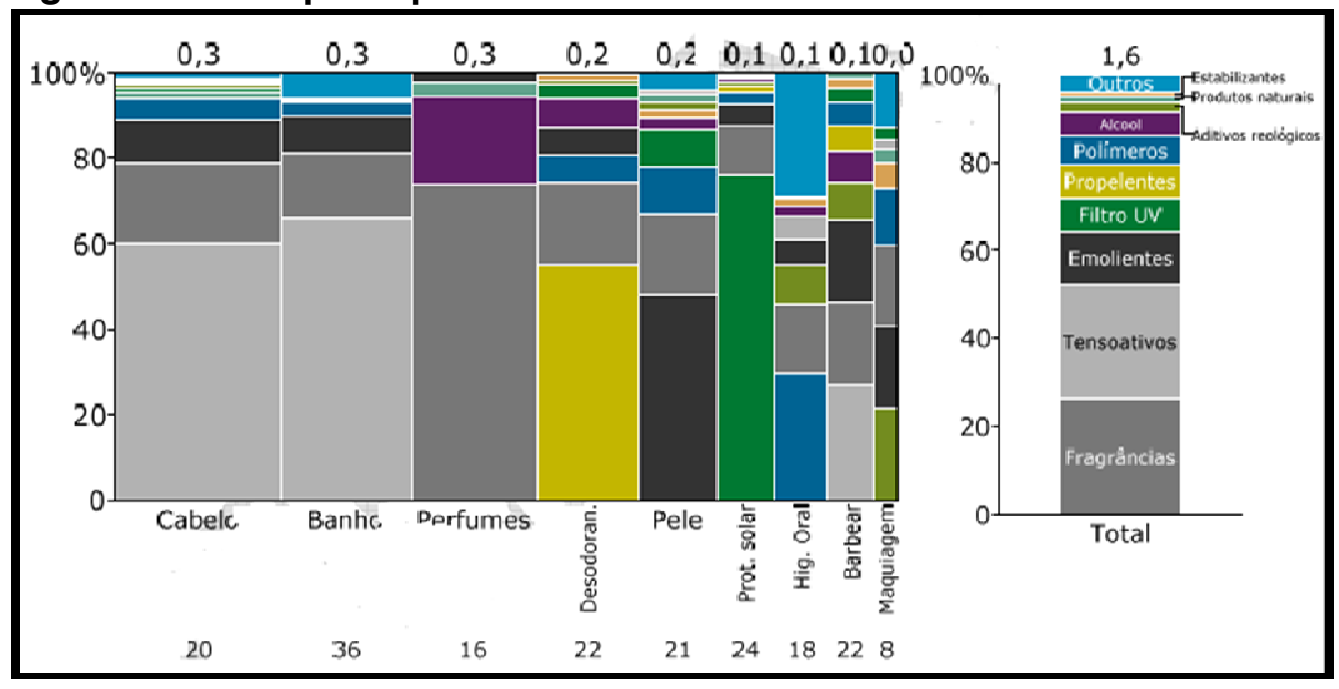

Fuente: BNDES (2014, p. 15).

\footnotetext{
${ }^{94}$ ARGENTINA (2014). [14]

${ }^{95}$ BNDES (2014). [19]

${ }^{96}$ BNDES (2014, p. 15). [19]
} 
Los tensoactivos o fragancias son señalados como principales productos intermedios en la composición de productos para el cabello, baño y perfumes. Están presentes en la mayoría de los productos que componen el segmento de HPPC en mayor o menor proporción. Emolientes, filtros, propelentes y alcohol son algunos de los productos clasificados como intermedios.

En el área de la cosmética, el maquillaje para labios y ojos y el maquillaje facial de forma general presentaron el mayor crecimiento (15\% y $14,3 \%$ respectivamente) en 2013. Los esmaltes contribuyeron con un aumento de 10,3\% en el índice de consumo de las mujeres. La interacción entre el intercambio Brasil/Argentina obtuvo un índice de crecimiento significativo en esas categorías de productos. Los valores alcanzados en 2012 y 2013. Así como las estimaciones hasta el 2017 pueden ser observadas por la Tabla $17 .^{97}$

\section{Tabla 17 - Cosmética facial}

\begin{tabular}{|l|c|c|c|c|c|}
\hline Brasil & $\mathbf{2 0 1 2}$ & $\mathbf{2 0 1 3 *}$ & $\mathbf{2 0 1 7 *}$ & $\begin{array}{c}\text { Var \% } \\
\mathbf{1 2 \times 1} \mathbf{1}\end{array}$ & $\begin{array}{c}\text { CAGR } \\
\mathbf{( 1 2 - 1 7 )}\end{array}$ \\
\hline Total Geral & $\mathbf{6 , 8}$ & $\mathbf{7 , 8}$ & $\mathbf{1 3 , 0}$ & $\mathbf{1 2 , 4 \%}$ & $\mathbf{1 3 , 9 \%}$ \\
\hline Olhos & 1,7 & 2,0 & 3,5 & $11,8 \%$ & $15,3 \%$ \\
\hline Face & 1,6 & 1,9 & 3,2 & $13,5 \%$ & $14,3 \%$ \\
\hline Lábios & 1,7 & 2,0 & 3,5 & $13,9 \%$ & $15,3 \%$ \\
\hline Unhas & 1,7 & 1,9 & 2,8 & $10,4 \%$ & $10,3 \%$ \\
\hline
\end{tabular}

Fuente: ABIHPEC/ABDI/SEBRAE (2014, p. 154).

*Previsiones.

En base a los informes presentados por ABIHPEC, ABDI y SEBRAE, se debe considerar además que cada una de dichas categorías de productos responde por aproximadamente el $25 \%$ del total facturado por el mercado brasileño. Se resalta que el mercado argentino, además de ser la mayor fuente de algunas materias primas del sector de cosméticos, es también el principal origen de las importaciones y destino de las exportaciones brasileñas de cosméticos, cuyos principales destinos son, principalmente, los países de América del Sur. Aunque ese volumen de negocios haya sido reducido en 2013 por imposiciones tarifarias de parte de Argentina a los países excluidos del MERCOSUR, lo que alcanzó también a los sectores y países del entorno, el volumen de negocios aún es grande.

Teniendo en cuenta los mismos informes, se considera importante mencionar que Brasil posee un crecimiento anual del sector de cosméticos mucho mayor que el de los demás países del mundo. Ello se debe al hecho de que consigue vender a precios menores que la competencia en el mercado externo (por adaptar sus productos a las condiciones de compra de las clases $C$ y $D^{98}$, principales consumidores actuales del

\footnotetext{
${ }^{97}$ ABIHPEC/ABDI/SEBRAE (2014, p. 154). [4]

${ }^{98}$ www.sae.gov.br
} 
sector en el país). Esa relación comercial bilateral derivada de los productos cosméticos es ampliada por la presencia de productos intermedios como fragancias 0 tenso activos y que responden por significativa parte de esa relación. El sector de cosméticos y la producción de productos intermedios se extienden a otros sectores, como el alimenticio, la industria farmacéutica, la médica e industrias químicas, destacando así la necesidad de reglamentar el uso y la composición de los productos del sector a sus diversos usos.

Las organizaciones que regulan el sector de cosméticos y las estructuras que apoyan dichos organismos son descritos en el próximo tópico.

\subsubsection{Políticas del sector de productos cosméticos entre Brasil y Argentina}

En el "Sistema Informático MARIA (SIM), similar ao Sistema Integrado de Comércio Exterior (SISCOMEX) no Brasil, são registradas as informações relativas à documentação que ampara as operações de comércio exterior da Argentina"99.

Entre Brasil y Argentina se verifica gran dinamismo en acuerdos de representación, distribución, complemento productivo, franquicias, formación de joint ventures, participación en el capital de empresas, alianzas estratégicas o proyectos de inversión conjuntos. Sin embargo, con muchos acuerdos derivados de normalización y regulación, la relación bilateral entre los principales representantes del MERCOSUR, se precisa describir en detalle el sector con el fin de aclarar los principales aspectos del negocio de cosméticos. Para ello se considera relevante abordar la política de regulación de los cosméticos y de distribución del producto en el mercado, como se aborda en los ítems a continuación.

\subsubsection{Políticas de regulación y fiscalización de cosméticos}

En Brasil, la producción y comercialización de productos de HPPC obedecen a la legislación sanitaria local, fiscalizada por la Agencia Nacional de Vigilancia Sanitaria (ANVISA). Sin embargo, la asociación Brasileña de Normas Técnicas (ABNT) y el Instituto Nacional de Medición, Normalización y Calidad Industrial (INMETRO), dentro de sus áreas de competencia, también intervienen en la regulación productiva y comercial del sector. Otros organismos que también tienen competencia, intervienen en la regulación productiva y comercial del sector. Ellos son: el Servicio Brasileño de

\footnotetext{
${ }^{99}$ ARGENTINA (2012, p. 76). [14] Traducción de Melisa Roldán: “Sistema Informático MARIA (SIM), similar al Sistema Integrado de Comercio Exterior (SISCOMEX) en Brasil, es registrada la información relativa a la documntación que ampara las operaciones de comercio exterior de Argentina".
} 
Apoyo a las Micro y Pequeñas Empresas (SEBRAE); la Agencia Brasileña de Desarrollo Industrial (ABDI); la Agencia Brasileña de Promoción de Exportaciones e Inversiones (APEX); y la Asociación Brasileña de la Industria de Higiene Personal, Perfumería y Cosméticos (ABIHPEC), quienes también contribuyen a la normalización, especificación y construcción de control de calidad y planificación del desarrollo para el sector. Muchos Planes de Desarrollo Sectorial (PDS) son derivadas de esas organizaciones estructurales. ${ }^{100}$

ANVISA $^{101}$ lista la normalización brasileña vigente para todos los productos cosméticos conforme establece el Cuadro 1.

\section{Cuadro 1 - Legislación en vigencia para la importación y exportación de cosméticos brasileños}

\begin{tabular}{|c|c|}
\hline Norma & Contenido \\
\hline $\begin{array}{l}\text { Ley } n^{\circ} \\
6.360 / 1976\end{array}$ & $\begin{array}{l}\text { Somete al Sistema de Vigilancia Sanitaria los medicamentos, insumos } \\
\text { farmacéuticos, drogas, cosméticos, productos relacionados con la higiene, } \\
\text { saneamiento y otros. }\end{array}$ \\
\hline $\begin{array}{l}\text { Decreto } \mathrm{n}^{\circ} \\
79.094 / 1977\end{array}$ & $\begin{array}{l}\text { Reglamenta la Ley } \mathrm{n}^{\circ} 6.360 \text { / 1976, que somete al sistema de vigilancia } \\
\text { sanitaria los medicamentos, insumos farmacéuticos, drogas, cosméticos, } \\
\text { productos relacionados con la higiene, saneamiento y otros. }\end{array}$ \\
\hline $\begin{array}{l}\text { Ordenanza } \\
\text { MS } n^{\circ} \\
1.480 / 1990\end{array}$ & $\begin{array}{l}\text { Dispone sobre las Normas y Requisitos Técnicos a los que quedan sujetos } \\
\text { los productos absorbentes higiénicos descartables de uso externo e } \\
\text { intravaginal, destinados al aseo corporal (absorbentes higiénicos de uso } \\
\text { externo e intravaginal, absorbentes de leche materna y pañales para bebes } \\
\text { y adultos). }\end{array}$ \\
\hline $\begin{array}{l}\text { Ordenanza } \\
\mathrm{n}^{\circ} 97 / 1996\end{array}$ & $\begin{array}{l}\text { Dispone sobre las Normas y Requisitos Técnicos a los que quedan sujetos } \\
\text { cepillos de dientes, con o sin pigmentos o colorantes en las cerdas. }\end{array}$ \\
\hline $\begin{array}{ll}\text { RDC } & n^{\circ} \\
10 / 1999\end{array}$ & $\begin{array}{l}\text { Las mamaderas, chupetes, mordillos y picos, toallas higiénicas descartables } \\
\text { destinadas al aseo corporal, los cepillos de dientes y los hisopos no son } \\
\text { responsables de registro en ANVISA, aunque están sujetos al régimen de } \\
\text { vigilancia sanitaria para los demás efectos de la Ley } n^{\circ} 6.360 / 1976 \text {, del } \\
\text { Decreto } n^{\circ} 79.094 \text { / } 1977 \text { legislación correlativa complementaria. }\end{array}$ \\
\hline $\begin{array}{ll}\mathrm{RDC} & \mathrm{n}^{\circ} \\
481 / 1999 & \end{array}$ & Trata de los parámetros microbiológicos para productos cosméticos. \\
\hline $\begin{array}{l}\text { Ley } \mathrm{n}^{\circ} \\
9.782 / 1999\end{array}$ & $\begin{array}{l}\text { Define el Sistema Nacional de Vigilancia Sanitaria, crea la Agencia } \\
\text { Nacional de Vigilancia Sanitaria y establece otras medidas. }\end{array}$ \\
\hline $\begin{array}{l}\text { Decreto } n^{\circ} \\
3.029 / 1999\end{array}$ & $\begin{array}{l}\text { Aprueba el Reglamento de la Agencia Nacional de Vigilancia Sanitaria y } \\
\text { establece otras medidas. }\end{array}$ \\
\hline $\begin{array}{ll}\text { RDC } & n^{\circ} \\
128 / 2002\end{array}$ & $\begin{array}{l}\text { Quedan exentos de Autorización de Funcionamiento de Empresa, en esta } \\
\text { Agencia, los fabricantes e importadores de materias primas, insumos y } \\
\text { componentes destinados a la fabricación de productos sanitarios } \\
\text { domiciliares, cosméticos, productos de higiene personal, perfumes y otros } \\
\text { relacionados, quedando sin embargo sujetos al control sanitario, conforme } \\
\text { lo establecido en la legislación sanitaria vigente. }\end{array}$ \\
\hline $\begin{array}{ll}\text { RDC } & n^{\circ} \\
261 / 2002 & \end{array}$ & $\begin{array}{l}\text { Determina que la empresa interesada en obtener copia de documentos o de } \\
\text { procesos administrativos en el ámbito de la Agencia, al formular el } \\
\text { requerimiento, deberá satisfacer las exigencias y condiciones constantes del } \\
\text { anexo. }\end{array}$ \\
\hline $\begin{array}{ll}\text { RDC } & n^{\circ} \\
204 / 2005 & \end{array}$ & $\begin{array}{l}\text { Reglamente el procedimiento de peticiones sometidas a análisis por los } \\
\text { sectores técnicos de ANVISA y deroga la RDC } n^{\circ} 349 / 2003 \text {. }\end{array}$ \\
\hline $\begin{array}{ll}R D C & n^{\circ} \\
211 / 2005 & \end{array}$ & $\begin{array}{l}\text { Quedan establecidas la definición y la clasificación de productos de higiene } \\
\text { personal, cosméticos y perfumes. }\end{array}$ \\
\hline
\end{tabular}

\footnotetext{
100 ABIHPEC (2014). [1]

${ }^{101}$ ANVISA (2013,p. 4). [12]
} 


\begin{tabular}{|lc|l|l|}
\hline $\begin{array}{l}\mathrm{RDC} \\
332 / 2005\end{array}$ & $\mathrm{n}^{\circ}$ & $\begin{array}{l}\text { Las empresas fabricantes y/o importadoras de productos de higiene } \\
\text { personal, cosméticos y perfumes, instaladas en el territorio nacional, } \\
\text { deberán implementar un sistema de Vigilancia de Cosméticos, a partir del } \\
31 / 12 / 2005 .\end{array}$ \\
\hline $\begin{array}{l}\mathrm{RDC} \\
343 / 2005\end{array}$ & $\mathrm{n}^{\circ}$ & $\begin{array}{l}\text { Trata la regulación de productos cosméticos de modo general y sus } \\
\text { categorias. }\end{array}$ \\
\hline $\begin{array}{l}\mathrm{RDC} \\
176 / 2006\end{array}$ & $\mathrm{n}^{\circ}$ & $\begin{array}{l}\text { Aprueba el Reglamento Técnico "Contratación de Tercerización para } \\
\text { Productos de Higiene Personal, Cosméticos y Perfumes". }\end{array}$ \\
\hline $\mathrm{RDC}$ & $\mathrm{n}^{\circ}$ & $\begin{array}{l}\text { Dispone sobre los procedimientos de petición y recaudación electrónica en } \\
\text { el ámbito de ANVISA y de sus Coordinaciones Estatales y Municipales de } \\
\text { Vigilancia Sanitaria y establece otras medidas. }\end{array}$ \\
\hline $\begin{array}{l}\mathrm{RDC} \\
92 / 2008\end{array}$ & $\mathrm{n}^{\circ}$ & $\begin{array}{l}\text { Establece reglas generales para los productos de higiene personal, } \\
\text { cosméticos y perfumes de grado 1 y de grado 2, cuando son fabricados en } \\
\text { Brasil y destinados exclusivamente a la exportación. }\end{array}$ \\
\hline
\end{tabular}

Fuente: ANVISA (2013, p. 4).

Los 17 ítems que componen la regulación de las acciones orientadas a la clasificación, nomenclatura, formulación, conservación, condiciones de comercialización y legislación afines para el sector de HPPC son fiscalizadas tanto por Brasil como por Argentina.

No obstante, se destaca que el sector de HPPC entre Brasil y Argentina es muy variado. El primer criterio a considerar es la definición del término "cosméticos" para los dos países. El MERCOSUR adopta la misma definición dictada por la Unión Europea (EU), establecida por la resolución n² 2011 de 2005 de ANVISA:

Produtos para higiene pessoal, cosméticos, perfumes $e$ as substâncias ou preparados formados por substâncias naturais e sintéticas, e suas misturas, para uso externo em diversas partes exteriores do corpo humano, pele, sistema capilar, unhas, lábios e órgãos genitais externos, dentes e as membranas mucosas da cavidade bucal, com o exclusivo ou principal objetivo de limpar, perfumar, alterar a aparência elou corrigir odores corporais elou protegê-los e mantê-los em boas condições ${ }^{102}$.

EI MERCOSUR es regido por una serie de divisiones descritas por la Nomenclatura Común del MERCOSUR (NCM), que determinan un código para cada tipo de producto en sus segmentos específicos ${ }^{103}$. Como ejemplo, se observa la Tabla 18, que detalla la relación bilateral Argentina/Brasil considerando los cosméticos según los códigos adoptados, revelando la facturación obtenida por la importación y exportación del segmento.

\footnotetext{
102 ANVISA (RESOLUÇÃO No 211, 2005). [13] Traducción de Melisa Roldán: "Productos para higiene personal, cosméticos, perfumes y las sustancias o preparaciones hechas con sustancias naturales y sintéticas, y sus combinaciones, para uso externo en diversas partes exteriores del cuerpo humano, piel, sistema capilar, uñas, labios, órganos genitales externos, dientes y membranas mucosas de la cavidad bucal, con el exclusivo o principal objetivo de limpiar, perfumar, alterar la apariencia y/o corregir olores corporales y/o protegerlos y mantenerlos en buenas condiciones".

${ }^{103}$ ALICEWEB (2014, p. 1). [6]
} 
Tabla 18 - Importación y exportación de productos HPPC Argentina-Brasil entre 2009 y 2013 según el código NCM

\begin{tabular}{|c|c|c|c|c|c|c|}
\hline \multicolumn{7}{|c|}{ Importación Argentina x Brasil (US\$ FOB) } \\
\hline $\begin{array}{l}\text { Código } \\
\text { NCM }\end{array}$ & HPPC & 2013 & 2012 & 2011 & 2010 & 2009 \\
\hline 3304 & $\begin{array}{l}\text { Productos de } \\
\text { belleza, } \\
\text { maquillaje para } \\
\text { ojos, labios, } \\
\text { cuidados para la } \\
\text { piel }\end{array}$ & 16.945 .030 & 20.779 .466 & $\begin{array}{r}18.657 .10 \\
6\end{array}$ & 9.962 .867 & 5.011 .425 \\
\hline 3302 & $\begin{array}{l}\text { Mezclas básicas } \\
\text { industriales }\end{array}$ & 8.321.301 & 9.247 .764 & 6.396 .657 & 3.809 .676 & 3.460 .668 \\
\hline 3301 & $\begin{array}{l}\text { Aceites } \\
\text { esenciales }\end{array}$ & 2.894.721 & 2.584 .410 & 3.587 .112 & 2.965 .465 & 4.295 .002 \\
\hline \multicolumn{7}{|c|}{ Exportación Argentina x Brasil (US\$ FOB) } \\
\hline $\begin{array}{l}\text { Código } \\
\text { NCM }\end{array}$ & HPPC & 2013 & 2012 & 2011 & 2010 & 2009 \\
\hline 3304 & $\begin{array}{l}\text { Productos de } \\
\text { belleza, } \\
\text { maquillaje para } \\
\text { ojos, labios, } \\
\text { cuidados para la } \\
\text { piel }\end{array}$ & 18.283.112 & 19.676.334 & $\begin{array}{r}21.729 .31 \\
9\end{array}$ & 16.766.338 & n.d. ${ }^{*}$ \\
\hline 3302 & $\begin{array}{l}\text { Mezclas básicas } \\
\text { industriales }\end{array}$ & 24.194 .108 & 25.414 .810 & $\begin{array}{r}17.117 .88 \\
7\end{array}$ & 14.147 .431 & n.d. ${ }^{*}$ \\
\hline 3301 & $\begin{array}{l}\text { Aceites } \\
\text { esenciales }\end{array}$ & 4.243 .570 & 4.511 .019 & 3.488 .401 & 3.533 .666 & n.d. ${ }^{*}$ \\
\hline
\end{tabular}

Fuente: ALICEWEB (2014, p. 1).

*El informe no divulgó el resultado detallado por producto y/o código en la exportación para el año 2009.

Se destaca la dificultad para listar todos los productos derivados del sector de cosméticos, pues fórmulas primarias y composiciones básicas como aceites y esencias también componen este vasto universo, además de pertenecer a otros sectores, como el de alimentos, por ejemplo, impidiendo una separación correcta y precisa de los valores destinados solamente al sector de cosméticos.

Sin embargo, para que la comercialización bilateral entre Brasil y Argentina suceda, hay algunas reglas impuestas en cada país, que regulan los sistemas de intercambio (importación y exportación) dentro del bloque y que establecen directrices, tanto en la observación de los componentes de los productos como en las especificaciones y orientaciones que deben constar en los rótulos de cosméticos y productos HPPC.

De acuerdo con la Resolución RDC $n^{\circ} 211$, del 14 de julio de 2005, los productos cosméticos de la relación bilateral son clasificados en dos tipos ${ }^{104}$ :

- Productos Grado 1: son productos de higiene personal, cosméticos y perfumes cuya formulación cumple con la definición adoptada en el ítem 1 del Anexo I de

${ }^{104}$ ANVISA (2005). [13] 
esta Resolución. Se caracterizan por poseer propiedades básicas 0 elementales, cuya comprobación no sea inicialmente necesaria y no requieran informaciones detalladas en cuanto a su modo de uso y sus restricciones, debido a las características intrínsecas del producto.

- Productos Grado 2: son productos de higiene personal, cosméticos y perfumes cuya formulación cumple con la definición adoptada en el ítem 1 del Anexo I de la Resolución y que poseen indicaciones específicas, cuyas características exigen comprobación de seguridad y/o eficacia, así como información, advertencias, modo y restricciones de uso.

Los ingredientes utilizados en cosméticos son regulados de acuerdo con la Disposición argentina 1112/99 y sus actualizaciones periódicas, que contienen listas de sustancias prohibidas y restringidas y listas positivas de colorantes, filtros UV y conservantes, hechas en base a los Anexos de la Directiva Europea de Cosméticos. Argentina también adopta la lista de Food and Drug Administration (Administración de Comida y Medicamentos, FDA - EUA) de ingredientes prohibidos, lista de colorantes aprobados y todos los activos de venta libre (OTC - Over The Counter) aprobados en productos que son considerados cosméticos en el MERCOSUR (por ejemplo: shampoos anti caspa, antritranspirantes, cremas dentales anti caries y protectores solares) ${ }^{105}$.

El comercio bilateral exige que los productos del sector contengan las siguientes especificaciones en el rótulo y/o embalaje, que puede ser primaria y/o secundaria ${ }^{106}$ :

- Rótulo obligatorio, constando en el embalaje el nombre del producto y grupo/tipo al que pertenece, en caso de no estar implícito el nombre.

- En el embalaje primario: Marca primaria y secundaria; número de registro/resolución; lote o partida primaria.

- En el embalaje secundario: Plazo de validad (mes/año); contenido; país de origen; fabricante/importador; domicilio del fabricante/importador; modo de uso (si fuera el caso); advertencias/restricciones de uso (si fuera el caso).

- Rótulo específico: composición/ingredientes; inscripción en el registro nacional de persona jurídica (CNPJ); finalidad del producto, cuando no implícita en el nombre.

- Observaciones: cuando no exista embalaje secundario, toda la información requerida debe figurar en el embalaje primario.

Os Cosméticos argentinos são regulados pela Resolução $n^{\circ} 155 / 98$ de 13 de Julho de 1998 do Ministério da Saúde e Ação Social (MSAS). A Resolução dá poder ao Ministério, através da

\footnotetext{
${ }^{105}$ BRASIL (2007, p. 6). [23].

${ }^{106}$ ANVISA (2005). [13]
} 
Administração Nacional de Medicamentos, Alimentos e Tecnologia Médica (ANMAT), de regular os cosméticos, conforme necessário. $A$ Disposição 374/ 2006 contém regras para rotulagem. Existem também regulamentos sobre registro de produto, boas práticas de fabricação, pesos e medidas e outros que se aplicam a $\operatorname{cosméticos}^{107}$.

Controles adicionales son exigidos según las reglas fitosanitarias de la Administración Nacional de Medicamentos, Alimentos y Tecnología Médica - ANMAT. Este órgano interviene en la fiscalización y control de sanidad y calidad de los productos que puedan afectar a la salud humana, incluyendo las importaciones de drogas, productos, químicos, reactivos, fórmulas farmacéuticas, medicamentos, elementos de diagnóstico, materiales y tecnologías médicas, productos de higiene, cosmética humana, drogas y materias primas que los integren (estas son fiscalizadas por el Instituto Nacional de Medicamentos - INAME, subordinado a la ANMAT) ${ }^{108}$.

Pero, de forma general, en relación a los cosméticos, no difieren de los conceptos establecidos por Brasil en cuanto a la rotulación y observaciones en los embalajes, además de las convenciones y regulaciones ya citadas en ese estudio. Se resalta también, que en relación a los precios, las tarifas de importación y exportación de los productos importados y exportados dentro del bloque para los países miembros del MERCOSUR es cero, o sea, hay acuerdos que establecen, con raras excepciones (como es el caso del azúcar de caña y remolacha) a la exención de impuestos y tarifas aduaneras entre los países miembro.

Concierne, pues, mencionar cómo son los canales de distribución de las mercancías en las relaciones bilaterales Brasil/Argentina, conforme aborda el subtítulo a continuación.

\subsubsection{Políticas de Distribución}

La apertura de la economía y el proceso de integración económica provocaron, en los países del MERCOSUR, el aumento progresivo de la presencia de productos importados en los respectivos mercados internos. A causa de ello, se observó mayor "modernização nos hábitos de consumo e de compra, apoiados na estabilidade

\footnotetext{
${ }^{107}$ BRASIL (2007, p. 6). [23] Traducción de Melisa Roldán "Los cosméticos argentinos son regulados por la Resolución n 115/98, 13 de Julio de 1998 del Ministerio de Salud y Acción Social (MSAS). LA Resolución da poder al Ministerio, a través de la Administración Nacional de Medicamentos, Alimentos y Tecnología Médica (ANMAT), de regular los cosméticos, conforme lo necesario. La Disposición 374/2006 contiene reglas para rotulación. Existen también reglamentos sobre registro de producto, buenas prácticas de fabricación, pesos y medidas y otros que se aplican a cosméticos."
}

${ }^{108}$ ARGENTINA (2012). [14] 
econômica e no sistema de crédito aos consumidores, apesar das crises econômicas pelas quais atravessam atualmente as economias da região" ${ }^{109}$.

Los canales de distribución consisten en el camino recorrido por la mercancía, desde el productor hasta los importadores y usuarios finales. La elección del canal de distribución adecuado es esencial para el éxito en la actividad exportadora. Los factores que influyen en la elección del mismo son:

a) Naturaleza del producto: dimensión, peso, presentación, plazo de vencimiento;

b) Características del mercado: hábitos de compra, poder adquisitivo, localización geográfica, destino del producto (consumo final o industrial);

c) Calificación de los agentes intermediarios: experiencia, capacidad administrativa y otras referencias. ${ }^{110}$

Los principales canales de distribución en Argentina son los agentes y los comerciantes. El agente es una persona física o jurídica que actúa en la transferencia de bienes y servicios que, sin asumir la titularidad legal sobre los bienes comercializados, recibe comisión por participar en la operación. Los comerciantes adquieren las mercancías, es decir, asumen la titularidad y posesión legal de los bienes comercializados. En Argentina, los agentes intermediarios ejercen considerable influencia en la cadena de distribución, ya que grandes importadores y distribuidores están concentrados en pocas regiones. El mercado se caracteriza por su polarización, con la existencia de dos segmentos bien definidos, uno sofisticado y otro popular de precios bajos. $^{111}$

El escenario de facturación positiva, el mercado logístico para el segmento de cosméticos, perfumería e higiene personal enfrenta diversos desafíos para continuar su desarrollo en Brasil y en su relación con Argentina. La falta de infraestructura y la restricción de tráfico en las grandes metrópolis son algunos de los problemas enfrentados y que pueden también impactar negativamente en la expansión del sector de cosméticos. El sector precisa acompañar las tendencias del mercado, crear alternativas de consumo y respetar la fecha de vencimiento, formulas de composición química y mantenimiento de productos frágiles en buen estado durante la distribución de los productos al mercado (de bienes y de insumos), que dependen

\footnotetext{
${ }^{109}$ ARGENTINA (2012, p. 91). [14] Traducción de Melisa Roldán: “modernización en los hábitos de consumo y de compra, apoyados en la estabilidad económica y en el sistema de crédito a los consumidores, a pesar de las crisis económicas por las que atravieran actualmente las economías de la región."

${ }^{110}$ BRASIL (2012). [20]

${ }^{111}$ ARGENTINA (2012). [14]
} 
considerablemente de un movimiento logístico bien estructurado y capacitado, aún poco eficiente si se considera la calidad de las rutas y los puertos. ${ }^{112}$.

El transporte terrestre y ferroviario binacional, efectuado por empresas brasileñas y argentinas, se realiza principalmente por el puente Uruguayana - Paso de Los Libres. La mayoría de los productos importados por Argentina llega al país por vía marítima y moviliza más del $80 \%$ del volumen de cargas de las importaciones y exportaciones. El transporte marítimo con Brasil es regulado por la Conferencia de Flete BrasilArgentina, que comprende el movimiento en los principales puertos argentinos y brasileños. ${ }^{113}$

Hay dos caminos para la entrada de productos no perecederos en el mercado argentino, además de la exportación directa. La Figura 8 muestra el canal corto y el canal largo para esas operaciones, que incluyen el sector de cosméticos. ${ }^{114}$.

Figura 8 - Formas de entrada de las exportaciones en el mercado argentino

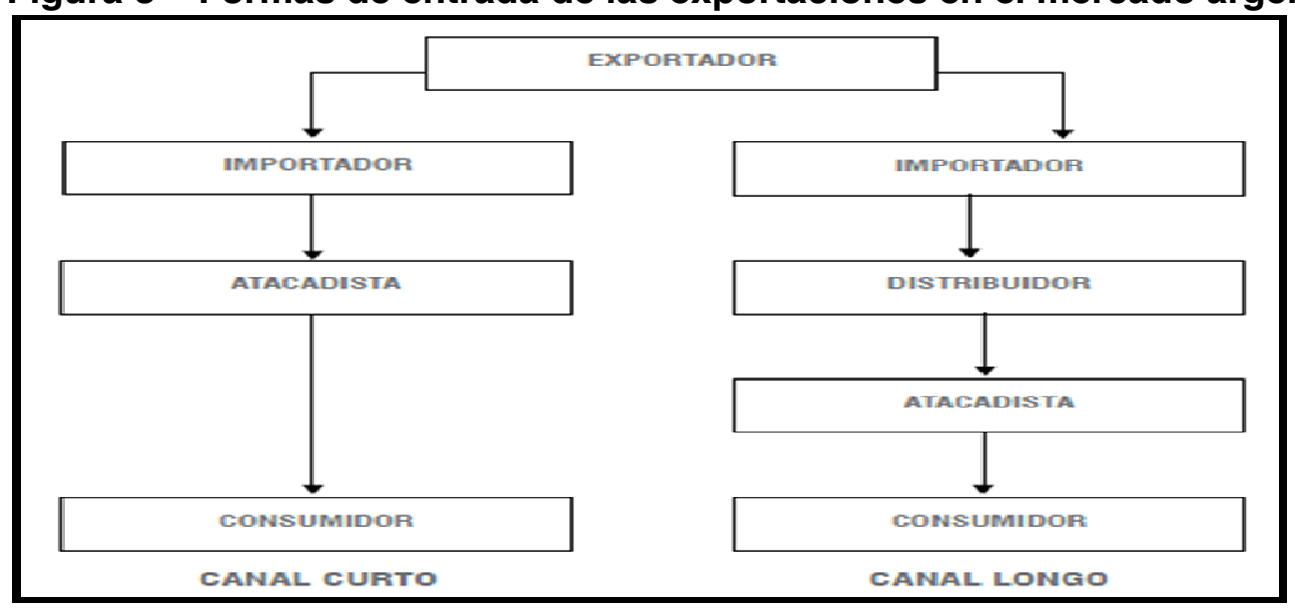

Fuente: Argentina (2012, p. 95).

En el embarque de productos en dirección a Argentina, el exportador brasileño debe proveer toda la documentación exigida, que normalmente está compuesta de:

a) Factura comercial;

b) Romaneo (Packing list);

c) Conocimiento de embarque;

d) Certificado de origen;

e) Otros certificados (como certificados sanitarios o de seguridad y calidad cuando sean aplicables) ${ }^{115}$.

El escenario de relaciones comerciales bilaterales entre Brasil y Argentina precisa mejores movimientos logísticos, considerando el principal limitante de las

\footnotetext{
112 BRASIL (2013). [21]

113 ARGENTINA (2012). [14]

${ }^{114}$ ARGENTINA (2012, p. 95). [14]

115 BRASIL (2014). [22]
} 
importaciones y exportaciones, teniendo en cuenta que el sector de cosméticos y sus actuaciones periféricas precisan, muchas veces, de cuidados especiales de conservación, manejo, transporte y condiciones de mantenimiento. El tráfico de las grandes ciudades y la calidad de puertos y rutas es un desafío sustancial a ser enfrentado. Considerando el aumento del consumo de productos importados en ambos mercados, el acompañamiento de tendencias mundiales de modernización y el poder de compra de cosméticos intensificado por las políticas de crédito; y a pesar de la crisis económica regional, ambos países merecen inversiones capaces de sustentar su importancia y eficiente crecimiento a nivel mundial en el sector; destacándose Argentina y Brasil como productores, consumidores, importadores y exportadores importantes en ese escenario. Fortalecidos, además, por las relaciones creadas por la actuación del MERCOSUR como bloque económico en acentuado crecimiento.

Frente a este aporte teórico, se definen los objetivos de este estudio: el objetivo general y los objetivos específicos, como se demuestra en los tópicos a seguir. 


\section{Objetivo General}

El objetivo general de este estudio es:

Analizar el sector industrial de cosméticos entre Brasil y Argentina. 


\section{Objetivos específicos}

Los objetivos específicos de este estudio incluyen las siguientes investigaciones:

a. Identificar las perspectivas del comercio bilateral entre Brasil y Argentina en el sector de cosméticos, enumerando los aspectos positivos del comercio bilateral en el MERCOSUR;

b. Apuntar las principales oportunidades del mercado brasileño y argentino de cosméticos;

c. Apuntar las principales amenazas del mercado brasileño y argentino de cosméticos;

d. Observar las sugerencias de las empresas investigadas para aumentar importaciones y exportaciones de cosméticos entre los dos países. 


\section{Tema de investigación e hipótesis}

El tema de investigación y las hipótesis incluyen:

\subsection{Tema de investigación}

Alrededor del mundo, la internacionalización pasó a ser percibida como una oportunidad, una forma estratégica de crecimiento y competitividad tanto para neutralizar a la competencia, como para explorar ventajas competitivas o diversificarse en relación a los proveedores y mercados consumidores. Pero la internacionalización requiere que se adopte una estrategia de penetración en el mercado objetivo. Las negociaciones para entrada y salida de productos de un país hacia otro fueron facilitadas por los acuerdos internacionales que, en relación a Brasil, involucran, sobre todo, el MERCOSUR. ${ }^{116,117}$ Esas relaciones son dictadas, principalmente, por la política establecida para el bloque económico. $Y$ en ese sentido, Brasil y Argentina mantienen una relación intensa, considerando que son los principales representantes del MERCOSUR en negocios e importancia económica dentro del bloque.

Teniendo en cuenta que Brasil y Argentina son sede de grandes empresas productoras de cosméticos, siendo, por lo tanto, mercados especializados en la rama y capaces de atender a otros mercados con grandes niveles de exigencia cualitativa, la pregunta de investigación de este estudio es: el destino de las importaciones y exportaciones de Brasil y Argentina en la rama de cosméticos ¿refleja el cumplimiento de exigencias de calidad comercial o es promovido por la proximidad geográfica y por acuerdos como los realizados dadas las relaciones del MERCOSUR?

A partir de esta pregunta, se plantean hipótesis para el alcance de los objetivos de este estudio, conforme se encuentra a continuación.

\footnotetext{
${ }^{116}$ HILAL; HEMAIS (2003). [46]

${ }^{117}$ BARRETO; ROCHA (2003). [16].
} 


\subsection{Hipótesis}

Considerando que el MERCOSUR tiene como objetivo generar las condiciones para el crecimiento de los países que lo componen como competidores internacionales en la importación y exportación de productos de los más diversos segmentos, en relación al comercio bilateral entre Brasil y Argentina, son hipótesis de este estudio que:

La mayoría de las empresas reconoce que el MERCOSUR afectó positivamente la relación entre Brasil y Argentina en el sector de cosméticos, y ese contexto se confirma considerándose:

- Que los acuerdos sobre cosmética entre Brasil y Argentina obedecen a reglas mundialmente aceptadas y claramente definidas por el MERCOSUR, agregando cada una de las exigencias al acuerdo bilateral firmado, como sistemas de control, fiscalización y legislación específicos para los cosméticos. En el caso de Argentina, el gobierno atiende a criterios de composición, sanidad y embalaje adoptados por el mercado europeo. Entre Brasil y Argentina, las divisiones de segmentos de productos que componen el sector de cosméticos son amparadas por la Nomenclatura Común del MERCOSUR (NCM), que determina un código para cada tipo de producto. Se verifica gran dinamismo en acuerdos de representación, distribución, complementación productiva, franquicias, formación de joint ventures, participación en capital de empresas, alianzas estratégicas o proyectos de inversión conjuntos ${ }^{118}$. De esta forma, se toma como hipótesis de este estudio que la relación bilateral mejora la calidad de los productos cosméticos, ya que posee reglas claras y aceptadas tanto en el mercado consumidor como por los acuerdos del MERCOSUR.

- Se considera que el mercado brasileño de HPPC representa el $10 \%$ del mercado global y que el crecimiento del consumo de productos fabricados en Brasil y exportados a otros países son más baratos, pues en los últimos 5 años experimentaron crecimiento de precios inferiores a la inflación, aumentando así el interés comercial para la demanda productiva brasileña y desatándose Argentina y Brasil como productores, consumidores, importadores y exportadores importantes en ese escenario; considerándose aún el aumento del consumo de productos cosméticos en el mercado interno de Brasil y Argentina, intensificado por las políticas de crédito ${ }^{119}$; se toma la hipótesis de ese estudio que hubo aumento de la exportación de productos cosméticos para los dos países.

\footnotetext{
${ }^{118}$ ALICEWEB (2014). [6]

${ }^{119}$ ABIHPEC (2014). [4]
} 
- Considerándose que Brasil tiene en Argentina la mayor fuente de sus importaciones y el mayor consumo de sus productos cosméticos y de HPPC de forma general; y los 10 principales destinos de las exportaciones de productos cosméticos brasileños, pero, que el volumen de negocios entre Brasil y Argentina es 15 veces mayor al del comercio entre los demás países componentes del MERCOSUR; reitera la importancia de la proximidad geográfica como interés comercial ${ }^{120}$; se toma la hipótesis de este estudio de que aumenta la importación de materia prima como resultado de esa relación bilateral.

${ }^{120}$ ALTEMANI (2008). [8] 


\section{Metodología}

La metodología utilizada para el desarrollo del proyecto involucra un conjunto de técnicas y concepciones teóricas ${ }^{121}$, detallado por los tópicos a seguir.

\subsection{Alcance de la investigación}

En este trabajo se adoptó una metodología cuantitativa que, de acuerdo con Yin ${ }^{122}$, tiene el objetivo de proveer criterios y comprensión. Posee un foco amplio, en el cual el investigador pretende entender los fenómenos bajo la óptica de los actores involucrados en el contexto. Según Malhotra ${ }^{123}$, las investigaciones cuantitativas son más adecuadas para obtener opiniones y actitudes explícitas y conscientes de los entrevistados, ya que utilizan cuestionarios o instrumentos estructurados.

En cuanto al tipo de investigación, ésta se clasifica como descriptiva y exploratoria, que tiene por premisa usar patrones textuales, como cuestionarios, para observar, registrar y analizar los fenómenos sin, mientras tanto, entrar en el mérito de su contenido. No hay interferencia del investigador, que sólo intenta percibir, con el necesario cuidado, la frecuencia con que el fenómeno acontece ${ }^{124}$. Gil ${ }^{125}$ informa que las investigaciones descriptivas tienen como objetivo primordial la descripción de las características de determinada población o fenómeno, estableciendo relaciones entre variables. Son innumerables los estudios que pueden ser clasificados bajo este título y una de sus características más significativas está en la utilización de técnicas estandarizadas de recolección de datos, tales como el cuestionario y la observación sistemática. Las investigaciones descriptivas son, junto con las exploratorias, las que habitualmente realizan los investigadores sociales que se ocupan de la actuación práctica.

Ese aparato teórico permite que el abordaje exploratorio sea transformado en un abordaje descriptivo, que tienen como premisa mejorar las prácticas por medio de la observación, análisis y descripciones objetivas, con la intención de validar el

\footnotetext{
${ }^{121}$ MALHOTRA (2001). [61]

${ }^{122}$ YIN (2005). [79]

${ }^{123}$ MALHOTRA (2001). [61]

${ }^{124}$ THOMAS; NELSON; SILVERMAN (2007). [76]

${ }^{125}$ GIL (2002, p. 42). [42]
} 
contenido. No hay interferencia del investigador en este proceso, que sólo intenta percibir, con el cuidado necesario, la frecuencia con que el fenómeno acontece. ${ }^{126 ; 127}$

\subsection{Población y muestra}

La población de este estudio son empresas cosméticas que aceptan responder al cuestionario propuesto por la presente investigación y que mantiene relaciones de comercio bilateral entre Brasil y Argentina y tienen sede en uno de los dos mercados. Fueron enviadas encuestas a 50 empresas, 30 brasileñas y 20 argentinas. Se resalta la gran dificultad en obtener respuesta por parte de las empresas argentinas. De las empresas brasileñas, hubo $100 \%$ de retorno, considerándose que la investigadora acordó horario con el responsable del sector de importación y exportación (o profesional equivalente), o con el propietario de la empresa e hizo las preguntas directamente, vía telefónica, transcribiendo las respuestas obtenidas. De las empresas argentinas hubo $15 \%$ de retorno de las encuestas y el envío de las respuestas se realizó vía e-mail.

Debido a la garantía de que no se expondría el nombre de las empresas, tampoco de quienes respondieron a las encuestas en representación de ellas, cada empresa fue enumerada por orden aleatorio y se mantuvo esa forma de divulgación a lo largo de toda la presentación de los resultados obtenidos. Entre la población consultada, los cuestionarios validados (totalmente respondidos) y que fundamentaron esa indagación están expuestos en el Cuadro 2.

Cuadro 2 - Empresas cosméticas consultadas en Brasil y en Argentina

\begin{tabular}{|l|l|}
\hline \multicolumn{1}{|c|}{ Empresas } & \multicolumn{1}{|c|}{ Origen } \\
\hline $1,3,33$. & Argentina \\
\hline $2,4,5,6,7,8,9,10,11,12,13,14,15,16,17,18,19,20,21,22,23$, & Brasil \\
$24,25,26,27,28,29,30,31,32$. & \multicolumn{2}{|c|}{} \\
\hline
\end{tabular}

Fuente: Elaboración propia

Por medio del Gráfico 7 se obtiene mejor perspectiva de la composición de la muestra, conformada por 33 empresas en total, algunas argentinas y otras brasileñas.

\footnotetext{
${ }^{126}$ THOMAS; NELSON; SILVERMAN (2007). [76]

${ }^{127}$ FASSIO; PASCUAL; SUÁREZ (2002). [36]
} 
Gráfico 7 - Origen de las empresas que componen la muestra de la investigación

ORIGEN DE LAS EMPRESAS

CONSULTADAS

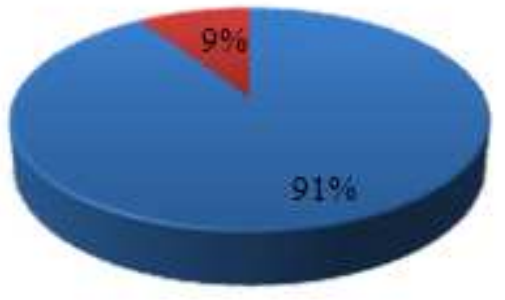

Brasileñas

Argentinas

Fuente: Datos de la investigación

A continuación se detalla la construcción de la encuesta y la recolección de datos aplicado a esa muestra.

\subsection{Instrumento utilizado y colecta de datos}

Para diseñar la encuesta de este estudio se utilizaron datos pertinentes al comercio bilateral entre Brasil y Argentina, disponibles en diferentes fuentes y capaces de trazar un marco teórico adecuado para responder a los objetivos específicos y orientar las cuestiones de incumbencia para la investigación de la relación bilateral entre las empresas del sector. El Cuadro 3 retrata las fuentes utilizadas para buscar información y elaborar el cuestionario.

Cuadro 3 -Construcción de la fundamentación teórica consultada para formular el cuestionario

\begin{tabular}{|c|c|c|}
\hline Aspectos & Autores & $\begin{array}{c}\text { Fuente de investigación } \\
\text { de los datos }\end{array}$ \\
\hline $\begin{array}{l}\text { Comercio bilateral de } \\
\text { Brasil y Argentina en el } \\
\text { segmento de cosméticos; }\end{array}$ & $\begin{array}{l}\text { ABIHPEC }(2014,2013) \\
\text { ALICEWEB }(2014) \\
\text { ALTEMANI }(2008) \\
\text { ANVISA }(2005) \\
\text { ARGENTINA }(2014) \\
\text { BRASIL }(2014,2012) \\
\text { FIGUEIREDO }(2014) \\
\text { GOMES (2010) } \\
\text { MOREIRA; MIRANDA (2012) } \\
\text { RIBEIRO; PINCHEMEL (2011) }\end{array}$ & $\begin{array}{l}\text { Sitios gubernamentales, } \\
\text { balanzas comerciales, } \\
\text { informes del sector, } \\
\text { libros, artículos y diversas } \\
\text { publicaciones. }\end{array}$ \\
\hline $\begin{array}{l}\text { Acuerdos sobre } \\
\text { cosmética entre Brasil y } \\
\text { Argentina; }\end{array}$ & $\begin{array}{l}\text { ABIHPEC (2014) } \\
\text { ABIHPEC/ABDI/SEBRAE (2014) } \\
\text { ALICEWEB }(2014) \\
\text { ANVISA }(2013,2005) \\
\text { ARGENTINA }(2014,2012) \\
\text { BNDES }(2014,2013,2010) \\
\text { BRASIL (2007) } \\
\text { FIESP / CIESP (2014) }\end{array}$ & $\begin{array}{l}\text { Sitios gubernamentales, } \\
\text { balanzas comerciales, } \\
\text { informes del sector, } \\
\text { libros, artículos y diversas } \\
\text { publicaciones. }\end{array}$ \\
\hline $\begin{array}{l}\text { Políticas de importaciones } \\
\text { y exportaciones } \\
\text { bilaterales de cosméticos. }\end{array}$ & $\begin{array}{l}\text { ABIHPEC } \\
\text { ALEM; CAVALCANTI (2005) } \\
\text { ALICEWEB (2014) }\end{array}$ & $\begin{array}{l}\text { Sitios gubernamentales, } \\
\text { balanzas comerciales, } \\
\text { informes del sector, }\end{array}$ \\
\hline
\end{tabular}




\begin{tabular}{|l|l|l|}
\hline & AMAL; KEGEL (2006) & libros, artículos y diversas \\
publicaciones. \\
ANVISA & \\
ARGENTINA (2014, 2012) & \\
BRASIL (2014, 2012) & \\
CIGNACCO (2009) & \\
KOTLER; ARMSTRONG (2003) & \\
HILAL; HEMAIS (2003) & \\
MAÑAS; GIORDANO (2007) & \\
MCGAHAN; PORTER (2003) & \\
MELIN (1992) & \\
MORAN (2000) & \\
& TEIXEIRA (2003) & \\
& TUBINO (2000) & \\
SANTOS (2008) & \\
WIND; MAIN (2002) &
\end{tabular}

Fuente: Elaboración propia

La construcción es la síntesis de aquello que se pretende y la validación de dicha construcción resulta de la acumulación de varias pruebas, que precisan ser analizadas en detalles con el fin de constatar los elementos que puedan aclarar el significado del instrumento. Éste orienta al aparato teórico a tratar aquellos asuntos que constituyen la base del proyecto. ${ }^{128}$ En este sentido, el cuestionario formulado (disponible en el Anexo B y la carta de presentación que acompaña, disponible en el Anexo A), dejó a disposición seis preguntas a los encuestados, orientadas a atender las proposiciones del estudio. Siendo cuatro preguntas cerradas y dos abiertas, dando la oportunidad a los encuestaos de manifestar plenamente su opinión.

La recolección de los datos fue realizada durante el mes de mayo de 2015 y realizada en tres fases.

En la primera fase se realizó un relevamiento de las empresas a las cuales se enviarían los cuestionarios. Los mismos fueron enviados vía e-mail a todas las empresas y fueron agendados los horarios para el contacto de la investigadora con los encuestados.

En la segunda fase, fueron realizados los contactos con las empresas y fueron registrados debidamente los resultados (resaltando que los contactos con las empresas argentinas continuaron vía e-mail). De esa forma, la encuesta fue realizada a modo de entrevista directa informal, que para Gil: "É recomendada nos estudos exploratórios, que visam abordar realidades poucos conhecidas pelo pesquisador, ou então oferecer visão aproximativa do problema pesquisado." 129

Rápidamente se inició la tercera fase, la exploración de los primeros resultados cuantitativos. El material fue organizado para encontrar una explicación a los datos

\footnotetext{
${ }^{128}$ MINAYO (2000). [66]

${ }^{129}$ GIL (2002, p. 116). [42] Traducción de Melisa Roldán: "Es recomendada en los estudios exploratorios, que pretenden abordar realidades poco conocidas por el investigador, u ofrecer una visión aproximada del problema indagado".
} 
brutos. Fueron organizados en tablas y gráficos, alcanzando así los resultados y generando las consideraciones finales y relacionándolas con la fundamentación teórica. $^{130}$

De esa forma, es necesario explicar cómo fueron interpretados los datos, conforme describe el ítem a seguir.

\subsection{Análisis de datos}

Los datos colectados fueron presentados considerándose los objetivos específicos de forma clara y explicativa. El análisis verifica la relación entre los resultados y otros factores, validando, organizando, delimitando y clasificando las respuestas en relación a los objetivos. ${ }^{131}$.

Considerando los objetivos específicos propuestos, este estudio los relaciona al cuestionario aplicado a diferentes empresas del sector de cosméticos, tanto con sede en Brasil como en Argentina, dejando en claro la relación entre ambos, de acuerdo con la estructura de la investigación, mostrado en el Cuadro 4.

\section{Cuadro 4 - Estructura de la investigación}

\begin{tabular}{|l|l|}
\hline \multicolumn{1}{|c|}{ Objetivos Específicos } & \multicolumn{1}{|c|}{$\begin{array}{c}\text { Instrumento de } \\
\text { Recolección }\end{array}$} \\
\hline $\begin{array}{l}\text { Identificar las perspectivas del comercio bilateral entre Brasil y } \\
\text { Argentina en el sector de cosméticos, enumerando los aspectos } \\
\text { positivos del comercio bilateral en el MERCOSUR; }\end{array}$ & Preguntas: 1, 2, 3 4. \\
\hline $\begin{array}{l}\text { Apuntar las principales oportunidades del mercado brasileño y } \\
\text { argentino de cosméticos; }\end{array}$ & Pregunta: 5. \\
\hline $\begin{array}{l}\text { Apuntar las principales amenazas del mercado brasileño y } \\
\text { argentino de cosméticos; }\end{array}$ & Pregunta: 5. \\
\hline $\begin{array}{l}\text { Observar las sugerencias de las empresas investigadas para } \\
\text { aumentar importaciones y exportaciones de cosméticos entre } \\
\text { los dos países. }\end{array}$ & Pregunta: 6. \\
\hline
\end{tabular}

Fuente: Elaboración propia

Esa relación entre las preguntas permitió conocer la opinión de cada empresa acerca de cómo es visto el mercado internamente, evaluar los miedos y conquistas adquiridas a partir de la actuación del bloque económico en el segmento de cosméticos y observar las sugerencias de cada empresa para ampliar el mercado del sector de forma bilateral.

No obstante, para resaltar las características observadas por la recopilación de datos, aisladamente o en comparación con otros aspectos, es necesario expresar los resultados a través de números o características. De forma general, la frecuencia relativa de un acontecimiento es la razón entre el número de veces que se verifica y el

\footnotetext{
${ }^{130}$ MAGNUSSON (1967). [60]

${ }^{131}$ ANDRADE (2003, p. 154). [10]
} 
número total de casos, lo que genera el porcentaje su ocurrencia. ${ }^{132}$

Para realizar el relevamiento estadístico, los datos recolectados fueron organizados por el software Excel, generando tablas y gráficos. La tabla es un cuadro que resume un conjunto de observaciones, mientras los gráficos son formas de presentar los datos, haciendo posible una lectura fácil y vivaz de los resultados investigados ${ }^{133}$.

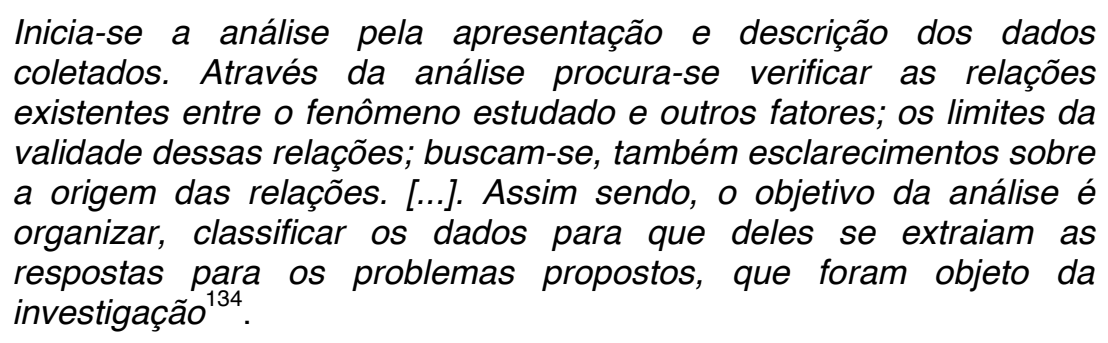

A partir de ese contexto, se dio el análisis exploratorio y descriptivo, que presentó resultados e interferencias a partir de dos contextos abordados y los relacionó a la revisión hecha por el marco teórico.

Sin embargo, para que la importancia de un proyecto sea conocida, éste debe enumerar el alcance de sus contribuciones, como detalla el tópico a seguir, que describe la justificación para el presente estudio.

\subsection{Justificación del estudio del tema}

Esta investigación atiende, de forma técnica, a las exigencias del curso de Maestría en Marketing Internacional de la Universidad Nacional de La Plata (UNLP), como exigencia para la conclusión de los estudios y obtención del título de magíster.

Este estudio aborda, como eje principal, el interés comercial de Brasil en los países que componen el MERCOSUR ${ }^{135}$, investigando la integración que el país posee con Argentina, es decir, la relación comercial entre los dos mayores integrantes del grupo MERCOSUR, orientando la investigación a la importación y exportación de productos cosméticos. Así, considerando que más del $80 \%$ del intercambio comercial del MERCOSUR está compuesto por bienes industrializados y que un segmento que se viene destacando está volcado al área de los cosméticos. La investigación del tema asume gran relevancia, pues considera que grandes empresas transnacionales, en

\footnotetext{
${ }^{132}$ CERVO; BERVIAN (2002). [28]

${ }^{133}$ HAIR JR. et al. (2005). [44]

${ }^{134}$ ANDRADE (2003,p. 154). [10] Traducción de Melisa Roldán: "Se inicia el análisis por la presentación y descripción de los datos recopilados. A través del análisis se intenta verificar las relaciones que existen entre el fenómeno estudiado y otros factores; los límites de validación de esas relaciones; también se busca esclarecer sobre el origen de las relaciones. [...] . Siendo así, el objetivo del análisis es organizar, clasificar los datos para que de ellos se extraigan las respuestas a los problemas propuestos, que fueron objeto de investigación."

${ }^{135}$ IDOETA (2011). [50]
} 
especial ubicadas en Brasil y en Argentina, se especializan en la producción de estos bienes, lo cual influye tanto en los productos importados y exportados como en los patrones de origen y destino de las mercancías ${ }^{136}$, marcando, de esa forma, el especial interés en estudiar el tema.

Los acuerdos económicos, como los propuestos por el MERCOSUR, traen un incentivo para enfrentar un mercado globalizado, siempre creciente y en constante transformación. Para que esos acuerdos alcancen el éxito anhelado es necesario estudiar los abordajes adoptados para que se extraigan estrategias, puntos positivos, negativos y de impacto en las relaciones y en las negociaciones propuestas. ${ }^{137}$ Esas contribuciones pueden ser importantes para evaluar el comercio entre bloques.

Las posibilidades creadas por el MERCOSUR incentivando el libre comercio entre sus países miembro favorecen también el aprendizaje que se obtiene de estos acuerdos comerciales. En este sentido, este proyecto puede ampliar el número de estudios que analizan la relación bilateral entre Brasil y Argentina, señalando y sistematizando los datos referentes al comercio de cosméticos, trazando, de esa forma, el aspecto social de la investigación.

De forma práctica, este proyecto posibilita relacionar el campo industrial de cosméticos a otros países componentes del MERCOSUR e identificar barreras, dificultades, ventajas y posibilidades de inversión en el segmento, comparándose el comercio de Brasil y de Argentina con estos países. De la misma forma, se pretende la relación con otros estudios que buscan ampliar el conocimiento sobre el comercio bilateral entre Brasil y Argentina, trazando aspectos relevantes y similares en todos los estudios e identificando un perfil de las barreras y ventajas relacionadas al comercio entre los dos países. Aunque algunas dificultades sean ampliamente conocidas en cuanto al comercio común entre los países del Cono Sur, puede explorarse la formación de estrategias alternativas.

Este estudio contribuye, además, al perfeccionamiento y crecimiento personal de la investigadora, considerando la importancia de los aprendizajes adquiridos, "toda pesquisa [...] ganha significado quando relacionada às teorias de nossos predecessores e à pesquisa de nossos contemporâneos"138.

\footnotetext{
${ }^{136}$ HIRATUKA (2008). [47]

${ }^{137}$ ALMEIDA (2007). [7]

${ }^{138}$ CALDAS, FACHIN; FISCHER (2001, p. 67). [26] Traducción de Melisa Roldán: “Toda investigación [...] adquiere significado cuando es relacionada a las teorías de nuestros antecesores y a la investigación de nuestros contemporáneos".
} 


\section{Resultados}

Los resultados derivados de la realización del cuestionario a 33 empresas del ramo de cosméticos, tanto en Brasil como en Argentina, fueron copilados con el fin de alcanzar los objetivos específicos de la investigación y están expuestos a continuación.

\subsection{Perspectivas para el sector cosmético y ventajas del MERCOSUR}

Por medio del cuestionario efectuado fue posible observar cómo las empresas de cosméticos perciben el ambiente comercial y establecer comparaciones sobre el desarrollo de los negocios a partir del MERCOSUR. Cuando se preguntó si el MERCOSUR afectó la industria cosmética entre Brasil y Argentina, las empresas respondieron conforme muestra el Gráfico 8.

\section{Gráfico 8 - EI MERCOSUR afectó a la industria cosmética entre Brasil y Argentina?}

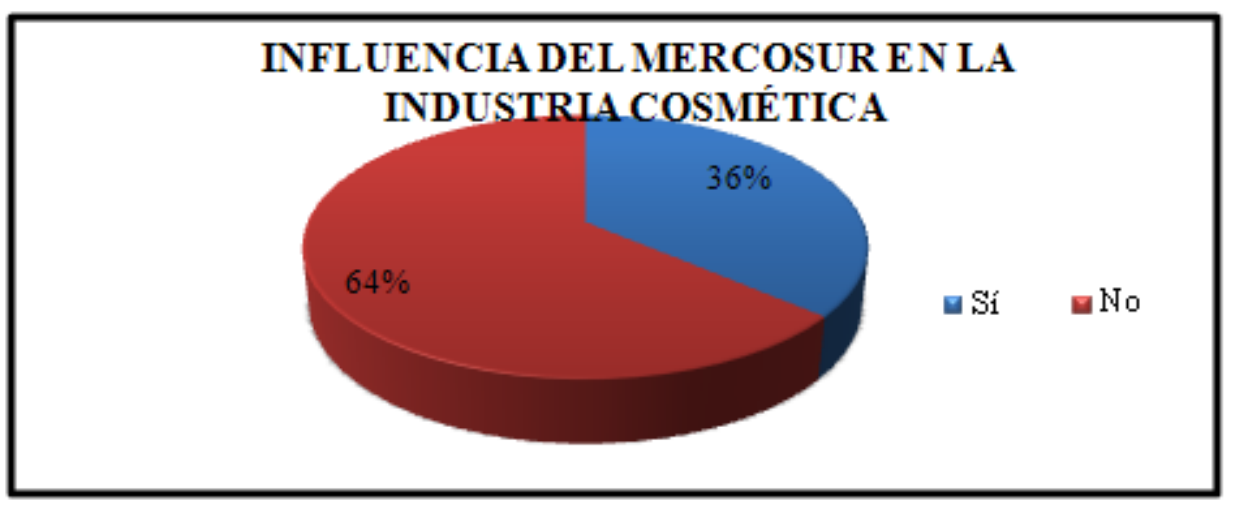

Fuente: Elaboración propia

Se observa, a partir del Gráfico 8, que el 64\% de las empresas no perciben la influencia directa del MERCOSUR en los resultados de sus negocios. Sin embargo, el $36 \%$ de las empresas que reconocen la influencia del MERCOSUR en el volumen de negocios entre Brasil y Argentina, considerándose a la industria cosmética, lo hacen de forma positiva, conforme el Gráfico 9. 


\section{Gráfico 9 - ¿Cómo influyó el MERCOSUR en la industria cosmética?}

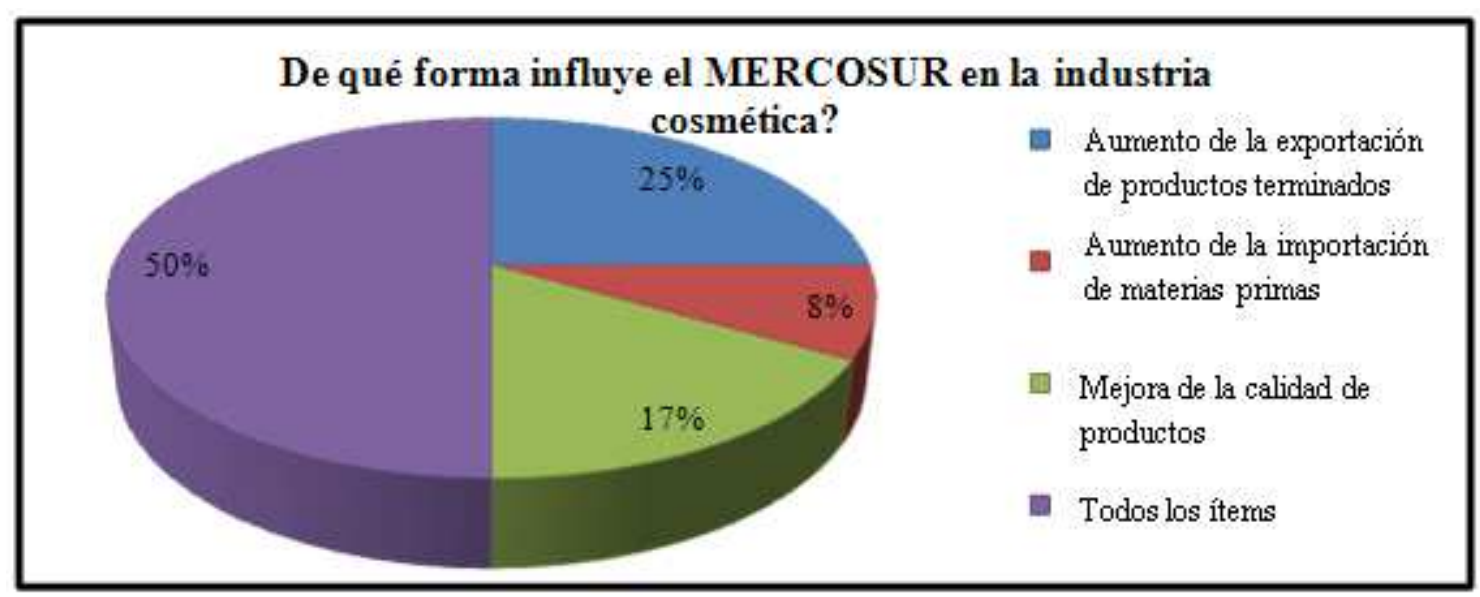

Fuente: Elaboración propia

El aumento de la exportación de productos terminados, con el $25 \%$ de representatividad; el aumento de las importaciones de materia prima, representando el $8 \%$ de las empresa consultadas; y la mejora de calidad de los productos, de forma general, fue marcado por el $17 \%$ de las empresas como puntos en que la relación de Brasil y Argentina fue influida por el MERCOSUR, muestra que hay solamente puntos positivos para las empresas en la relación comercial bilateral facilitada por la formación del bloque comercial. Lo que es reiterado por el $50 \%$ de las empresas que observaron la ocurrencia de estos tres aspectos positivos afines a sus negocios como resultado de esa relación dentro del bloque.

De esa forma, aunque no todas las empresas consultadas constataron avances a partir de las relaciones del MERCOSUR, 97\% de ellas señalaron perspectivas positivas para el sector de cosméticos en el MERCOSUR, conforme muestra el Gráfico 10.

\section{Gráfico 10 - Perspectivas para el sector de cosméticos dentro del MERCOSUR}

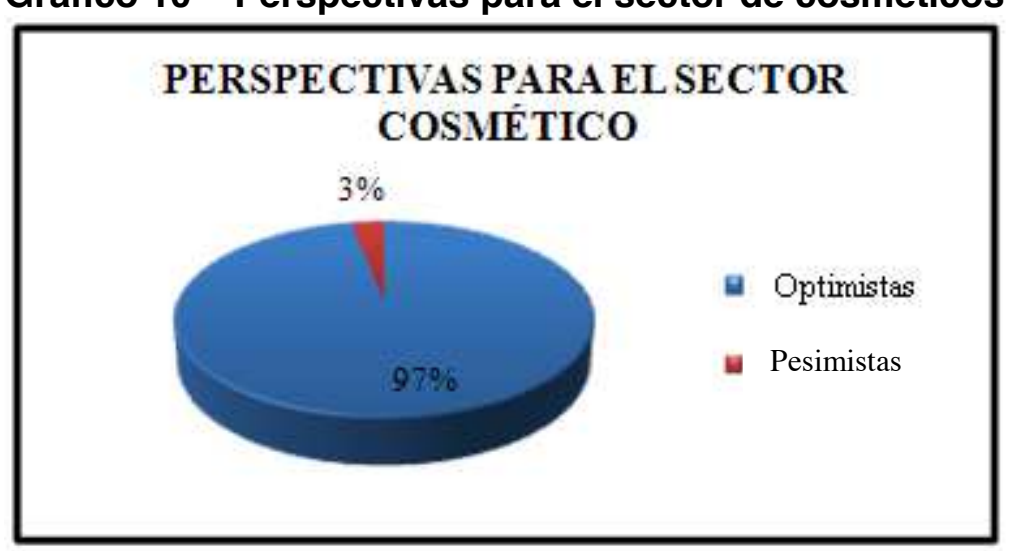

Fuente: Elaboración propia

La perspectiva optimista mostrada por el Gráfico 10 está amparada por el considerable 
crecimiento del mercado de cosméticos, que incluso enfrentando crisis en el mercado mundial, viene presentando un crecimiento por arriba de la media en Brasil. Según ABIPHEC ${ }^{139}$ hubo un crecimiento acumulado de $270 \%$ en las exportaciones entre 2003 y 2012 , y las importaciones crecieron $508 \%$ en el mismo período. Resaltando además que el sector continúa creciendo más que el PBI brasileño y presenta crecimiento superior a los demás sectores de la industria del país y del desempeño del mercado mundial de HPPC.

El resumen de esos abordajes muestra el panorama de las respuestas obtenidas por medio de la encuesta a las empresas, considerando que se cuestionaba si el MERCOSUR influyó en la industria cosmética, si hubo impacto, en qué afectó y cuáles eran las perspectivas para el sector, tanto aquellas ya sentidas, en corto y mediano plazo. Los datos fueron sintetizados en el Cuadro 5.

Cuadro 5 - Resumen de las perspectivas y alcance de las acciones

\begin{tabular}{|c|c|c|c|}
\hline Empresa & $\begin{array}{l}\text { ¿Influyó el } \\
\text { MERCOSUR } \\
\text { en la } \\
\text { cosmética? }\end{array}$ & ¿En qué influyó? & $\begin{array}{l}\text { Perspectivas } \\
\text { para los } \\
\text { cosméticos }\end{array}$ \\
\hline 1 & No & & Optimistas \\
\hline 2 & Sí & $\begin{array}{l}\text { Aumento de la exportación de productos } \\
\text { finales }\end{array}$ & Optimistas \\
\hline 3 & No & & Optimistas \\
\hline 4 & No & & Pesimistas \\
\hline 5 & Sí & Aumento de la importación de materia prima & Optimistas \\
\hline 6 & No & & Optimistas \\
\hline 7 & No & & Optimistas \\
\hline 8 & Sí & $\begin{array}{l}\text { Mejora de la calidad de los productos, } \\
\text { aumento de la exportación de productos } \\
\text { finales, aumento de la importación de materia } \\
\text { prima. }\end{array}$ & Optimistas \\
\hline 9 & No & & Optimistas \\
\hline 10 & Sí & $\begin{array}{l}\text { Aumento de la exportación de productos } \\
\text { finales }\end{array}$ & Optimistas \\
\hline 11 & No & & Optimistas \\
\hline 12 & Sí & $\begin{array}{l}\text { Mejora de la calidad de los productos, } \\
\text { aumento de la exportación de productos } \\
\text { finales, aumento de la importación de materia } \\
\text { prima. }\end{array}$ & Optimistas \\
\hline 13 & Sí & $\begin{array}{l}\text { Aumento de la exportación de productos } \\
\text { finales }\end{array}$ & Optimistas \\
\hline 14 & No & & Optimistas \\
\hline 15 & No & & Optimistas \\
\hline 16 & No & & Optimistas \\
\hline 17 & No & & Optimistas \\
\hline 18 & Sí & $\begin{array}{l}\text { Mejora de la calidad de los productos, } \\
\text { aumento de la exportación de productos } \\
\text { finales, aumento de la importación de materia } \\
\text { prima. }\end{array}$ & Optimistas \\
\hline
\end{tabular}

${ }^{139}$ ABIPHEC (2014). [4] 


\begin{tabular}{|c|c|c|c|}
\hline 19 & No & & Optimistas \\
\hline 20 & No & & Optimistas \\
\hline 21 & Sí & $\begin{array}{l}\text { Mejora de la calidad de los productos, } \\
\text { aumento de la exportación de productos } \\
\text { finales, aumento de la importación de materia } \\
\text { prima. }\end{array}$ & Optimistas \\
\hline 22 & No & & Optimistas \\
\hline 23 & Sí & $\begin{array}{l}\text { Mejora de la calidad de los productos, } \\
\text { aumento de la exportación de productos } \\
\text { finales, aumento de la importación de materia } \\
\text { prima. }\end{array}$ & Optimistas \\
\hline 24 & No & & Optimistas \\
\hline 25 & No & & Optimistas \\
\hline 26 & Sí & $\begin{array}{l}\text { Mejora de la calidad de los productos, } \\
\text { aumento de la exportación de productos } \\
\text { finales, aumento de la importación de materia } \\
\text { prima. }\end{array}$ & Optimistas \\
\hline 27 & No & & Optimistas \\
\hline 28 & No & & Optimistas \\
\hline 29 & No & & Optimistas \\
\hline 30 & No & & Optimistas \\
\hline 31 & Sí & $\begin{array}{l}\text { Mejora de la calidad de los productos, } \\
\text { aumento de la exportación de productos } \\
\text { finales }\end{array}$ & Optimistas \\
\hline 32 & No & & Optimistas \\
\hline 33 & Sí & Mejora de la calidad de los productos & Optimistas \\
\hline
\end{tabular}

Fuente: Elaboración propia

Así, se puede confirmar parcialmente la hipótesis de que la mayoría de las empresas reconoce que el MERCOSUR influyó positivamente en la relación entre Brasil y Argentina en el sector de cosméticos. En realidad, la mayoría no percibió esa relación entre el sector de cosméticos y el MERCOSUR, ya que el 64\% de las empresas no citaron aspectos positivos derivados de la misma. Sin embargo, aunque el impacto haya sido realmente sentido por el $36 \%$ de los encuestados, los resultados confirmaron todas las variables del estudio, que presupone mejora de la calidad de los productos, aumento de la exportación de productos finales y aumento de la importación de materias primas. Esas variables fueron siempre positivas y reconocidas análogamente en el $50 \%$ de las empresas encuestadas.

De forma aislada, la variable que más se destacó fue la exportación de productos terminados, que alcanzó en promedio el $41,5 \%$ de participación en las respuestas obtenidas. La calidad de los productos obtuvo una media de $33,5 \%$ y las importaciones alcanzaron el $24,5 \%$ de representatividad en los resultados. O sea, el beneficio de aumentar la calidad de los productos, la exportación y la importación (de productos finales y de materia prima, respectivamente), demuestra que los acuerdos del bloque económico contribuyen a ampliar las negociaciones del mercado cosmético.

Esos resultados son confirmados al observarse que casi todas las empresas 
entrevistadas (97\%) poseen perspectivas optimistas en relación al desempeño del sector de cosméticos a partir de los movimientos comerciales del MERCOSUR como bloque económico. Infiriendo, que aún indirectamente, hay una lectura positiva derivada de la relación comercial entre Brasil y Argentina. De esa forma, es importante explicitar cómo las empresas encuestadas perciben a las oportunidades que brinda dicha relación, como muestra el tópico a continuación.

\subsection{Oportunidades para el sector de cosméticos de Brasil y Argentina}

Cabe resaltar que al investigar las oportunidades percibidas por las empresas encuestadas dentro del MERCOSUR para el sector de cosméticos, el 6\% de los encuestados no reconocieron las oportunidades, es decir, no prevén un panorama optimista en las relaciones dentro del bloque. Sin embargo, se observa que el $94 \%$ de las empresas consiguen enumerar aspectos positivos en el área de la cosmética para la relación de Brasil y Argentina en el MERCOSUR, como señala el Gráfico 11.

\section{Gráfico 11 - Las empresas, ¿perciben las oportunidades para la industria cosmética?}

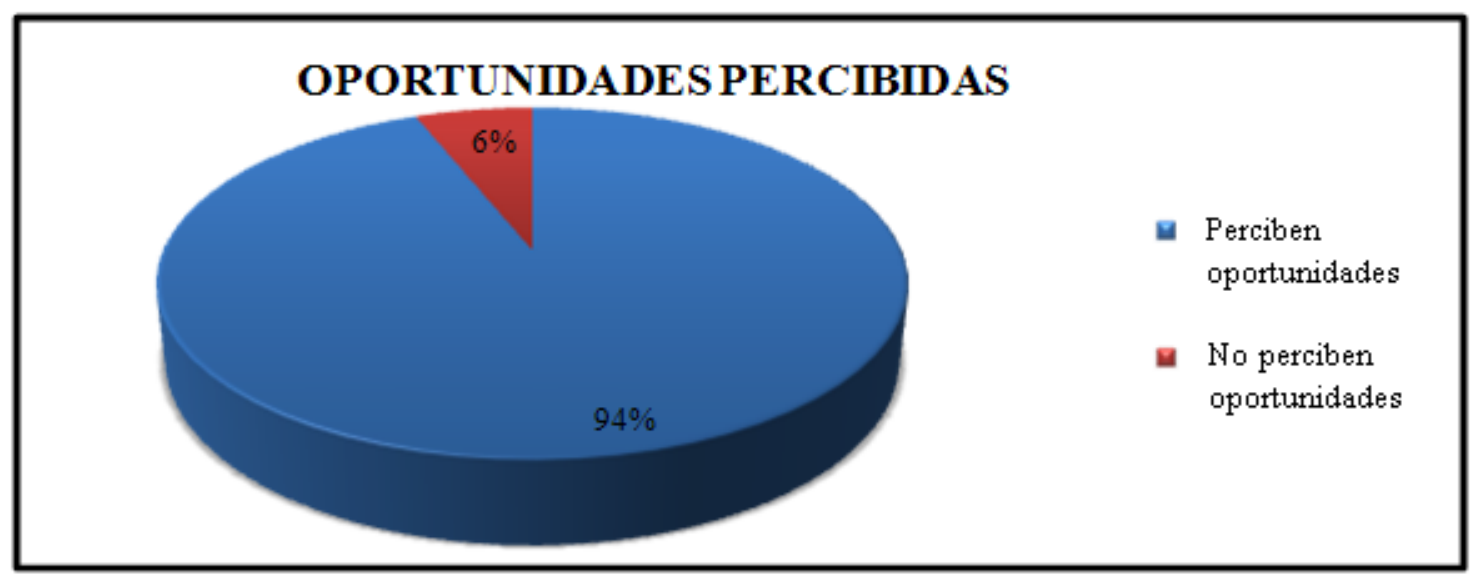

Fuente: Elaboración propia

Reconocer las oportunidades vuelve a la empresa competitiva. Tubino ${ }^{140}$ afirma que las empresas/países deben decidir rápidamente ante las oportunidades y amenazas identificadas en el mercado, optimizando sus ventajas competitivas. Además, el éxito del negocio depende, en gran parte, de la capacidad de adecuarse a los cambios del micro y/o macroambiente. Se infiere, por lo tanto, que al reconocer las oportunidades del mercado, las empresas entrevistadas adquieren posturas adecuadas para mantenerse competitivas.

Entre los aspectos citados por las empresas como oportunidades de la relación entre Brasil y Argentina en el segmento cosmético, facilitada y posibilitada por el

\footnotetext{
${ }^{140}$ TUBINO (2000). [77]
} 
MERCOSUR, están aquellas mostradas en el Cuadro 6.

Cuadro 6 - Oportunidades percibidas en el área de cosméticos para la relación de Brasil y Argentina en el MERCOSUR

\begin{tabular}{|c|c|}
\hline Empresa & Oportunidades \\
\hline 1 & No percibe oportunidades. \\
\hline 2 & Oportunidad de nuevos consumidores \\
\hline 3 & Impacto sobre la preservación de la naturaleza \\
\hline 4 & Crecimiento de la clase media \\
\hline 5 & Aumento de la renta media y de la expectativa de vida \\
\hline 6 & Aumento de mujeres en el mercado de trabajo \\
\hline 7 & Bono demográfico (consumidores generando renta) \\
\hline 8 & Capacidad de compra de las clases C y D \\
\hline 9 & Mayor consumo de los jóvenes y público masculino \\
\hline 10 & Mercado en alza \\
\hline 11 & Aumento de la renta \\
\hline 12 & Crecimiento de la clase media \\
\hline 13 & Preocupación del mercado masculino, además del femenino \\
\hline 14 & Distribución puerta a puerta mantiene la renta \\
\hline 15 & Mercado creciente \\
\hline 16 & Aumento de la clase $\mathrm{C}$ \\
\hline 17 & Consumidor preocupado por el bienestar \\
\hline 18 & Mayor preocupación por el bienestar \\
\hline 19 & Mantención del canal de ventas directas \\
\hline 20 & Tecnología aumenta gama de produtos \\
\hline 21 & Mayor preocupación por la belleza \\
\hline 22 & Aumento de la renta y preocupación por la belleza \\
\hline 23 & Público masculino preocupado por el bienestar y la belleza \\
\hline 24 & Preocupación por el bienestar y la felicidad \\
\hline 25 & Aumento de la participación y de la renta de las mujeres en el mercado \\
\hline 26 & Aumento de la renta \\
\hline 27 & Aumento de los canales de ventas \\
\hline 28 & Aumento de la renta del consumidor \\
\hline 29 & Preocupación por el bienestar y la salud \\
\hline 30 & Aumento del mercado consumidor \\
\hline 31 & $\begin{array}{l}\text { EI MERCOSUR da lugar a la apertura del mercado en toda América del Sur y } \\
\text { aumenta el mercado de consumo en general }\end{array}$ \\
\hline 32 & Mayor mercado objetivo considerando la expansión de las clases sociales \\
\hline 33 & No percibe oportunidades \\
\hline
\end{tabular}

Fuente: Elaboración propia

Para mejor comprensión de las oportunidades citadas se generó el Gráfico 12 agrupando los datos similares en grupos que evalúan los siguientes aspectos: consumo, canales de ventas, tendencias, tecnología y apertura de mercado. 


\section{Gráfico 12 - Resumen de las oportunidades del mercado cosmético Brasil - Argentina}

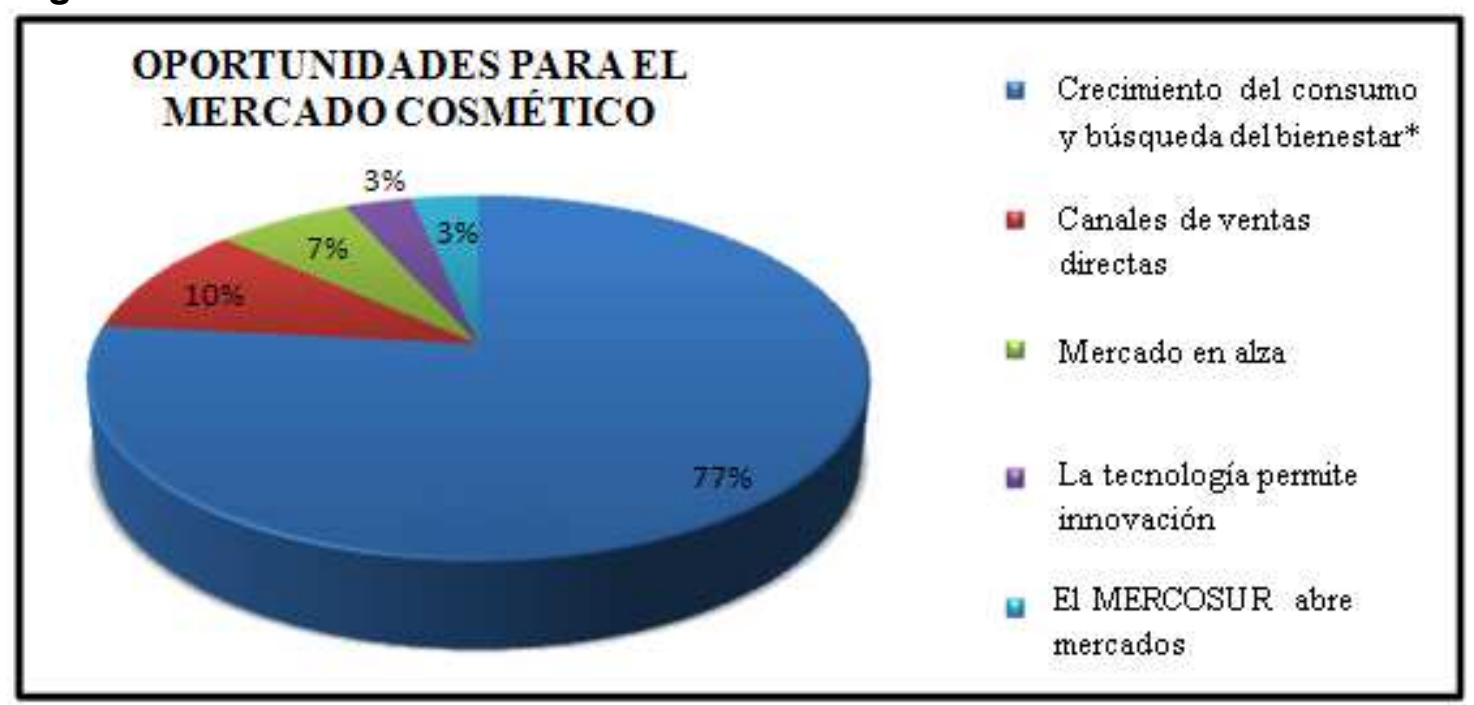

* = (mayor consumo de productos masculinos y jóvenes; de la clase media $\mathrm{C}$ y $\mathrm{D}$; aumento del número de mujeres en el mercado de trabajo; mayor expectativa de vida de la población y valorización del bienestar).

Fuente: Elaboración propia

El crecimiento del mercado, tanto involucrando mayor consumo de productos masculinos y jóvenes; el aumento del poder adquisitivo de la clase media, C y D; el elevado número de mujeres en el mercado de trabajo y el aumento de las expectativas de vida de la población, que valoriza cada vez más el bienestar y la calidad de vida, así como se preocupa por la belleza estética, fueron citados por las empresas encuestadas responsables del $77 \%$ de las oportunidades de crecimiento percibidas. Las ventas directas, sobre todo de puerta en puerta, son señaladas por el $10 \%$ de las empresas como ventajas competitivas del sector. Las ventajas del mercado (en alza, pues el mercado de cosméticos de Brasil y Argentina crece más que la media mundial) significa $7 \%$ del total de ventajas identificadas, y respectivamente con el $3 \%$ de representatividad, aparecen la tecnología (que permite innovación en los productos, también generando competitividad) y las oportunidades de abertura de mercado (posibilitada por el MERCOSUR). Brasil y Argentina, por lo tanto, poseen para el sector oportunidades más significativamente orientadas al consumidor.

Y la participación de ese segmento que impacta en las relaciones elevando la competitividad de las empresas y dando lugar a la apertura del mercado y el mantenimiento del crecimiento de importaciones y exportaciones.

No obstante, las relaciones de Brasil y Argentina en el sector de cosméticos también poseen algunas amenazas en potencial, como presenta el ítem a seguir. 


\subsection{Amenazas para el sector de cosméticos de Brasil y Argentina}

Las amenazas citadas por las empresas encuestadas apuntan un panorama muy diferente a las oportunidades enumeradas. Las principales barreras para el desarrollo del sector están enumeradas en el Cuadro 7.

\section{Cuadro 7 - Amenazas percibidas en el área de cosméticos para la relación de Brasil y Argentina en el MERCOSUR}

\begin{tabular}{|c|c|}
\hline Empresas & Amenazas \\
\hline 1 & Comercio de materia prima sintética \\
\hline 2 & No citó amenazas \\
\hline 3 & Impacto sobre la preservación de la naturaleza \\
\hline 4 & Dependencia del dólar y los riesgos de las barreras políticas \\
\hline 5 & Volatilidad de los mercados mundiales \\
\hline 6 & No citó amenazas \\
\hline 7 & Volatilidad política y económica \\
\hline 8 & Falta de marketing para fortalecimiento de la marca \\
\hline 9 & No citó amenazas \\
\hline 10 & Falta de adaptación a los consumidores es un riesgo \\
\hline 11 & Riesgo de no innovar en un mercado cada vez más exigente \\
\hline 12 & Liderazgo, pues es un mercado con grandes players \\
\hline 13 & Capacidad de inversión en economías volátiles \\
\hline 14 & Mejorar investigaciones requiere inversión \\
\hline 15 & Volatilidad del dólar e inestabilidad política \\
\hline 16 & Falta de crédito para inversión \\
\hline 17 & Falta de excelencia de los proveedores \\
\hline 18 & Falta de inversión en marketing \\
\hline 19 & Fidelización de los consumidores \\
\hline 20 & Recursos para inversión con altos costos \\
\hline 21 & No entender las necesidades del mercado objetivo; falta de innovación \\
\hline 22 & Invertir en innovación, marketing y fortalecimiento de marca \\
\hline 23 & No citó amenazas \\
\hline 24 & Faltan recursos para inversión en innovación \\
\hline 25 & Alto costo de los recursos para inversión \\
\hline 26 & Volatilidad de las economías de escala mundial \\
\hline 27 & Volatilidad de las economías; inconstancias gubernamentales \\
\hline 28 & Alto costo da captación de recursos para inversiones \\
\hline 29 & Los grandes players tienen más poder de invertir y reducir costos \\
\hline 30 & Volatilidad política de Argentina \\
\hline 31 & No citó amenazas \\
\hline 32 & $\begin{array}{l}\text { Falta de innovación de los productos considerando la multiplicidad de estos } \\
\text { en el mercado }\end{array}$ \\
\hline 33 & $\begin{array}{l}\text { El alto costo del dólar disminuye la competitividad, pues la industria es muy } \\
\text { variada }\end{array}$ \\
\hline
\end{tabular}

Fuente: Elaboración propia

Para comprender mejor los asuntos que fueron citados por las empresas entrevistadas, los ítems de cada aspecto fueron agrupados, permitiendo generar el Gráfico 13, que muestra más claramente las conclusiones obtenidas. 


\section{Gráfico 13 - Resumen de las amenazas del mercado cosmético Brasil - Argentina}

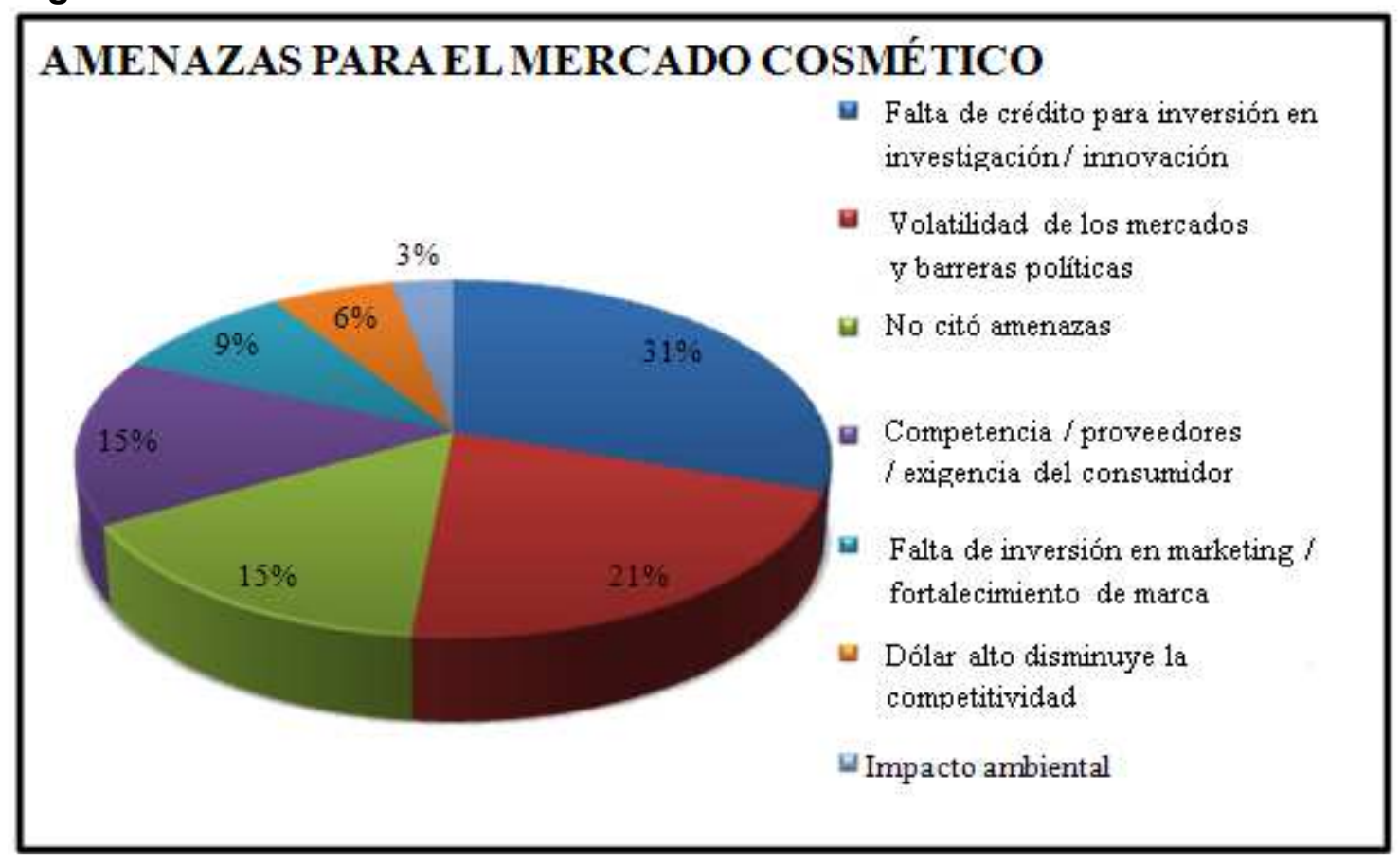

Fuente: Elaboración propia

La falta de crédito para invertir en investigaciones e innovación (que posee alto costo), fue citada por las empresas como la principal amenaza del mercado cosmético (con $31 \%$ de representatividad). El segundo ítem mencionado como amenaza justifica al primero, es decir, la volatilidad del mercado (con crisis y cambios constantes) impone y derriba barreras comerciales entre los diversos sectores de la economía. Como ejemplo claro de ello, Argentina, muy recientemente aplicó sanciones políticas a la penetración de algunos productos en el país de interferencia administrativa en el volumen de negocios.

Las empresas que no citaron amenazas y aquellas que apuntaron a la competencia, los proveedores y los consumidores exigentes obtuvieron 15\% de representatividad.

La competencia con grandes players, que poseen mayor crédito para invertir en investigación y conquistan el mercado con innovación son amenazas para las pequeñas y medianas empresas, las cuales no disponen de recursos para invertir en investigación para nuevos productos ni en mejoras de los ya existentes. Citan como agravante un mercado proveedor de baja calidad y productos que todavía utilizan materias primas sintéticas, más accesibles y capaces de reducir el costo del producto final, pero que no poseen la calidad obtenida en productos naturales. El consumidor, cada vez más exigente, no siempre valora ese contexto, lo que lleva a que muchos de ellos opten por el mejor precio, o por el producto con mayor marketing y fortalecimiento de la marca. La variedad de productos en el mercado también es una amenaza, pues 
la competencia no depende sólo de la calidad y del precio final del producto al consumidor; sino de la inestabilidad política de los mercados, el precio del dólar (citado por el $6 \%$ de los encuestados) que interfiere en la capacidad de competir con los grandes players ${ }^{141}$, considerándose la variedad de productos y la falta de inversión en marketing (citado por el $9 \%$ de las empresas entrevistadas como amenaza). El fortalecimiento de la marca, obtenido por el marketing, es una amenaza para las pequeñas y medianas empresas, así como el poder de los grandes players. El impacto ambiental de las acciones de las empresas y la falta de oportunidad e inversión por la búsqueda de una imagen de empresa consciente también fue considerado amenaza por el $3 \%$ de las empresas. El público consumidor, consciente tanto de las leyes que deben ser seguidas por las empresas, como de las acciones de cada una para contribuir con la preservación del medio ambiente, demuestran mayor fidelidad a los productos de empresas con responsabilidad social. Muchas empresas, aún ecológicamente adecuadas, no siempre poseen poder de inversión para divulgar esas acciones, o no poseen poder adquisitivo necesario para adecuarse a las leyes.

Sin embargo, se puede inferir que el $52 \%$ de las amenazas citadas por las empresas investigadas están orientadas al campo político de Brasil y Argentina; pues la falta de inversión, dificultada por el elevado costo de intereses para invertir en innovación (con $31 \%$ de los resultados), así como la volatilidad de los mercados y las barreras políticas (mencionadas por el $21 \%$ de los encuestados) sólo dependen de la voluntad y de acciones políticas para ser resueltas. No es simple el conjunto de acciones capaces de resolver y/o disminuir estas barreras, pero sí es perfectamente posible formularlo, considerándose la actuación del bloque económico como posible conductor de esas negociaciones.

De esta forma, las sugerencias de las empresas investigadas para aumentar importaciones y exportaciones de cosméticos entre los dos países finaliza la discusión de los resultados.

\subsection{Sugerencias para aumentar importaciones y exportaciones de cosméticos entre los dos países}

La pregunta solicitó comentarios de lo que sería relevante para el sector de cosméticos considerando las importaciones y exportaciones entre Brasil y Argentina. Dio lugar a opiniones, críticas o elogios a la actuación de los dos países en el MERCOSUR.

Las sugerencias obtuvieron $82 \%$ de participación de las empresas encuestadas que

\footnotetext{
${ }^{141}$ Expresión que se refiere a las empresas que, por su productividad o desempeño, lideran el mercado en el cual están insertas.
} 
utilizaron diversos abordajes para explicar cómo creen que sea posible aumentar importaciones y exportaciones de cosméticos entre Brasil y Argentina. Entre las sugerencias, una compilación de datos posibilitó la elaboración del Gráfico 14, que muestra inclusive al $18 \%$ de las empresas que prefirieron no opinar.

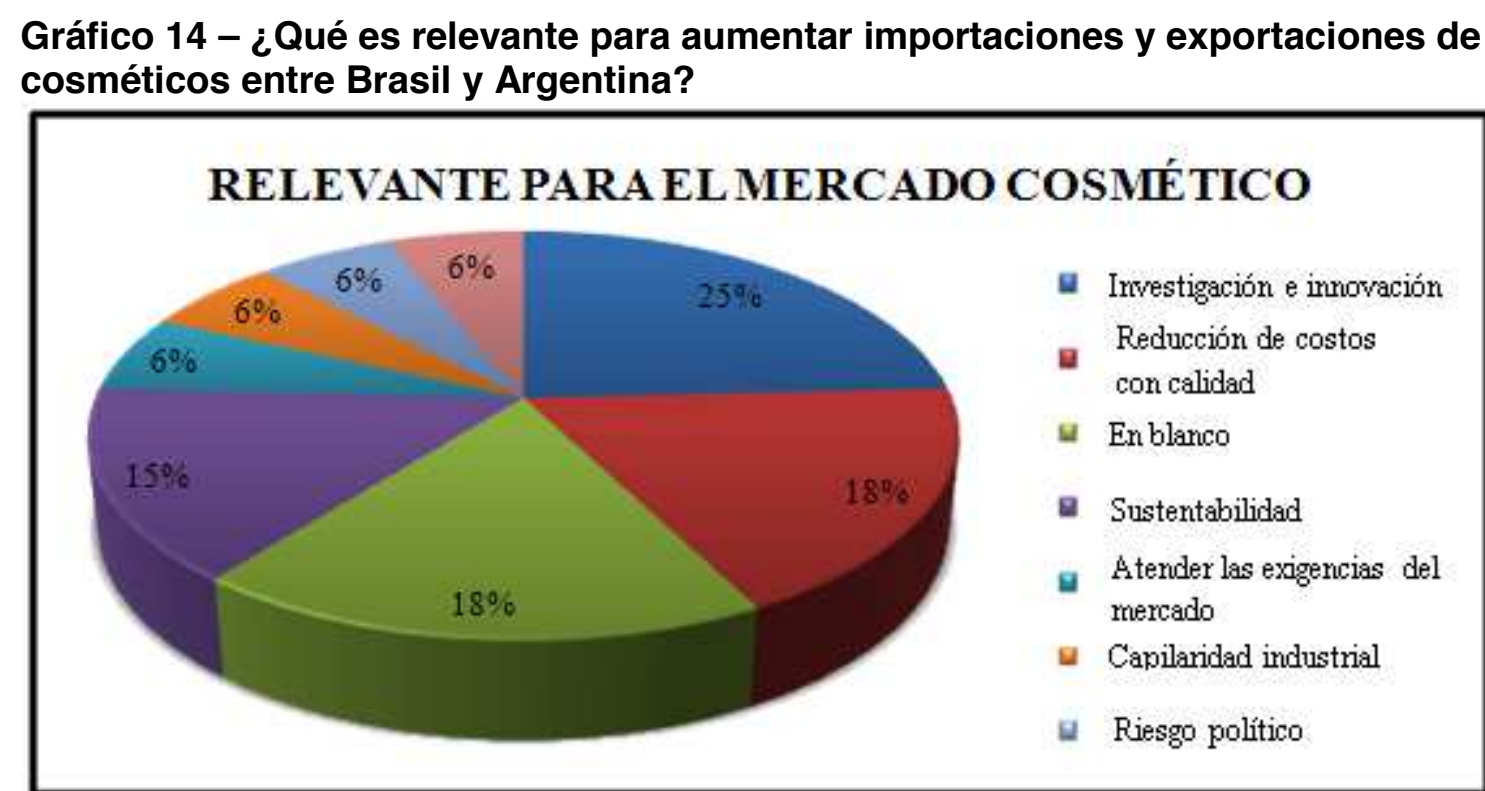

Fuente: Elaboración propia

Según las empresas encuestadas, lo relevante para ampliar el sector cosmético, como muestra el Gráfico 14, es invertir en investigación e innovación (25\% de representatividad). Ese ítem ya fue destacado como amenaza al sector de cosméticos, pues la competencia diversificada, principalmente las grandes empresas, dificulta la obtención de crédito de empresas pequeñas para ser destinado a investigación e innovación, considerándose la tasa de interés elevada que se cobra a quien no posee capital propio de inversión o precisa auxilio de otros inversores. Reducir los costos del producto final sin disminuir la calidad de los productos también fue considerado importante por el $18 \%$ de los encuestados. La variación de materia prima, con uso de productos sintéticos, por ejemplo, que disminuyen el precio del producto final, además de que también interfieren en la reducción de la calidad, no es una alternativa para mantener el mercado, cuyos consumidores valoran cada vez más esos ítems. Así, además de ser preciso atender a los diversos mercados de consumidores, está el control de sustancias de algunos países (especialmente los europeos), que prohíben determinados compuestos para que el producto pueda penetrar en sus mercados. Eso influye en la decisión de mantener la calidad en detrimento del precio, lo que reduce el lucro y el poder de reinversión de las empresas menores, que ya poseen la desventaja de disputarse el mercado con los grandes competidores.

La sustentabilidad también obtuvo un margen significativo de respuestas (15\%) como opción que interfiere relevantemente en los negocios de cosméticos. Se destaca que 
la preocupación de las empresas por adecuarse a las exigencias legales repercute en la forma en que el consumidor evalúa sus propios productos, desde el uso de materias primas de calidad (y la forma de retirarlas y mantener la producción del medio ambiente); hasta la forma como la empresa reduce las agresiones al medio ambiente a partir de las necesidades de producción (como el tratamiento del agua y el reciclaje de residuos). El uso de nuevas opciones de embalaje, por ejemplo, con materiales reciclables y biodegradables, es una de las opciones usadas por las empresas, además de asumir posturas de responsabilidad y acción social para con los consumidores, lo que impacta en la fuerza que la marca pasa a adquirir en el mercado consumidor. Sin embargo, el marketing posee un papel relevante en ese sentido, y en todas las empresas pueden invertir capital en ambos modos de aumentar la competitividad (invertir en sustentabilidad y en campañas de marketing).

De esa forma, atender las exigencias del mercado y del consumidor (cada vez más diversificado y exigente); invertir en la creación de plantas industriales en distintos sitios geográficos (lo que hace que la empresa sea capaz de actuar en diferentes segmentos del mercado con potencial fuerza de ventas); reducir el riesgo político (marcado actualmente por inestabilidad y crisis); mantener el volumen de ventas (en canal directo y tiendas), e invertir en el fortalecimiento de la marca a través del marketing (cada ítem con representatividad de 6\% entre los encuestados) fueron citados como aspectos complementarios que necesitan ser atendidos para impactar de forma positiva en el mercado de cosméticos entre Brasil y Argentina a partir de las actuaciones del MERCOSUR. Es decir, el camino para ampliar la actuación en el sector cosmético ya está trazado y se alinea con los aspectos y autores mencionados en la revisión de la literatura de este estudio, que tratan estas cuestiones destacando las relaciones estables para el mercado internacional. 


\section{Consideraciones finales}

Esta investigación tuvo por objetivo analizar la industria de cosméticos entre Brasil y Argentina. Para ello se valió de metodología cuantitativa y análisis exploratorio y descriptivo de los datos, permitiendo la generación de gráficos, cuadros y tablas capaces de representar de forma viva y dinámica las contribuciones alcanzadas. Las consideraciones finales presentan respuestas a los objetivos e hipótesis, así como responden a la pregunta de investigación.

Al identificar el comercio bilateral total de Brasil y Argentina en el sector de cosméticos enumerando los aspectos positivos del comercio bilateral del MERCOSUR, se pretende alcanzar el primer objetivo específico del estudio. Entre los resultados se observa que el crecimiento del sector en ambos países está por encima de la media del crecimiento anual, alcanzado por los demás países. Brasil creció en los últimos 18 años de $8 \%$ a $20 \%$ (dependiendo del producto) en el segmento HPPC y entre estos, los cosméticos se destacan en la facturación, (alcanzando margen medio de ganancias de 10\%); mientras que el mercado mundial alcanzó entre $3 \%$ y $5 \%$ de crecimiento en los productos HPPC de forma general, inclusive cosméticos. Aunque el sector de cosméticos aún represente una pequeña parte de los negocios bilaterales entre Brasil y Argentina (cerca de $2,5 \%$ del total), demuestra un potencial de crecimiento bien por encima de las perspectivas encontradas en otros segmentos, lo que justifica los resultados obtenidos por el análisis de ese primer objetivo específico, que nombró aspectos optimistas en relación al sector para la mayoría de los encuestados. Sin embargo, la hipótesis del presente estudio presupone que la mayoría de las empresas reconocería que el MERCOSUR influenció significativamente esa relación, lo cual no se confirmó. Solamente el $36 \%$ de los encuestados relacionaron al MERCOSUR a los resultados obtenidos. No obstante, las variables de esa hipótesis fueron totalmente confirmadas, considerando que se preestablece que habría mejora de la calidad de los productos, aumento de la exportación de productos finales y de las importaciones de materia prima. Esas variables fueron confirmadas por todas las empresas que reconocieron la importancia del MERCOSUR para el comercio bilateral; y citadas concomitantemente por el $50 \%$ de las empresas indagadas; es decir, ampliaron las negociaciones del sector en todos estos aspectos.

En relación a los resultados del segundo objetivo específico que buscó las principales oportunidades del mercado brasileño y argentino de cosméticos, la investigación 
identificó que casi la totalidad de las empresas perciben que hay oportunidades, pues citaron el crecimiento del mercado, involucrando mayor consumo de productos masculinos y jóvenes; el aumento del poder adquisitivo de la clase media, C y D; el elevado número de mujeres en el mercado de trabajo; y el aumento de la expectativa de vida de la población, que valora cada vez más el bienestar, la estética y la calidad de vida, como responsables por las oportunidades de ese crecimiento. Las ventas directas, sobre todo de puerta en puerta; el mercado en alza; la tecnología/ innovación de los productos y las oportunidades de apertura del mercado también son ventajas citadas. Brasil y Argentina, por lo tanto, poseen oportunidades mejor orientadas al consumidor. La participación de ese segmento impacta en las relaciones, elevando la competitividad de las empresas y dando lugar a la apertura del mercado y el mantenimiento del crecimiento de importaciones y exportaciones.

El tercer objetivo específico consistía en encontrar las principales amenazas del mercado de cosméticos brasileño y argentino, identificando la falta de crédito para invertir en investigación e innovación (que posee alto costo), como la principal amenaza del mercado cosmético, derivado y también agravado por la volatilidad del mercado (con crisis y cambios constantes). Otros tipos de amenazas listadas fueron la competencia y los consumidores exigentes; un mercado proveedor de baja calidad; y la utilización de materias primas sintéticas para la fabricación de productos, siendo las mismas más accesibles y capaces de contribuir a bajar el costo del producto final, aunque no se obtiene de los mismos la misma calidad que de los productos naturales. Se mencionan también la falta de inversión en marketing para el fortalecimiento de la marca como reductor de las oportunidades necesarias para el crecimiento del sector. La variedad de productos en el mercado también es una amenaza, pues interfiere en la capacidad de competir con las grandes empresas. Así, se puede inferir que la mayoría de las amenazas citadas por las empresas están orientadas al campo político de Brasil y Argentina, pues la falta de inversión y la volatilidad de los mercados y sus barreras políticas sólo dependen de la voluntad y de acciones políticas para ser resueltas. No se simplifica el conjunto de acciones capaces de resolver y/o disminuir esas barreras, aunque las mismas podrían formularse perfectamente, considerando la actuación del bloque económico como posible conductor de esas negociaciones.

Al observar las sugerencias de las empresas encuestadas para aumentar importaciones y exportaciones de cosméticos entre Brasil y Argentina, atendiendo así al cuarto y último objetivo específico del estudio, se observó que lo más relevante para ampliar el sector cosmético es invertir en investigación e innovación; seguido por la necesidad de reducir costos del producto final sin disminuir la calidad de los mismos, invertir en la sustentabilidad, en marketing para fortalecer la marca, estar atento a las 
exigencias del mercado y del consumidor, reducir el riesgo político y mantener los canales de ventas. Estas fueron las opciones más citadas para ampliar el comercio bilateral, lo que es reiterado por la literatura acerca del tema.

Esas consideraciones permiten responder a la pregunta que orienta la presente investigación: El destino de las importaciones y exportaciones de Brasil y Argentina en el sector de cosméticos, ¿refleja la atención de las exigencias de calidad comercial o son movidos por la proximidad geográfica y por acuerdos, como aquellos dados a partir de las relaciones del MERCOSUR? A partir de los datos expuestos, se infiere que la relación mercadológica responde más a la proximidad geográfica y a los acuerdos dentro del bloque, con ganancias debidas a la reducción de costos, tarifas, logística y fortalecimiento productivo frente a competidores, que a los aspectos orientados a atender las exigencias comerciales de calidad productiva 0 de adecuación de los preceptos mercadológicos de consumidores, aunque tanto Brasil como Argentina posean respeto y conceptos de mercado de gran calidad en la importación y exportación de cosméticos en todos los países del mundo, ocupando porcentajes significativos de penetración, inclusive en los mercados más exigentes. Esa interferencia puede ser comprobada al observarse que el mercado de destino de los productos cosméticos alcanza en mayor volumen a los países componentes del MERCOSUR, tanto considerando al mercado brasileño como al argentino, de acuerdo con la literatura consultada.

Para contribuir aún más a los resultados aportados por el estudio, se sugiere que sea aplicada una investigación cuantitativa entre algunos productores/fabricantes y/o distribuidores de cosméticos, tanto de Brasil como de Argentina, para verificar la intensidad del conjunto de normas de producción, distribución y embalaje de los productos, de acuerdo a lo que pregona el acuerdo bilateral del sector de cosméticos. Esa evaluación también permitiría entender las barreras y amenazas, así como las oportunidades y facilidades de las relaciones del MERCOSUR en el sector de cosméticos, posibilitando una comparación con la presente investigación.

Cabe destacar además que los avances y discusiones en el área política pueden intervenir positivamente en el desempeño y ampliación de los mercados que abarcan los países miembros del MERCOSUR, y que el fortalecimiento del bloque económico puede ampliar considerablemente el campo de negocios y de penetración en los demás mercados del mundo, conquistando la importancia también en otros sectores. Pues, alrededor del mundo, la internacionalización pasó a ser percibida como una oportunidad, una forma estratégica de crecimiento y competitividad. ${ }^{142}$

\footnotetext{
${ }^{142}$ HILAL; HEMAIS (2003). [45]
} 


\section{Bibliografía}

ABIHPEC - Associação Brasileira da Indústria de Higiene Pessoal, Perfumaria e Cosméticos. (2014). Panorama do setor de HPPC 2014. São Paulo: ABIHPEC, v. 21, agosto de 2014.

ABIHPEC - Associação Brasileira da Indústria de Higiene Pessoal, Perfumaria e Cosméticos. (2013). Balança Comercial 2013. Disponible en: http://www.desenvolvimento.gov.br/arquivos/dwnl_1388692200.pdf. Consultado el: 05/10/2014.

ABIHPEC - Associação Brasileira da Indústria de Higiene Pessoal, Perfumaria e Cosméticos. (2012). Anuário 2012. Disponible en: http://www.abihpec.org.br/wpcontent/uploads/2012/12/ABIHPEC_2012_internet.pdf.

Consultado el: 05/10/2104.

ABIHPEC - Associação Brasileira da Indústria de Higiene Pessoal, Perfumaria e Cosméticos. ABDI - Agência Brasileira de Desenvolvimento Industrial. SEBRAE Serviço Brasileiro de Apoio às Micro e Pequenas Empresas. (2014). III Caderno de Tendências 2014-2015: Higiene pessoal, perfumaria e cosméticos. (2014). Disponible en: $\quad$ http://www.abihpec.org.br/2013/10/caderno-de-tendencias-2014-2015/. Consultado el: 29/09/2014.

ALEM, A. C.; CAVALCANTI, C. E. (2005). O BNDS e o apoio à internacionalização das empresas brasileiras: algumas reflexões. Revista do BNDS: v.12, n.24, p.43-76.

ALICEWEB MERCOSUL. (2013, 2014). Balança comercial entre Argentina e Brasil. Disponible en: http://alicewebmercosul.desenvolvimento.gov.br// consulta/ pesquisar. Consultado el: 02/10/2014.

ALMEIDA, C. M. P. R. (2007). Modelos de gestão estratégica de cadeias de organizações: um estudo exploratório. São Paulo: FEA USP, 463f, 2007. Tese. (Doutorado em Administração). Pós-Graduação em Administração de Empresas. Faculdade de Economia, Administração e Contabilidade, USP, São Paulo.

ALTEMANI, Henrique. (2008). A Política Externa Brasileira. $2^{\mathrm{a}}$ edição, São Paulo, Ed. Saraiva.

AMAL, Mohamed; KEGEL, Patrícia Luíza. (2006). O contexto econômico e institucional das relações União Europeia e América Latina e algumas considerações sobre o Acordo com o Mercosul. Revista del CESLA [On-line] 2006, (Sin mes): [Data de consulta: 11/02/2014]. Disponible en: <http://www.redalyc.org/articulo.oa?id=243321208013> ISSN 1641-4713. 
ANDRADE, Maria Margarida. (2003). Introdução à metodologia do trabalho científico. $6^{a}$ ed. São Paulo: Atlas.

ANTONIK, Luís Roberto. (2004). A Administração Financeira das Pequenas e Médias Empresas. Revista FAE BUSINESS, $\mathrm{n}^{\circ}$ 8, p. 35-38, maio. 2004. Disponible en: http://www.unifae.br/publicacoes/pdf/revista_da_fae/fae_v8_n1/rev_fae_v8_n1_09_ant onik.pdf. Consultado el: 10/03/2013.

ANVISA. (2013). Legislação sobre cosméticos. Disponible en: http://portal.anvisa.gov.br/wps/portal/anvisa/anvisa/transparencia/!ut/p/c4/04_SB8K8xL LM9MSSzPy8xBz9CP0os3hTQwNfRydDRwN_N2cjA08XVzOPUF-

PIGdvI_2CbEdFALBfe1Q!/?urile=wcm\%3Apath\%3A/anvisa+portal/anvisa/trasparencia/ assunto+de+interesse/publicacoes+transparencia/faq++perguntas+frequentes/cosmeticos+-+informacoes+gerais. Consultado el: 05/10/2014.

ANVISA. (2005). Resolução $N^{\circ} 211$, de 14 de julho de 2005. Disponible en: http://bvsms.saude.gov.br/bvs/saudelegis/anvisa/2010/res0007_24_02_2010.html.

Consultado el: 10/10/2014.

ARGENTINA. (2012, 2014). Site oficial do Ministério da Agricultura. Disponible en: http://www.agricultura.gov.br/arq_editor/file/Intercambio _book_argentina.pdf. Consultado el: 01/10/2014.

BARBOSA, Rosangela Nair de Carvalho. (2007). A economia solidária como política pública: uma tendência de geração de renda e de ressignificação do trabalho no Brasil. São Paulo: Cortez.

BARRETO, A.; ROCHA, A. (2003). A expansão das fronteiras: brasileiros no exterior. In: Rocha, A. (org.) As novas fronteiras: a multinacionalização das empresas brasileiras. Rio de Janeiro: Mauad.

BNDES. Banco Nacional de Desenvolvimento. (2010). Informe Setorial: Estrutura e estratégias da cadeia de higiene pessoal, perfumaria e cosméticos. Disponible en: http://www.bndes.gov.br/SiteBNDES/export/sites/default/bndes_pt/Galerias/

Arquivos/conhecimento/setorial/informe-14AI.pdf. Consultado el: 07/10/2014.

(2013). Potencial de diversificação da indústria química brasileira. Relatório 1.

Disponible en: http://www.bndes.gov.br/SiteBNDES/ export/sites/default/bndes_pt/Galerias/Arquivos/produtos/download/chamada_publica_ FEPprospec0311_Quimicos_Seminario1.pdf. Consultado el: 15/09/2014.

. (2014). Potencial de diversificação da indústria química brasileira. Relatório

4. Disponible en: http://www.bndes.gov.br/SiteBNDES/export/sites

/default/bndes_pt/Galerias/Arquivos/produtos/download/chamada_publica_FEPprospe c0311_Quimicos_segmentos_media_prioridade.pdf. Consultado el: 15/09/2014.

BRASIL. TEC - Tarifa Externa Comum. (2012). Decreto 1.343/94 alterado pela Resolução 05/11, que entrou em vigor em 01/01/2012. Ministério do Desenvolvimento, Indústria e Comércio Exterior, Brasília/DF. Disponible en: http://www.desenvolvimento.gov.br/sitio/interna/interna.php?area=5\&menu=1848.

Consultado el: 08/02/2013. 
(2013). Balança Comercial Brasileira de 2013. Disponible en: http://www.mdic.gov.br/arquivos/dwnl_1388692200.pdf. Consultado el: 02/10/2104.

(2014). Balança Comercial Brasileira de 2014. Disponible en: http://www.mdic.gov.br/sitio/interna/interna.php?area=5\&menu=2081. Consultado el: 02/10/2104.

(2007). Manual de Exportação do Brasil para a Argentina. ABIHPEC; ABDI;

SEBRAE, novembro de 2007.

BREDA, Tadeu; PEREZ, João. (2012). Com Venezuela, Mercosul terá 270 milhões de habitantes e PIB de US\$ 2,8 trilhões. 27 jul. 2012. Disponible en: http://www.redebrasilatual.com. br/mundo/2012/07/com-venezuela-mercosul-tera270milhoes-de-habitantes-e-pib-de-us-2-8-trilhoes. Consultado el: 07/02/2013.

BRITO, C. M. (1993). Estratégias de internacionalização e cooperação empresarial. Faculdade de economia do Porto. Working paper $n^{\circ} 38$. Porto, Portugal. Disponible en: http://www.fep.up.pt/docentes/cbrito/Estrat_Intern_e_Coop.pdf. Consultado el: $12 / 02 / 2014$.

CALDAS, M. P.; FACHIN, R.; FISCHER, T. (org.). (2001). Handbook de estudos organizacionais: teorizando sobre a teoria. Traduzido de: Clegg, S. R.; Hardy, C.; Nord, W. R. (org). Handbook of organizations studies. São Paulo: Atlas.

CAMPA, J. M.; GUILLÉN, M. F. (1996). Evolución y determinantes de la inversión en el extranjero por empresas españolas, Papeles de Economía Española. № 66, pp. 235247.

CERVO, Amado Luiz; BERVIAN, Pedro Alcino. (2002). Metodologia científica. São Paulo: Makron Books.

CIGNACCO, Bruno Roque. (2009). Fundamentos de comércio internacional para pequenas e médias empresas. Tradução de Bianca Justiniano e Flor Maria V. da Silva. São Paulo: Saraiva.

CHILD, J.; RODRIGUES, S. B. (2007). The process of SME internationalization: British firms entering Brazil. E \& G. Economia e Gestão, v. 7, p. 31-55.

COLLIS, Jill; HUSSEY, Roger. (2005). Pesquisa em Administração. $2^{\mathrm{a}}$ ed. Porto Alegre: Bookman.

DIAS, Sérgio Roberto et al. (2003). Gestão de marketing. São Paulo: Saraiva.

ETZOINI, Amitai. (1981). Organizações complexas. São Paulo: Atlas.

EUROMONITOR INTERNACIONAL. (2013). Beauty and personal care in Brazil. 2013a. Disponible en: http://www.euromonitor.com/colour-cosmetics-in-brazil/report. Consultado el: 4/09/2014.

FACHIN, Odília. (2003). Fundamentos de metodologia. $4^{\mathrm{a}}$ ed. São Paulo: Saraiva. 
FASSIO, Adriana; PASCUAL, Liliana; SUÁREZ, Francisco M. (2002). Introducción a la Metodología de la Investigación aplicada al Saber Administrativo. Buenos Aires, Argentina: Ediciones Cooperativas Billinghurst.

FIESP/CIESP. Panorama Brasil / Argentina. (2014). Disponible en: file:///C:/Documents\%20and\%20Settings/Windows\%20XP/Meus\%20documentos/Dow nloads/panorama-brasil-argentina-maio-2014\%20(1).pdf. Consultado el: 07/10/2014.

FIGUEIREDO, Luiz Alberto. (Ministro das Relações Exteriores). (2014). Figueiredo destaca aumento do comércio com Argentina. 06/02/2014. Disponible en: http://exame.abril.com.br/economia/noticias/figueiredo-destaca-aumento-do-comerciocom-argentina. Consultado el: 08/02/2014.

FRANQUILO, Érica. (2014). Indústria cosmética no Brasil: panorama e perspectivas para 2014. Fevereiro de 2014. Disponible en: http://www.cosmeticsonline.com.br/2011/materia/6\#3. Consultado el: 05/10/2104.

GARCIA, Renato; FURTADO, João. (2002). Estudo da competitividade de cadeias integradas no Brasil: impactos das zonas de livre comércio - cadeia: cosméticos. Campinas / SP: UNICAMP-IE-NEIT; MDCI; MCT; FINEP.

GIL, Antônio Carlos. (2001). Gestão de pessoas: enfoque nos papéis profissionais. São Paulo: Atlas.

GIL, Antônio Carlos. (2002). Como elaborar projetos de pesquisa. $4^{\mathrm{a}}$ ed. São Paulo: Atlas.

GOMES, Eduardo Biacchi. (2010). Blocos Econômicos - Solução de Controvérsias. $3^{\mathrm{a}}$ ed. revista e atualizada. Curitiba: Ed. Juruá.

HAIR JR., J. F. et al. (2005). Fundamentos de métodos de pesquisa em administração. Porto Alegre: Bookman.

HILAL, A; HEMAIS, C. A. (2003). O processo de internacionalização na ótica da Escola Nórdica: Evidências empíricas em empresas brasileiras. Revista de Administração Contemporânea, v.7, n.1, p.109-124.

HILAL, A; HEMAIS, C. A. (2001). Da escola de Uppsala à escola nórdica de negócios internacionais: uma revisão analítica. In: ENCONTRO ANUAL DA ASSOCIAÇÃO NACIONAL DOS PROGRAMAS DE PÓS-GRADUAÇÃO EM ADMINISTRAÇÃO, 30, Anais..., Rio de Janeiro: ANPAD.

HIRATUKA, C. (coord.). (2008). Relatório de Acompanhamento Setorial (Volume I): Cosméticos. Projeto: Boletim de Conjuntura Industrial, Acompanhamento Setorial e Panorama da Indústria. Convênio: ABDI e NEIT/IE/UNICAMP. Campinas/SP: Maio de 2008.

HITT, M. A.; IRELAND, R. D.; HOSKISSON, R. E. (2002). Administração estratégica. São Paulo: Pioneira Thompsons Learning.

HYMER, S. (1976). The international operations of national firms: a study of direct foreign investment. Doctorate thesis. Cambridge, MA: The MIT Press. 
IDOETA, Paulo Adamo. (2011). Para que servem tantos blocos e grupos regionais? 02 de dezembro de 2011.2 Disponible en: http://www.bbc.co.uk/portuguese/noticias/2011/12/111201_blocosregionais_pai.shtml. Consultado el: 09/02/2013.

JOHANSON, J.; WIEDERSHEIM-PAUL, F. (1990). The internationalization process of the firms: four Swedish case studies. Journal of Management Studies, p. 305-322.

KEEGAN, W. J.; GREEN, M. C. (1999). Princípios de marketing global. São Paulo: Saraiva.

KOTABE, M.; HELSEN, C. (2000). Administração de marketing global. Tradução Ailton Bonfim Brandão; revisão técnica Maria Cecília Coutinho de Arruda. São Paulo: Atlas.

KOTLER, Philip; ARMSTRONG, Gary. (2003). Princípios de marketing. 9ª ed. São Paulo: Prentice Hall.

KOTLER, Philip. (2006). Administração de marketing. São Paulo: Prentice Hall.

KOTLER, Philip; KELLER, Kevin Lane. (2006). Administração de marketing: a bíblia do marketing. $12^{\mathrm{a}}$ Ed. Prentice Hall Brasil.

LEVY, M.; WEITZ, B. A. (2000). Administração de varejo. São Paulo: Atlas.

LORANGE, P; ROOS, J. (1996). Alianças estratégicas: formação, implementação e evolução. São Paulo: Atlas.

LUPPE, Marcos Roberto. Evidências das mudanças do padrão de consumo dos domicílios brasileiros: uma análise de diferentes categorias de produtos de consumo doméstico. 2011. PROVAR/FIA. Disponible en: http://provar.fia.com.br/publicacoes_artigos_completo_para_baixar.php?codigo=13.

Consultado el: 31/01/2015.

MAGNUSSON, D. (1967). Test theory: reading. Massachusetts: Addison-Wesley Publishing Company.

MALHOTRA, N. K. (2001). Pesquisa de marketing: uma orientação aplicada. Tradução de Nivaldo Montingelli Jr. e Alfredo Alves de Farias. Porto Alegre: Bookman.

MAÑAS, A. V.; GIORDANO, C. V. (2007). Um estudo sobre o impacto de tecnologias emergentes: o caso das etiquetas de radiofrequência na gestão da cadeia de suprimentos. In: XXXI ENANPAD, 2007, Rio de Janeiro. Encontro Científico de Administração. Porto Alegre: ENANPAD, v. 1.

MCGAHAN, A. M.; PORTER, Michael E. (2003). The emergence and sustainability of abnormal profits. Strategic Organization, v. 1, n. 1, p. 79-108.

MELIN, L. (1992). Internationalization as a strategy process. Strategic Management Journal, v.13, p. 99-118.

MILNER, Chris. (2005). Protection by tariff barriers and international transaction costs. Scottish Journal of Political Economy. V. 52, $\mathrm{n}^{\circ}$ 1, p. 105-121. 
MINAYO, Maria Cecília de Souza. (2000). Pesquisa social: teoria, método e criatividade. Petrópolis: Vozes.

MONTANA, Patrick J.; CHARNOV, Bruce H. (2003). Administração. $2^{a}$ ed. São Paulo: Saraiva.

MORAN, T. H. (2000). Inversión extranjera directa y desarollo. Cidade do México: Oxford University Press.

MOREIRA, Vagner Rangel; MIRANDA, Gabriel Vinicius Mamed de. (2012). O papel do Brasil no MERCOSUL. En: Âmbito Jurídico, Rio Grande, XV, n 96, jan. 2012. Disponible

en:

http://www.ambitojuridico.com.br/site/?nlink=revista_artigos_leitura\&artig_id=11029\&re vista_caderno=19. Consultado el: 21/02/2014.

PORTER, Michael E. (2004). Estratégia competitiva: técnicas para análise de indústrias e da concorrência. $2^{\mathrm{a}}$ ed. Rio de Janeiro: Elsevier.

PRADO, Maeli. (2012). País bate recorde em importação de cosméticos. Disponible en: http://www1.folha.uol.com.br/fsp/mercado/17800-pais-bate-recorde-em-importacaode-cosmeticos.shtml. Consultado el: 05/10/2014.

RIBEIRO, Elisa S.; PINCHEMEL, Felipe. (2011). Paradigmas da atuação brasileira no MERCOSUL. Revista Universitas: Relações Internacionais, Brasília, Vol. 9, nº 1.

SAE, Sitio Oficial de la Secretaría de Asuntos Estratégicos de Brasil. Disponible en: www.sae.gov.br

SANTOS, M. (2008). Por uma outra globalização: do pensamento único à consciência universal. $2^{\mathrm{a}}$ ed. Rio de Janeiro: Record.

STONER, J. A. F.; FREEMAN, R. E. (1995). Administração. Rio de Janeiro: Prentice Hall.

TEIXEIRA, Elson Adalberto. (2003). Teoria geral da administração e prática. Rio de Janeiro. Editora FGV.

THOMAS, Jerry R.; NELSON, Jack K.; SILVERMAN, Stephen J. (2007). Métodos de pesquisa em atividade física. 5 a ed. Porto Alegre: Artmed.

TUBINO, Dalvio Ferrari. (2000). Manual de planejamento e controle da produção. São Paulo: Atlas.

WIND, Jerry Y.; MAIN, Jeremy. (2002). Provocar mudanças. São Paulo: Qualitymark.

YIN, Robert K. (2005). Estudo de caso: planejamento e métodos. $2^{\mathrm{a}}$ ed. Porto Alegre: Bookman. 


\section{Anexo A: Carta de Presentación}

Estimados Señores y Señoras,

Mi nombre es Leila Aparecida Odorizzi; soy académica de la Maestría en Marketing Internacional, de la Universidad Nacional de La Plata y esta tesis ha sido dirigida por el Prof. Reinaldo Horacio Kopp. La presente investigación pretende contribuir con datos importantes sobre "El comercio bilateral de cosméticos entre Brasil y Argentina en el MERCOSUR", tema tan poco explorado y carente de información actualizada.

Vengo a presentarles el cuestionario utilizado en la investigación. El instrumento es simple y posee preguntas que deben ser respondidas con las opciones que mejor describan su experiencia profesional en el sector. Toda la información prestada permanecerá en absoluto secreto. No serán mencionados los nombres de las empresas, tampoco de los entrevistados.

Su participación es fundamental en la recolección de datos, que contribuirán a trazar los delineamientos del comercio bilateral entre los principales representantes del MERCOSUR (Brasil y Argentina).

Se solicita que los cuestionarios sean enviados al correo: leiladan@uol.com.br. En caso de tener dudas, la investigadora deja a disposición el teléfono (_47_) 91912350.

Desde ya, agradezco su colaboración, imprescindible para el éxito de esta investigación.

Atentamente,

Leila Aparecida Odorizzi - Maestrando 


\section{Anexo B: Encuesta realizada a las empresas}

1) Nombre de la empresa:

2) ¿El MERCOSUR afectó la industria cosmética de Brasil/Argentina?

( ) Sí ( ) No

3) Si usted respondió positivamente a la pregunta anterior, ¿en qué influyó?

( ) Mejora de la calidad de productos

( ) Aumento de la exportación de productos finales

() Aumento de las importaciones de materias primas

() Otros. Cite:

4) ¿Cuáles son las perspectivas de la industria cosmética dentro del MERCOSUR?

() Optimistas

() Pesimistas

5) ¿Cuáles son las oportunidades y amenazas de la industria cosmética entre Brasil/Argentina y otros países del mundo? Opine:

6) Pregunta opcional: Comente lo que usted encuentra relevante para el sector de cosméticos considerándolas importaciones y exportaciones entre Brasil y Argentina. Aporte sugerencias, critique o elogie la actuación del/en el MERCOSUR. 


\section{Aclaración}

"Declaro bajo juramento que esta tesis fue elaborada por mí, que no utilicé ningún otro material que no haya dado a conocer en las referencias y que no utilicé frases o párrafos de otros autores y que este trabajo de tesis nunca ha sido presentado ante un comité de evaluación de tesis y que no transgrede derechos de terceros." 